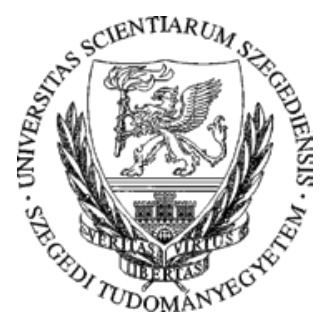

PhD Thesis

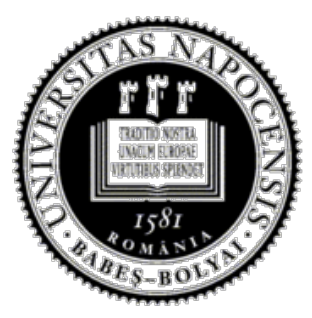

\title{
Synthesis, morpho-structural characterization and environmental application of titania photocatalysts obtained by rapid crystallization
}

\author{
Pap Zsolt
}

Thesis supervisors:

Prof. Dr. András Dombi

Dr. Károly Mogyorósi

University of Szeged

Szeged, Hungary
Prof. Dr. Ionel-Cătălin Popescu

Dr. Virginia Danciu Babes-Bolyai University

Cluj-Napoca, Romania

University of Szeged, Babes-Bolyai University

2011 
Motto:

The most exciting phrase to hear in science, the one that heralds the most discoveries, is not "Eureka!" (I found it!) but "That's funny..."

Isaac Asimov 


\section{Contents}

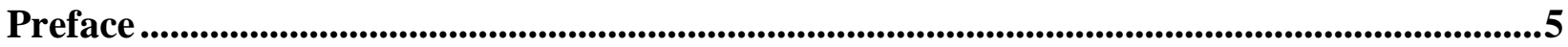

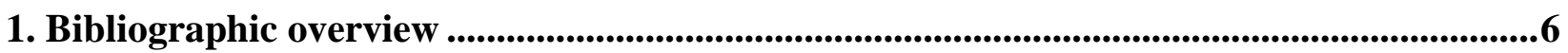

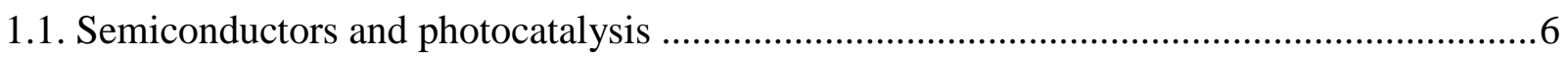

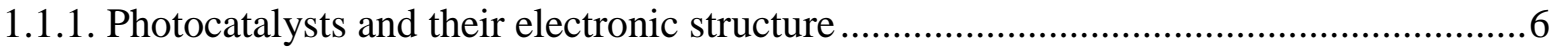

1.1.2. Photocatalysts and their doping with nonmetallic elements ................................... 9

1.2. The sol-gel method. A flexible way to obtain nanomaterials .......................................... 10

1.2.1. The hydrolysis process. The use of mineral and/or organic acids in the synthesis of

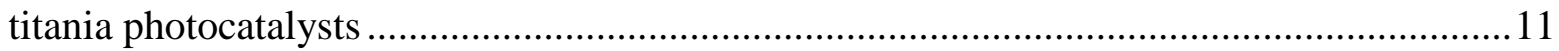

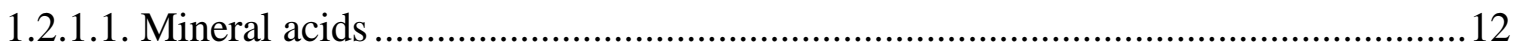

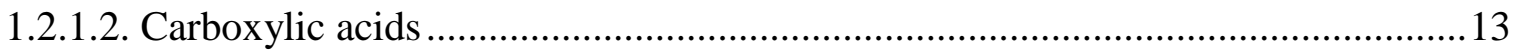

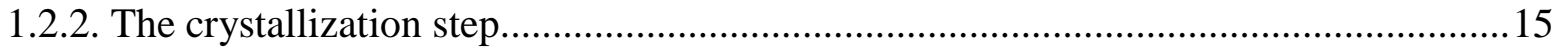

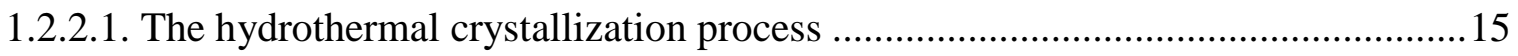

1.2.2.2. Crystallization by calcination ................................................................. 17

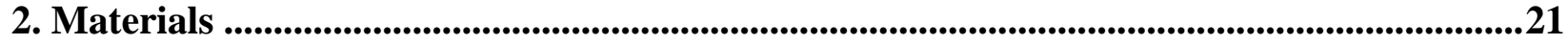

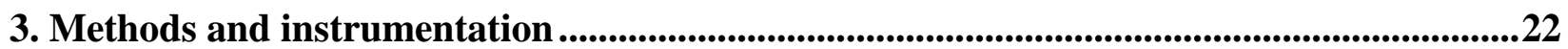

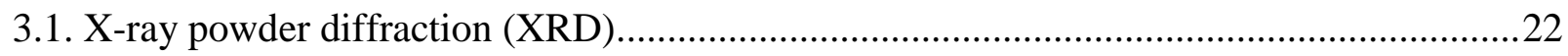

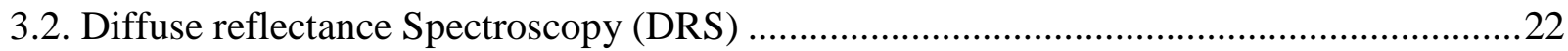

3.3. The specific surface area determination by nitrogen adsorption (BET evaluation method)

3.4. Thermogravimetry and differential thermal analysis (TG-DTA) .................................23

3.5. Scanning and transmission electron microscopy (SEM, TEM) ....................................23

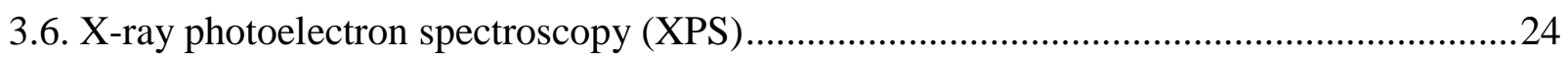

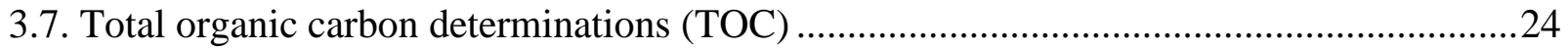

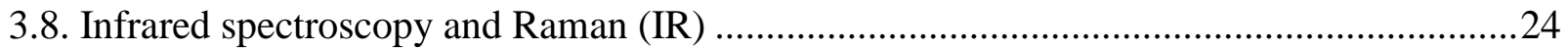

3.9. High performance liquid chromatography (HPLC) ...................................................2

3.10. Photoreactors and the evaluation of the reaction rates ..............................................25

3.11. Other instruments used throughout the experiments...............................................26

4. The main objectives of the present PhD thesis ...........................................................................227

5. The synthesis of the fast heat treated titanias..........................................................................29 
6. The influence of rapid heat treatment in still air on the photocatalytic activity of titania photocatalysts .......................................................................................................................................31

6.1. Structure and morphology of the obtained nanocatalysts .....................................................

6.2. Photocatalytic performance of the specially calcinated photocatalysts ................................36

7. Dynamic changes on the surface during the calcination of rapid heat treated $\mathrm{TiO}_{2} \ldots . . . . . . .48$

7.1. Characterization of the photocatalysts ............................................................................... 48

7.2. Correlations observed between the surface quality, bulk properties and the achieved photocatalytic performance ........................................................................................................52

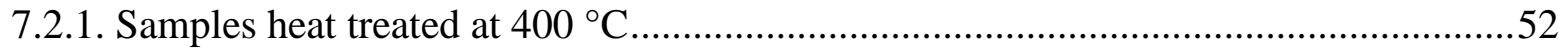

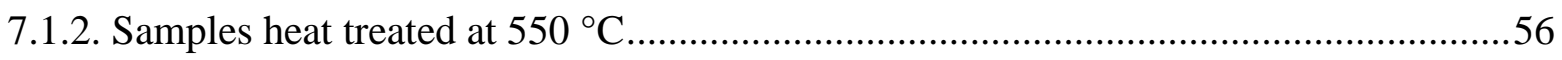

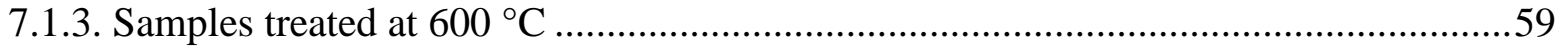

8. The synthesis of the fast heat treated nitrogen doped titanias..................................................62

9. Nitrogen doped titania photocatalysts properties made by rapid calcination.....................63

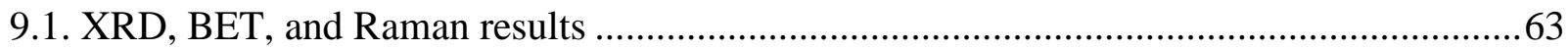

9.2. The influence of acids on the phase composition and light absorption of rapid heat treated N-doped titanias .................................................................................................................66

9.3. The influence of the calcination temperature on the structural and photocatalytical

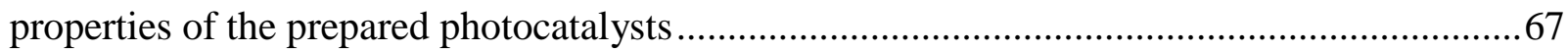

9.4. Correlation between the brookite particle size and visible light photocatalytic activity ....67

9.5. Comparison between traditionally calcined samples and fast heat treated samples ...........69

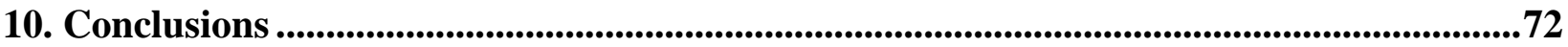

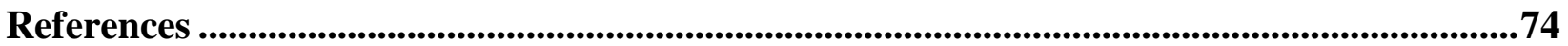

Scientific activity ............................................................................................................................8

Acknowledgements...................................................................................................................86

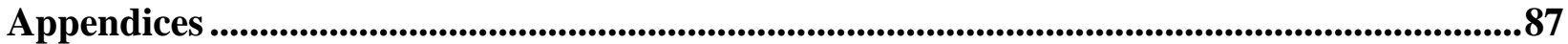




\section{Preface}

In the last century, due to the fast industrialization a very severe problem emerged, namely the intense water and air pollution. Throughout this time several technologies were developed in order to resolve the issue. However, each purification method has its own financial/efficacy limitations. Photocatalysis could be one of the future alternatives because of its low costs and effectiveness. As energy source uses light (both solar and artificial), the applied catalysts are non-toxic (such as $\mathrm{TiO}_{2}$ ) and the decomposition of the pollutants can be conducted until total mineralization $\left(\mathrm{CO}_{2}\right.$, water, ions).

In the past decades the numbers of publications regarding photocatalysis have increased significantly. Several semiconductor materials were experimented with, as potential photocatalysts. Among the most studied materials were: titanium dioxide $\left(\mathrm{TiO}_{2}\right)$ [1], zinc oxide $(\mathrm{ZnO})$ [2], tungsten trioxide $\left(\mathrm{WO}_{3}\right)$ [3], etc.

It seems that the most promising material could be $\mathrm{TiO}_{2}$ due to its high activity, nontoxicity and costs. This semiconductor was first time investigated in a photoelectrochemical process by Fujishima and Honda [1]. Their paper determined an exponential growth of the investigations about this nanomaterial. Several synthesis methods were developed to obtain the three known crystal phases (anatase [4-5], rutile [6-7] and brookite [8-9]) or their mixtures [1012] in different shapes (cubes [13], octahedrons [14], nanorods [6] etc.).

Among the synthesis procedures the sol-gel method was found as the most flexible in each point of view such as: wide range of titania precursors (for details please see section 1.2.) and the high number of doping possibilities (metals: nickel [15-16], iron [17-18], chromium [19], vanadium [20], tungsten [21], copper [22], cerium [23], europium [24-25]) and nonmetals (nitrogen [21, 26-27], sulfur [28-29], phosphorus [30], carbon [31-32], iodine [33], boron [3435]), fine tuning of the crystallinity [10]/ shape [6], crystal phase composition [10] and nevertheless synthesis of composite materials [36]. Because of the numerous synthesis ways and process complexity, a detailed study could be done for each step.

The present work emphasizes the importance of the crystallization process, induced by the heat treatment of amorphous titania. Details will be presented regarding the impact of the calcination on the:

- Crystal phase composition and primary particle size of the crystallites

- $\quad$ Surface morphology and particle geometry 
- The catalyst's surface chemical composition (including surface anchored groups)

- UV and visible light photocatalytic activity

The main thread of the thesis was built upon these ideas, research directions and will be presented in details. Several literature data will be brought up to emphasize the importance of a simple crystallization method, the calcination. These data will also show that the current research in the field of photocatalysis underestimates and sometimes mistreats the impact of the calcination. Experimental data (including over 80 photocatalytic experiments, X-ray diffraction data, diffuse reflectance spectra, infrared spectra etc.) were brought up to support our hypotheses.

\section{Bibliographic overview}

\subsection{Semiconductors and photocatalysis}

\subsubsection{Photocatalysts and their electronic structure}

The electric conductivity of a solid state material (i.e., the movement of electrons through the material) requires that the electrons occupy partially filled orbitals. This is achieved by occupancy of the conduction band. For metals, the conduction and valence bands overlap, so the conduction band can be easily occupied (Figure 1).

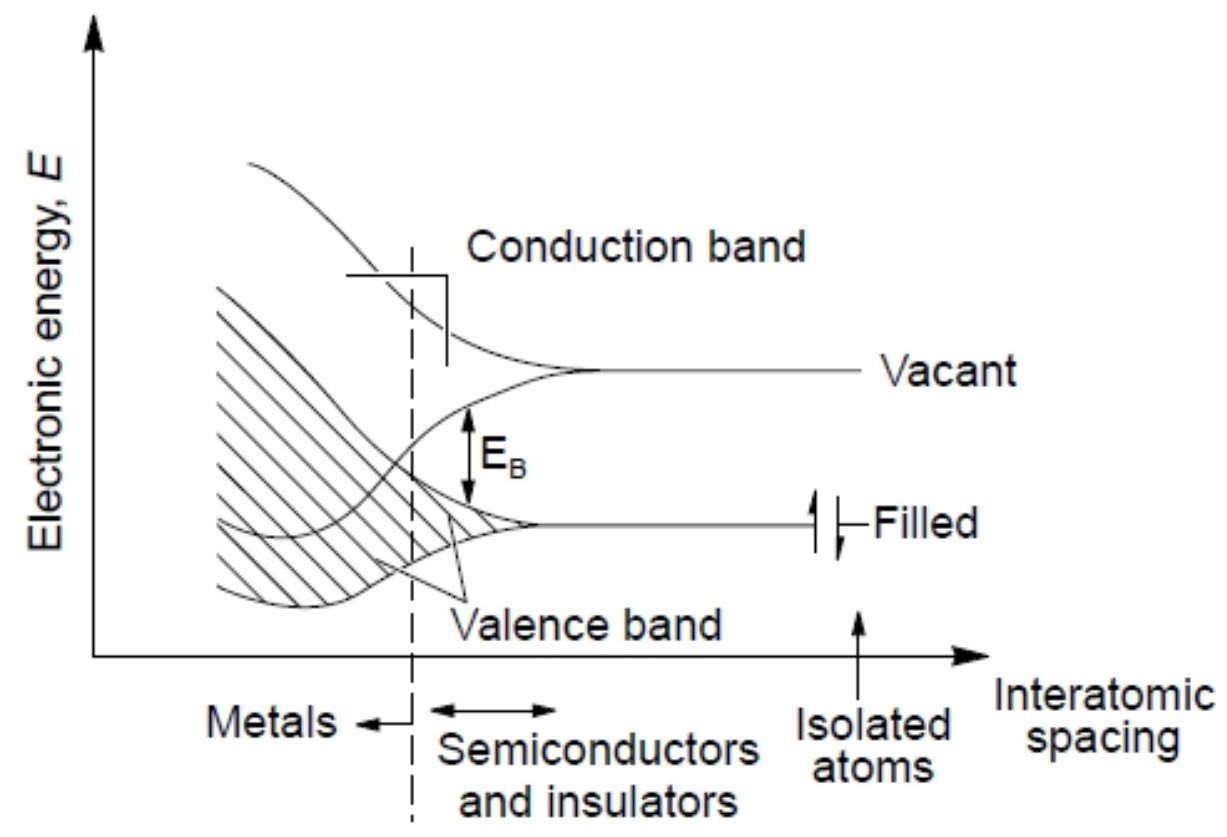

Figure 1 - The classification of the solid state materials based upon their electronic structure (band theory) 
For insulators, the band gap is sufficiently large that electrons cannot be spontaneously promoted from the valence band to the conduction band (Figure 1) [37]. However, for semiconductors, the band gap is not as wide, and electrons can be moved into the conduction band. The promotion of electrons leaves a positively charged vacancy in the valence band, which is referred to as a hole (Figure 2). These holes can be moved through space by the transfer of an electron to the vacancy; therefore, holes are considered to be mobile. Electrons could be excited to the conduction band either thermally or photochemically (Figure 2). Undoped semiconductors are referred to as intrinsic semiconductors (doped materials with semiconductive properties are named usually extrinsic semiconductors) [37]. Semiconductors in which the dominant (or majority) charge carriers are electrons are referred to as n-type semiconductors, whereas those in which holes are the majority charge carriers are referred to as p-type semiconductors.

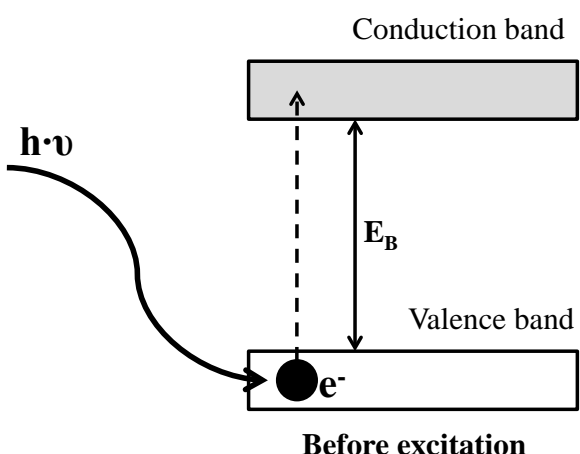

Before excitation

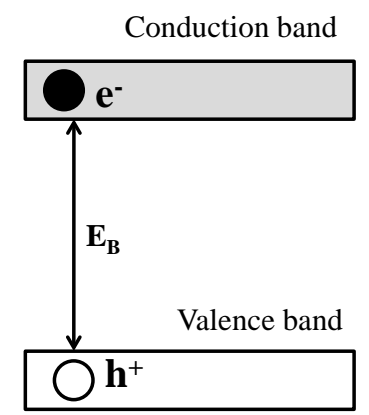

After excitation

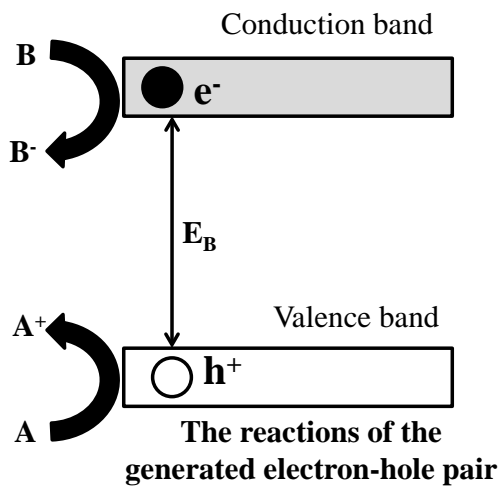

Figure 2 -The generation of electron-hole pairs (induced by $\lambda_{\text {irradiation }} / 1240 \approx \mathrm{E}_{\mathrm{B}}$-band gap energy)-simplified

In case of an intrinsic semiconductor, the current conduction occurs due to the crystal defects (i.e. $\mathrm{TiO}_{2}$, if the ratio of titanium atoms to oxygen atoms is $1: 2$, than the measured resistivity is in the range of $10^{8} \Omega \mathrm{m}$; if the ratio of the mentioned atoms changes to $1: 1.9998$, the new resistivity value is $0.11 \Omega \mathrm{m}$,) or thermal excitation (silica).

Another important concept in discussion of solid state materials is the Fermi level [38]. This is defined as the energy level at which the probability of occupation by an electron is $1 / 2$; for example, for an intrinsic semiconductor the Fermi level lies at the mid-point of the band gap. Doping, crystal defects changes the distribution of electrons within the solid, and hence changes the Fermi level. For an n-type semiconductor, the Fermi level lies just below the conduction band, whereas for a p-type semiconductor it lies just above the valence band. 
We now need to consider what happens at the (idealized) interface between a semiconductor and an electrolyte (i.e. water containing organic pollutants). In order for the two phases to be in equilibrium, their electrochemical potential must be the same. The electrochemical potential of the solution is determined by the redox potential of the electrolyte solution, and the redox potential of the semiconductor is determined by the Fermi level. If the redox potential of the solution and the Fermi level do not lie at the same energy level, a movement of charge between the semiconductor and the solution is required in order to equilibrate the two phases [38]. The excess charge that is now located on the semiconductor does not lie at the surface, as it would for a metal, but extends into the bulk material for a significant distance (100-10,000 А).
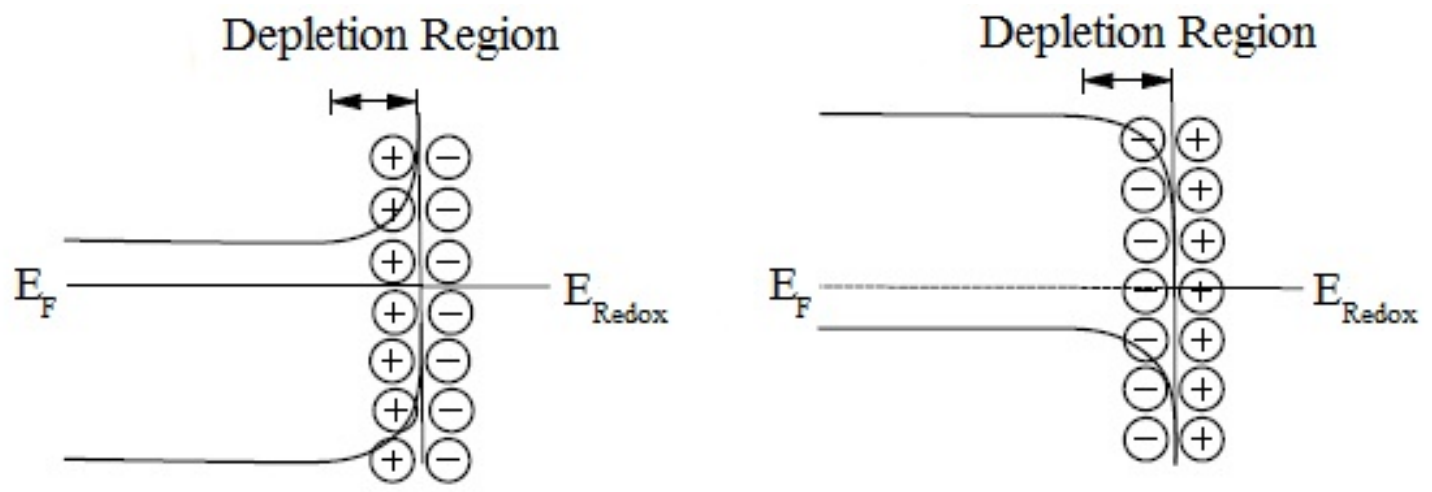

Figure $3-p$ and n-type of semiconductor in contact with aqueous systems

This region is referred to as the space charge region, and has an associated electrical field. Hence, there are two double layers to consider: the interfacial (particle/aqueous system) double layer, and the space charge double layer.

For an n-type semiconductor, the Fermi level is typically higher than the redox potential of the electrolyte, and hence electrons will be transferred from the electrode into the solution. Therefore, there is a positive charge associated with the space charge region, and this is reflected in an upward bending of the band edges. Since the majority charge carrier of the semiconductor has been removed from this region, this region is also referred to as a depletion layer.

For a p-type semiconductor, the Fermi layer is generally lower than the redox potential, and hence electrons must transfer from the solution to the electrode to attain equilibrium. This generates a negative charge in the space charge region, which causes a downward bending in the 
band edges. Since the holes in the space charge region are removed by this process, this region is again a depletion layer.

When the chosen semiconductor participates in a photocatalytic process it is absolutely necessary for both charge carriers to be implied in a charge transfer reaction (electrons drawn out by acceptors and the holes' interaction with donors). Without this, the charge carriers (holes or electrons) can accumulate in the semiconductor particle and that raises the recombination possibilities.

\subsubsection{Photocatalysts and their doping with nonmetallic elements}

One of the main goals in the field of photocatalysis is to achieve visible light activity. For

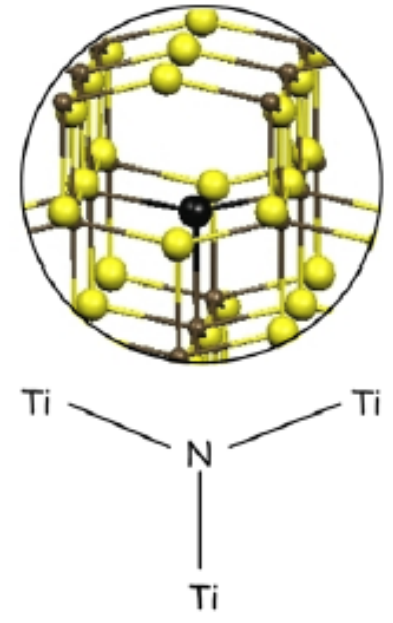

SUBSTITUTIONAL

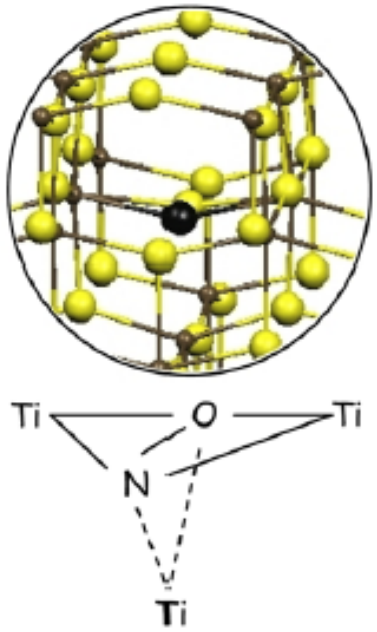

INTERSTITIAL

Figure 4 - Schematic representation of substitutional and interstitial nitrogen in the $\mathrm{TiO}_{2}$ lattice

this a necessary criteria for the photocatalyst is to absorb visible light. Natively, $\mathrm{TiO}_{2}$ is a UV active material, thus a solution is needed to achieve visible absorption. Several approaches were proposed, but one of the most promising one is the doping with nitrogen, as it was shown by Asahi et al [27]. Starting from this publication, studies regarding nitrogen doped titanias increased significantly [39].

Doping with transition metals has shown both positive and negative effects. Indeed, several authors have reported that although metal ion doping decreases the photo-threshold energy of $\mathrm{TiO}_{2}$, the metal ions may also serve as recombination centers for electrons and holes, 
thus reducing the overall activity of the photocatalyst [39]. However, by using nonmetal dopants (such as nitrogen) the previously mentioned problem can be avoided.

The most basic question concerns the chemical nature, the location in the solid, and the involvement in photoactivity of the nitrogen species. Different chemical species like $\mathrm{NO}_{\mathrm{x}}$ [4043], substitutional $\mathrm{N}$ [27, 44-46], or $\mathrm{NH}_{\mathrm{x}}$ [47] have been proposed. It is essential to know the nature of the incorporated atom (substitutional/ interstitial), because the behavior of these two species could be different and will affect the material properties accordingly.

\subsection{The sol-gel method. A flexible way to obtain nanomaterials}

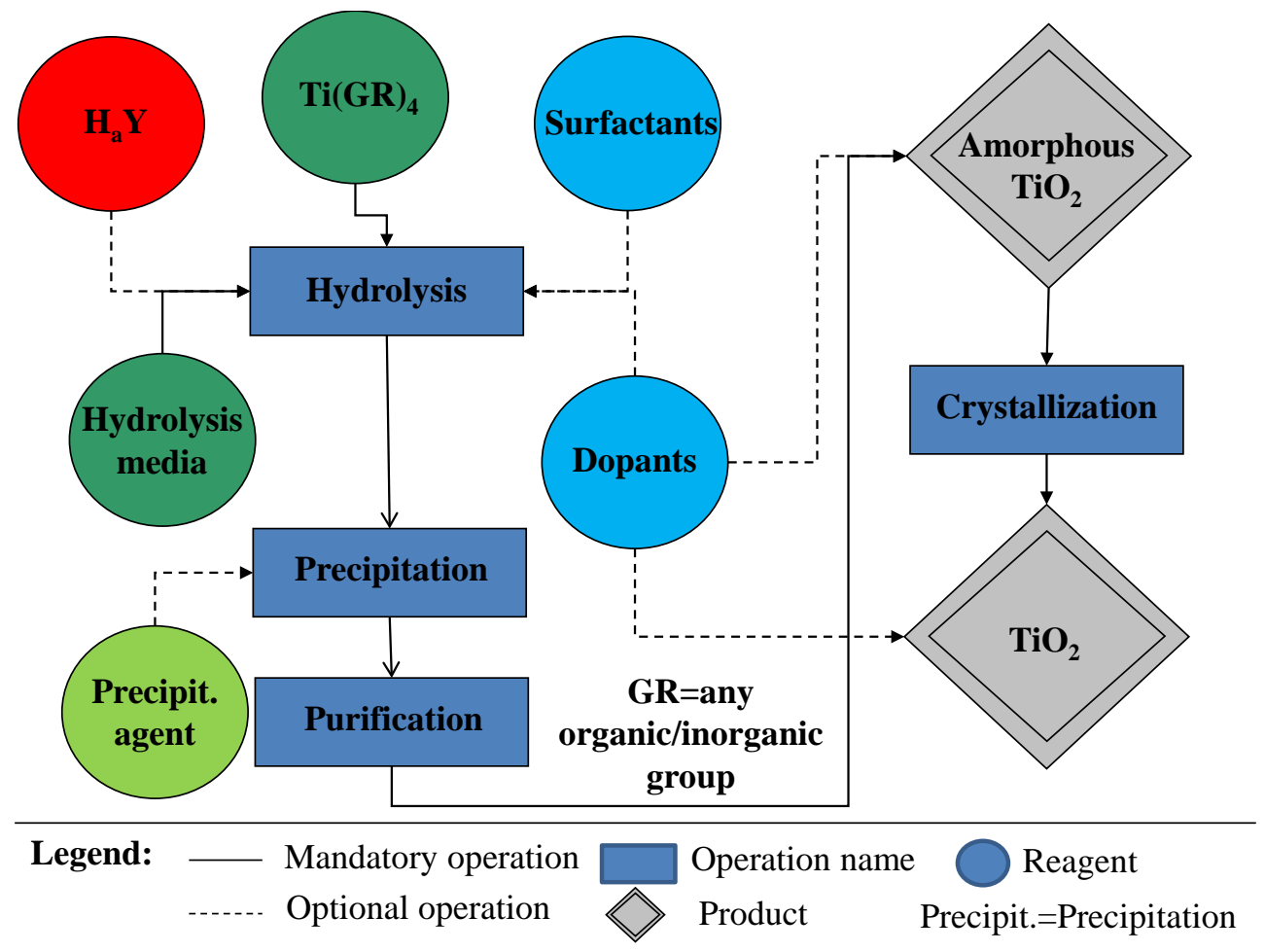

Figure 5 - Schematic representation of the sol-gel synthesis of titania photocatalysts

The sol-gel process is a well-known synthesis method for several materials, nanomaterials and composites. Also in the case of $\mathrm{TiO}_{2}$, it is the most frequently applied synthesis method. The present work will elucidate the importance and the role of two main steps in the sol-gel route, namely the importance of the hydrolysis conditions of the titanium precursor and the critical impact of the calcination on structural properties (surface / bulk) and photocatalytic activity of the obtained titania nanocrystals. 
In Figure 5 a typical $\mathrm{TiO}_{2}$ synthesis route is presented, detailing the major steps in this method. The enhanced flexibility of this method is clearly visible from this scheme thus the hydrolysis process is the first one that can be realized in many ways. Usually an inorganic $\mathrm{TiCl}_{4}$ $[11,48], \mathrm{TiOSO}_{4}$ [49] or organic precursor $\mathrm{Ti}(\mathrm{OR})_{4}$ [50-55] is used, depending on the desired crystal phase composition, particle size and shape. The hydrolysis media has to be adequate to the selected precursor and its nature. If a very fast hydrolysis is required then water is usually applied, if a slow, controlled reaction is needed then alcohols [56] (or any other non-aqueous media) are recommended to be used.

As complementary reagents, acids (or a mixture of acids) (noted $\mathrm{H}_{\mathrm{a}} \mathrm{Y}$ in Figure 5) can be applied to prevent instantaneous precipitation of the hydrolyzed precursor. Also depending on the acid's chemical properties they can be utilized to the fine tuning of the crystal phase composition (further details about acids in titania synthesis can be found in section 1.2.1.). If a specific shape of the crystallites is desired then surfactants [57] or other templates [58] can be used to control the crystallite formation process.

The next step in the synthesis is the precipitation. This could be done without adding a precipitation agent (i.e. ammonia) if the hydrolysis step was carried out under mildly acidic or neutral conditions. If desired, organic and inorganic (usually bases) compounds can be used to execute the process. Usually the obtained precipitate is amorphous - depending on the synthesis parameters - and contains adsorbed anions/ cations (depending on the suspension's $\mathrm{pH}$ ), organic compounds (if the precursor, the used acid or the precipitation agent was organic). After the amorphous material was synthesized it undergoes (in the most cases) a purification process mainly centrifugal washing with organic solvents or water.

The last step is the crystallization (this step will be presented more detailed in section 1.4.). This procedure can be done in several ways: calcination (for references, see section 1.4.2.), hydrothermal treatment (for a short overview please consult section 1.4.1.), microwave assisted [59], supercritical drying [60] etc.

\subsubsection{The hydrolysis process. The use of mineral and/or organic acids in the synthesis of titania photocatalysts}

Using mineral or organic acids is not mandatory, but they can help in the design of the crystallized catalysts' particle size, crystal phase composition and in some cases porosity. Several 
papers were published about this subject. Throughout this section of the thesis a short summary regarding the results obtained with acids used by other researchers for titania photocatalysts' solgel synthesis.

\subsubsection{Mineral acids}

The situation of hydrochloric acid $(\mathrm{HCl})$ is a special one, because it is formed during the hydrolysis of $\mathrm{TiCl}_{4}$ and therefore the investigation along with this precursor it is rather difficult. Despite of this, some papers report the influence of this acid on the hydrolysis of other precursors.

Dai et al. [61] reported the influence of $\mathrm{HCl}$ on the hydrothermal treatment of nanocrystalline titania $\left(\mathrm{TiOSO}_{4}\right.$ was used as titania precursor) templated by hexadecyl-trimethylammonium bromide. They found that by increasing the $\mathrm{HCl}$ concentration from $0 \mathrm{M}$ to $8 \mathrm{M}$ the anatase primary particle size (determined from XRD) goes through a maximum at $4 \mathrm{M}$ of $\mathrm{HCl}$ (Figure 6). Contradictory to this behavior the anatase content of the samples decreased going through a minimum at $5 \mathrm{M}$ of $\mathrm{HCl}$ (here the rutile content was nearly $50 \mathrm{wt} \%$ - Figure 6).

Similar effects were observed by Yuan et al. [62]. They studied the influence of hydrochloric acid on the porosity and crystal structure of sol-gel made titanias. It was observed that below $\mathrm{HCl}$ : Ti-precursor ratio 1 only anatase is formed with high porosity. At higher ratios the rutile phase appeared and the porous structure partially collapsed (confirmed by SAXS measurements).
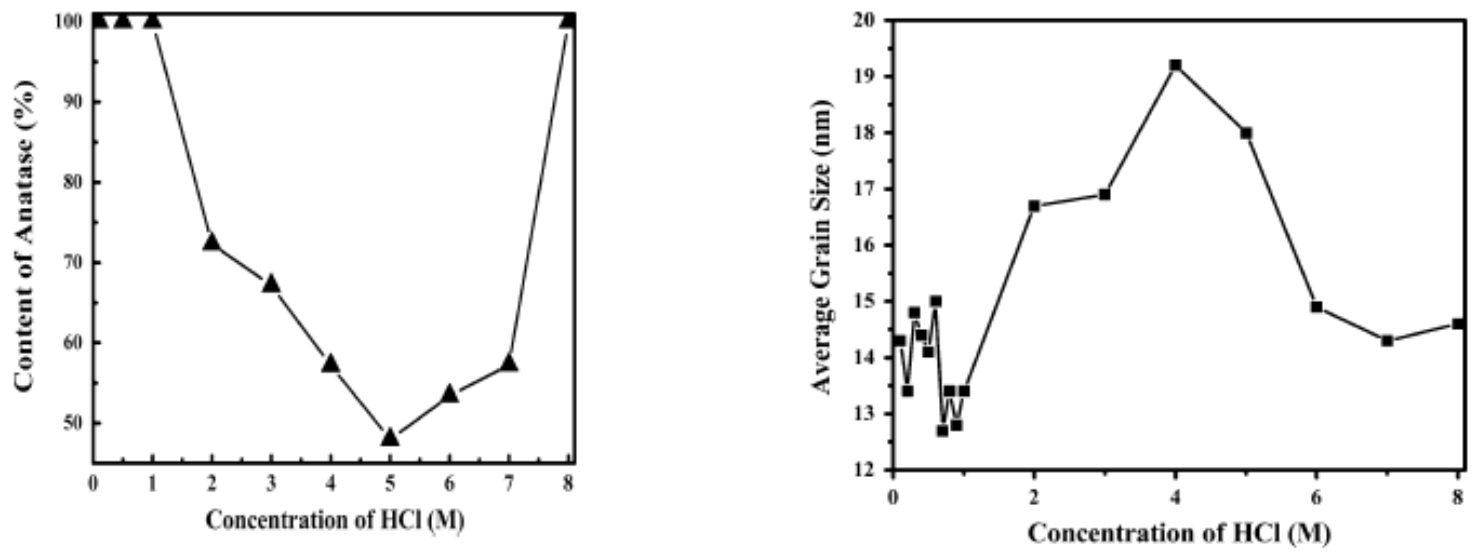

Figure 6 - The influence of $\mathrm{HCl}$ on the phase composition and particle size of the catalysts as observed by Dai et al.

[60] 
Rajesh et al. [63] investigated several mineral acids in the hydrolysis process of $\mathrm{TiCl}_{4}$ despite the difficulties mentioned before. The observations in this paper were in accordance with other works [61-62]. Also a high agglomeration tendency was observed in the crystallized nanoparticles. The difference compared to other similar publications is that a very interesting comparison was made with other mineral acids under the same conditions.

Hydrofluoric acid (HF) can be rarely found in a sol-gel synthesis of titania nanoparticles. Mostly fluorine "doping" is reported with fluoride ions [64], by introducing already crystalline titanium dioxide into a fluoride containing solution. However a publication appeared from Bai et al. [65] presenting results about highly ordered nanotube arrays. These nanomaterials were obtained electrochemically in a dilute $(0.5 \% \mathrm{HF})$ aqueous solution. The ordering and growth of these nanotubes and the wall thickness was investigated in the function of the applied current on the synthesis cell.

Nitric acid $\left(\mathrm{HNO}_{3}\right)$ was studied as catalyst in the hydrolysis process of sol-gel made titanias (mostly aerogels) [66]. In this process the nitric acid quantity dictates directly the gelation time and by this the final gel/aerogel [66] structure. Some of the papers report brookite formation in the presence of $\mathrm{HNO}_{3}$ such as the work published by Hao et al. [67]. They showed that for the brookite formation, the presence of $\mathrm{HNO}_{3}$ is crucial. Also, the work demonstrates that in template driven synthesis the presence of nitric acid is beneficial, because increases the thermal stability of the obtained mesoporous structure.

Besides the hydrolytic process several publications presents surface functionalization with $\mathrm{H}_{2} \mathrm{SO}_{4}, \mathrm{HNO}_{3}$, and $\mathrm{H}_{3} \mathrm{PO}_{4}$ [56, 68-69]. This procedure is done after the hydrolysis and precipitation is complete. Usually the whole impregnation is in fact a washing process with the desired acid's aqueous solution. By applying this treatment the thermal stability of the anatase phase increased, thus the usual anatase - rutile phase transformation shifted to higher temperature values.

\subsubsection{Carboxylic acids}

One of the most widely used organic acid in the sol-gel synthesis of titania is acetic acid. Chang et al. [70] reported a detailed study about the acetic acid's influence on the morphology and crystal phase composition of the obtained nanoparticles. They observed that without acetic acid the final, crystallized material contained only anatase with pseudo rod shaping. If the acetic 
acid is present in the hydrolytic system then the rutile formation occurs and the nanoparticles became rice-shaped. Unfortunately, they did not report any photocatalytic experiments. Also for synthetic purposes Yuan et al. [71] synthesized $\mathrm{TiO}_{2}$ coated $\mathrm{ZnS}$ catalyst. The acetic acid acted as a binding agent here (similar to functionalization) between the small $\mathrm{TiO}_{2}$ clusters and $\mathrm{ZnS}$ particles.

The role of acetic acid was also investigated in the case of titania nanotube formation. Tsuchiya et al. [72] obtained highly ordered $\mathrm{TiO}_{2}$ nanotube arrays in the presence of acetic acid. The paper discusses aspects about the morphological arrangement of the nanotubes and the possible formation mechanism.
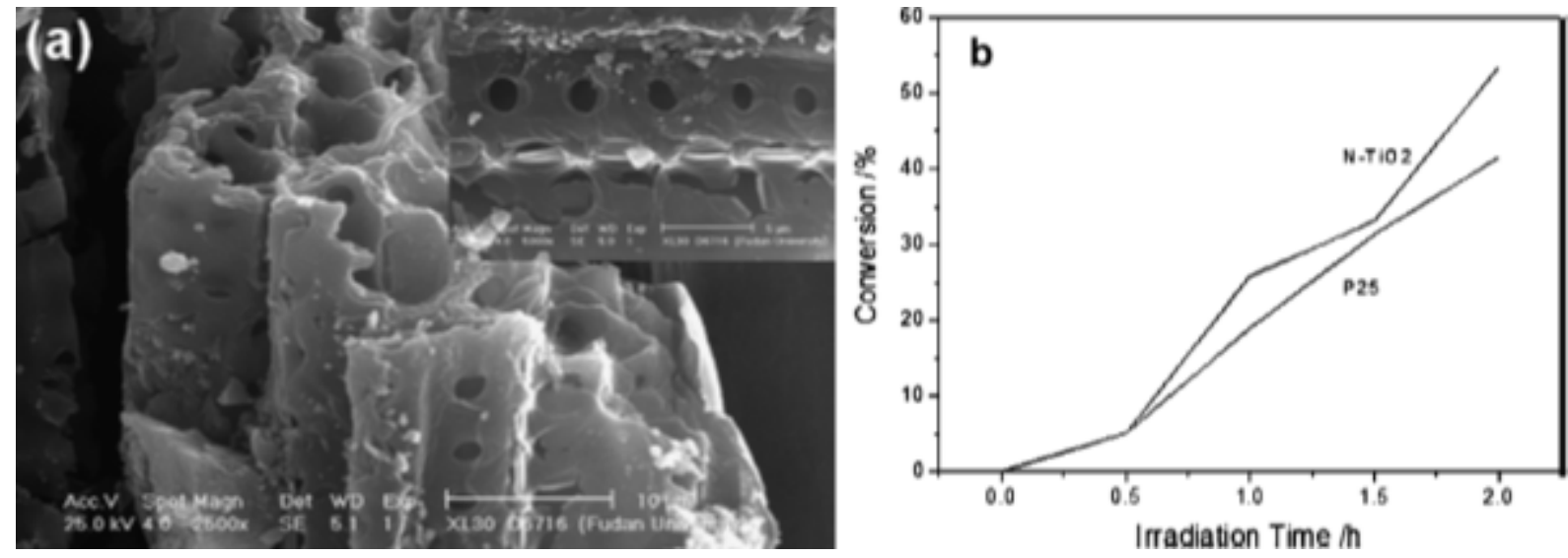

Figure 7 - Microtubes obtained by Xu et al. [4] with the help of acetic acid (a) and their application in phenol degradation under UV-light (b)

Nitrogen - doped titania microtubes (Figure 7) were synthesized for photocatalytic purposes by Xu et al. [4] using acetic acid in the hydrolysis procedure. It is known that acetic acid is a rather weak electrolyte. It forms with ammonia (excess) ammonium acetate $\left(\mathrm{CH}_{3} \mathrm{COONH}_{4}\right)$ which becomes a buffer, and can keep a stable $\mathrm{pH}$ range in this reaction system. During the hydrolysis process, the titania nanoparticles begin to form and tend to aggregate each other. The presence of acetic acid can control the assembly mode (to form microtubes) and rate of the amorphous titania nanoparticles. Photodegradation experiments were carried under visible and UV/visible light with phenol as the model pollutant. The obtained nanostructures' photocatalytic performance exceeded the Evonik Aeroxide P25’s degradation rate (Figure 7).

Regarding morphological aspects Zhang et al. [73] reinforced the observation made in reference [4], namely the formation of amorphous aggregates and their arrangement under the 
influence of acetic acid in ethanol. They noticed different micro and nanostructural arrangements, as follows: at micron scale the particles were ordered in hollow nanospheres; however the sphere's material contained rutile nanorods twisted between anatase aggregates (observed by using HR-TEM). The degradation of methyl orange in aqueous solutions was investigated successfully in the presence of these materials.

Papers regarding the synthesis of sol-gel made titanias in the presence of other organic acids are sparse. There can be found reports about citric acid assisted composite synthesis (mostly $\mathrm{SiO}_{2}-\mathrm{TiO}_{2}$ ) [74], fatty acid directed nanoparticle synthesis (it should be noted that here the fatty acids, mostly stearic acid [75] is taken in count as a surfactant).

Indeed, the hydrolysis process is crucial in each aspect of the nanomaterials' properties (crystal phase composition, morphology, surface-related properties, doping etc.). However, it should be emphasized here, that without the crystallization process all efforts to manipulate the nanocrystals' properties, are in vain. Thus the hydrolysis process is directly linked with the crystallization step, which will be detailed in the following sections.

\subsubsection{The crystallization step}

The last crucial step in the sol-gel synthesis of titania photocatalysts is the crystallization,

as we have shown in Figure 5. There are several methods to achieve high crystallinity from amorphous titania such as: hydrothermal treatment, calcination or other alternative crystallization methods such as microwave assisted crystallization, supercritical drying, etc. In this section of the thesis the hydrothermal treatment and the calcination is discussed in details.

\subsubsection{The hydrothermal crystallization process}

The first hydrothermal synthesis was performed in 1839 by Robert Bunsen. The crystals of barium carbonate and strontium carbonate that he grew under $200{ }^{\circ} \mathrm{C}$ and 100 bars were the first obtained by this method. After this breakthrough nearly all type of materials were synthetized by this procedure. Titania was also obtained by this method by several research groups. Their synthesis aimed shape control, doping (metals/non-metals) and even composite synthesis.

Nitrogen doped $\mathrm{TiO}_{2}$ nanocrystals were obtained by Wu et al. [76] using the hydrothermal method. They observed, as in most cases, that one of the critical parameters of this procedure is 
the treatment temperature. The main observation was in this paper that the final product's photocatalytic activity (methyl orange was used as a model pollutant) goes through a maximum as the treatment temperature increases.

Several attempts were made to obtain metal doped $\mathrm{TiO}_{2}$ nanocrystals by hydrothermal treatment of the amorphous slurries containing the dopant source. A relevant example could be the work done by León-Ramos et al. [77]. They obtained tungsten doped $\mathrm{TiO}_{2}$ nanoparticles, containing only pure anatase phase. The experiments revealed that by increasing the tungsten concentration, the crystallization degree of the titania increases concomitantly, under the same hydrothermal treatment condition. Similar observation were made by Wan et al. [78] by obtaining iron(III) doped titania: with the increase of the dopant concentration (in this case $\left.\mathrm{Fe}\left(\mathrm{NO}_{3}\right)_{3}\right)$ the crystallization degree of the sample increased and the rutile phase appeared.

Sometimes very complex, mixed (metal/non-metal) doping was achieved with the help of the hydrothermal treatment (Huang et al. [79]). Sb and S, Bi and S co-doped nanomaterials were obtained by the authors under hydrothermal conditions. They investigated 4-nitrophenol degradation under visible light correlating with the observed structural and morphological properties.

There are new reports about nanorod-shaped titanias, such as the papers published by Bae et al. [80-81]. They obtained $\mathrm{TiO}_{2}$ nanorods by hydrothermal treatment of $\mathrm{TiCl}_{3}$ in the presence of PVP (Polyvinylpyrrolidone) at $180{ }^{\circ} \mathrm{C}$ and 10 hours of treatment. No treatment parameters were investigated, but they managed to distinguish (with the help of $\mathrm{Pt}$ reduction and $\mathrm{Pb}$ oxidation to $\mathrm{PbO}_{2}$ ) the crystal facets. This would be unrealizable if the shape of the particles would not be controlled rigorously.

Yasui et al. [82] investigated the effect of the hydrothermal treatment temperature on the crystallinity of the final catalysts. The research group observed that by varying the temperature of the treatment no significant changes were observed in the crystal phase, although slight changes were observed in the particle size and porosity of the samples. The initial slurry's pH proved to be more critical. At acidic $\mathrm{pH}$ rutile was obtained and at basic $\mathrm{pH}$ values anatase.

Phan et al. [83] and Safei et al. [84] demonstrated that a lot of experiments could be done in the field of the conducted crystallization. Phan's group showed that a careful preparation of the initial slurry ( $\mathrm{pH}$, precursor) is necessary to obtain the desired shape and crystallinity/crystal 
phase. Safei and coworkers followed statistically (Plackett-Burman evaluation) several parameters that could change during the hydrothermal process.

As seen from the examples presented above, the hydrothermal treatment process requires an autoclave, high pressure (e.g. 80 bar), sometimes relatively high temperatures (e.g. $270{ }^{\circ} \mathrm{C}$ ) and in several cases a post calcination process for long time [13]. These facts made the process very expensive, circumstantial and not yet optimized for mass production of the photocatalytic materials. A solution could be the calcination as crystallization process, because requires affordable equipment (furnaces), no secondary post treatment processes are required and the only “dangerous" parameter is the applied, relatively high temperature. That is why the calcination is the most frequent crystallization technique applied for sol-gel made materials such as titanium dioxide.

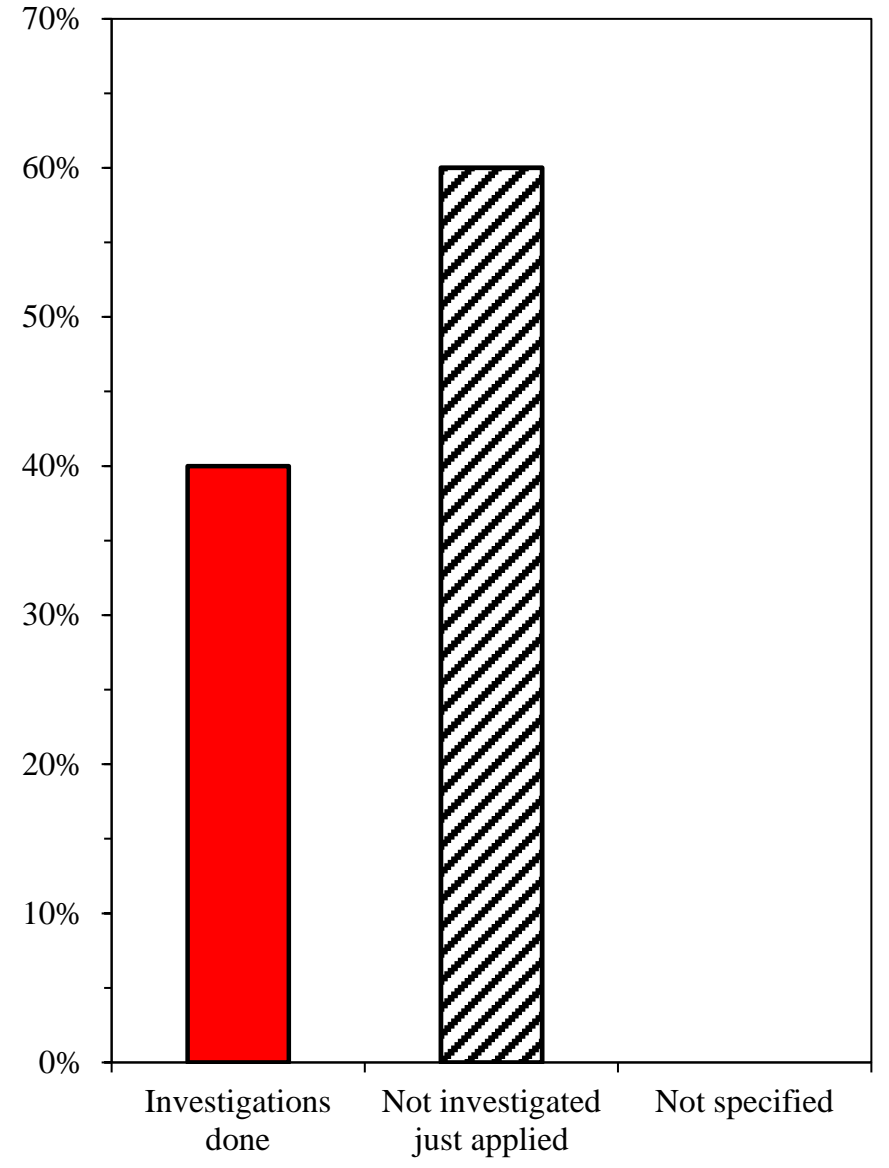

Figure 8 - The distribution of the papers' approach (in three categories) regarding the calcination temperature

\subsubsection{Crystallization by calcination}

The calcination is the most frequently used crystallization method for the sol-gel made titanias. The calcination parameters varied are usually the calcination temperature and sometimes the calcination atmosphere. However, nearly no reports are to be found in the literature regarding the calcination time, despite the easy controllability of this feature. To prove this a list of 50 papers is provided in Table 1, Appendices. The statistics presented in the following figures were estimated using 100 papers, but due to the long reference list only 50 are presented in Table 1, Appendices.

The calcination temperature in all cases is given, without exception. Despite 


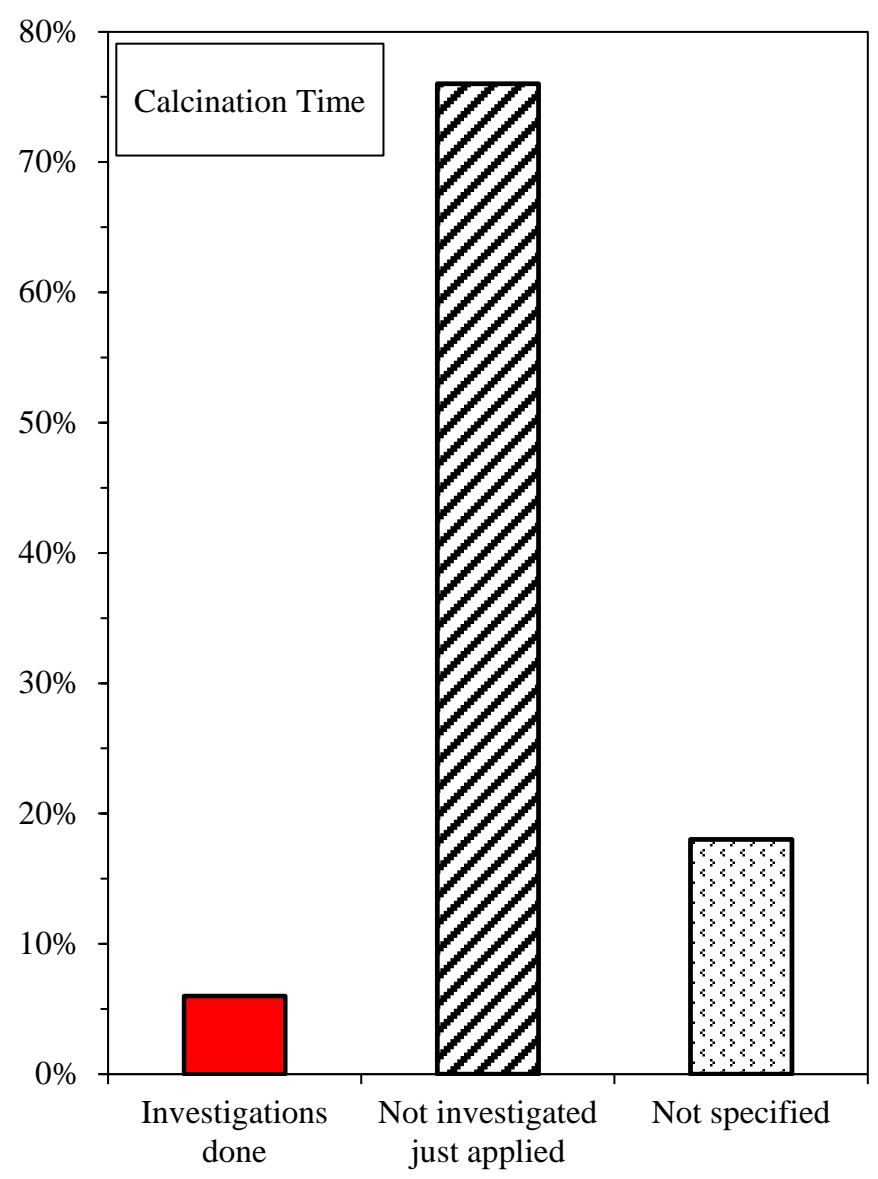

Figure 9 - The distribution of the papers' approach (in three categories) regarding the calcination time of this only $40 \%$ of the publications verified if indeed the treatment temperature had influence on their final catalysts’ properties.

In most situations the well-known anatase-rutile transformation is investigated as presented by Colón et al. [22, 56, 68-69]. Brookite formation after annealing is rarely reported in papers [85]. Furthermore $60 \%$ of the publications (Figure 8) just apply a given temperature without investigating the selected value.

Sometimes the calcination is used as a post-treatment method for already crystallized $\mathrm{TiO}_{2}$ (e.g. from hydrothermal treatment) [86], or just as a purification step (e.g. template removal). If we look upon this procedure, several authors

ignore the fact that by calcination in the presence of organic templates a carbon contamination is inevitable. Despite of this no experimental data were provided in these publications to prove or negate this fact.

The calcination atmosphere could be a critical parameter for the surface quality of the catalyst. The most frequently used atmosphere is air $[5,13,17,19-20,22,33,51,55-56,58,68-$ 69, 78, 87-91], sometimes nitrogen [21], oxygen [92], and $\mathrm{NH}_{3}$ [52] if nitrogen doping is desired. Usually, the calcination atmosphere's direct effect on the catalyst surface is mostly known, that's why no detailed investigations are presented in the papers.

Similarly to the calcination atmosphere, the calcination time (Figure 9) could be decisive in many aspects. This fact is revealed by the few studies made for the calcination time. Though these papers applied only long time heat treatments, usually $1 \mathrm{~h}$ or longer [3, 93-94]; shorter calcination times are not investigated at all. The fraction of the papers who tried to explain the 


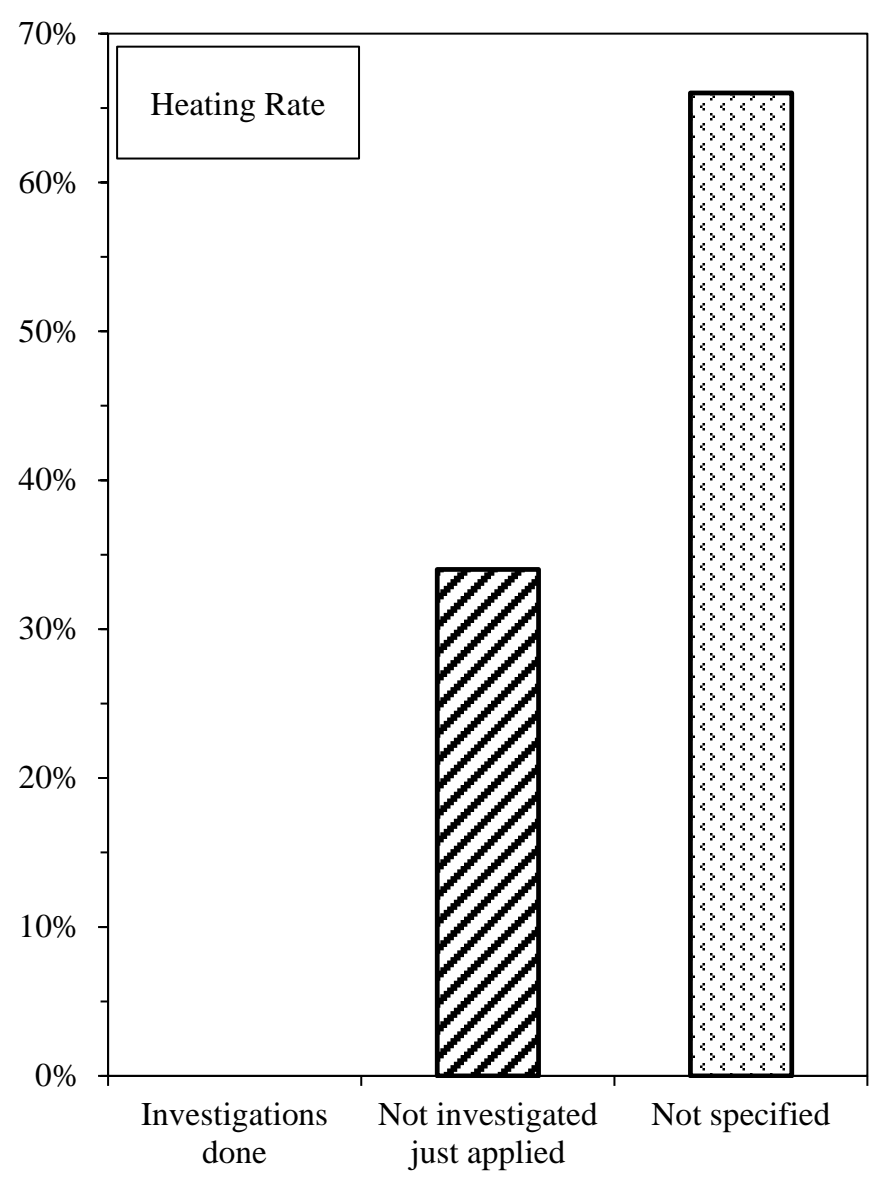

Figure 10 - The distribution of the papers' approach (in three categories) regarding the applied heating rate influence of the calcination time is $~ 5 \%$, whereas the ratio of the papers who did not even specify the value of the calcination time is nearly $19 \%[18,52$, 57, 66, 90, 95-97]. The rest of the studied papers (76\%) [5, 17, 19-23, 50-51, 56, 58, 61, 67-69, 79, 87-89, 91-92, 98-107] specify only the applied value without further comments or investigations. The total ignorance of the calcination time could be problematic if someone attempts to reproduce the presented results.

The situation is also critical in the case of the heating rates (Figure 10). In $\sim 65 \%$ of the papers taken in consideration $[3,5,13,17-18,20-22,33,50,52,55-57$, 61, 66, 68-69, 78, 87-88, 91-97, 99, 101102, 104-106, 108-109] the heating rate value is not provided and $35 \%$ of the

published material [19, 23, 28, 51, 58, 67, 79, 89-90, 100, 103, 107, 110] just simply gives the value without any supplementary explanation. Furthermore all the heating rates applied did not exceed the value of $20^{\circ} \mathrm{C} / \mathrm{min}$.

It is rather surprising, despite of being a very commonly used crystallization method, that some authors neglect the fact that the calcination parameters could have a major impact on the obtained nanomaterials structure, morphology and activity. Furthermore, if the necessary parameters are not provided, than the reproducibility of the published work could be questionable and may lead to major disagreements between the scientists working in the field of photocatalysis.

Fortunately a small number of papers appeared recently that proved that the calcination should be described carefully and in-detail. The most important is the work published by Joung et 
al. [111-112]. They managed to study the influence of the calcination time on the final properties of nitrogen doped titania. The mentioned paper presents two important study directions, namely:

i.) short calcination times in the frame of the photocatalytic activity

ii.) mechanistic aspects regarding the possible reaction, crystallization pathways during the calcination. Their managed to obtain highly active sol-gel made nitrogen doped $\mathrm{TiO}_{2}$ by doing the calcination only for 10-15 minutes (plus heating time) at 400 and $500{ }^{\circ} \mathrm{C}$. The activity of these samples was successfully tested for trichloroethylene decomposition under visible light with $\lambda \geq 420 \mathrm{~nm}$.

Beydoun et al. [113] obtained $\mathrm{Fe}_{2} \mathrm{O}_{3}-\mathrm{TiO}_{2}$ composites to investigate their photocatalytic and magnetic properties. They found that their titania was totally crystallized after 20 minutes of calcination. Furthermore, the highest photocatalytic activity was achieved at the shortest calcination time. These observations are similar to those described by Joung et al. [111-112].

The above mentioned research groups are probably the only ones discussing about short calcination times and their beneficial effects on the photocatalytic efficiency of titania nanomaterials. However, these papers did not provide any details regarding the study of the heating rate's influence, calcination atmosphere's importance or the calcination time's systematic study (related with other structural parameters). 


\section{Materials}

Titanium dioxide precursor used: $\mathrm{TiCl}_{4}$ titanium(IV) chloride (Purum, $\geq 98.0 \%$, SigmaAldrich)

Materials used during the hydrolytic process:

1.) $\mathrm{HCl}$ - hydrochloric acid (Reagent Grade, 37\%, Scharlau)

2.) $\mathrm{CH}_{3} \mathrm{COOH}$ - acetic acid (Reagent Grade, 97\%, Sigma-Aldrich)

3.) $\mathrm{NH}_{3}$ - aqueous solution of ammonia (puriss. p.a., 25\%, Scharlau)

4.) $\mathrm{HNO}_{3}$ - nitric acid (70\%, ACS reagent)

\section{Additional nitrogen source}

1.) Urea - (purum, $\geq 98.0 \%$, Sigma-Aldrich)

Materials used for the catalysts washing process

1.) Milli-Q water (all the solutions and suspensions were made with this type of water)

2.) Ethanol (purum, absolute alcohol, Fluka)

Materials used in the photocatalytic experiments

Reference photocatalysts:

1.) Evonik Aeroxide P25 (79\% anatase, 21\% rutile)

2.) Aldrich Anatase (>97\% anatase)

3) Sumitomo Chemicals’ TP-S201 (reference nitrogen doped photocatalyst)

\section{Model pollutants}

1.) Phenol (puriss, VWR chemicals)

2.) Monuron (puriss, Sigma-Aldrich)

\section{Eluents used for phenol and monuron separation (HPLC)}

1.) Milli-Q water (all the solutions and suspensions were made with this type of water)

2.) Methanol (HPLC grade, Promochem)

3.) Acetonitrile (HPLC grade, Promochem) 


\section{Methods and instrumentation}

\subsection{X-ray powder diffraction (XRD)}

X-ray diffraction (XRD) patterns were recorded on a Rigaku and Shimadzu 6000 diffractometer under the following conditions: $\lambda_{\mathrm{Cu} \mathrm{K \alpha}}=0.15406 \mathrm{~nm}, 40 \mathrm{kV}$, and $30 \mathrm{~mA}$, in the 20 $-40^{\circ}(2 \Theta)$ region. The average diameters of the particles were estimated using the Scherrer equation (Equation 1), where $K$ is the shape factor (it depends on the crystallite type), $\lambda$ is the applied X-ray's wavelength, $\beta_{S}$ is the line broadening at half the maximum intensity in radian for the sample, $\beta_{0}$ is the instrumental broadening in radian (determined by using silicon single crystal) and $\Theta$ is the Bragg angle:

$$
\mathrm{d}=\frac{\mathrm{K} \cdot \lambda}{\left[\left(\beta_{\mathrm{S}}-\beta_{0}\right) \cdot \cos \Theta\right]} \quad \text { Equation } 1 .
$$

The weight (W) fraction of each crystal phase was calculated for each sample from the peak areas of the anatase $\left(A_{A}\right)$, rutile $\left(A_{R}\right)$ and brookite $\left(A_{B}\right)$ peaks at $25.3^{\circ}(2 \Theta)(101), 27.5^{\circ}$ (110) $(2 \Theta)$ and $30.8^{\circ}(2 \Theta)(121)$ respectively. Throughout the calculation some correction factors $\left(\mathrm{k}_{\mathrm{A}}, \mathrm{k}_{\mathrm{B}}\right)$ were applied for each peak area, as follows [114](Equation 2):

$$
\begin{aligned}
& \mathrm{W}_{\mathrm{A}}=\frac{\mathrm{k}_{\mathrm{A}} \cdot \mathrm{A}_{\mathrm{A}}}{\mathrm{k}_{\mathrm{A}} \cdot \mathrm{A}_{\mathrm{A}}+\mathrm{A}_{\mathrm{R}}+\mathrm{k}_{\mathrm{B}} \cdot \mathrm{A}_{\mathrm{B}}} \\
& \mathrm{W}_{\mathrm{R}}=\frac{\mathrm{A}_{\mathrm{R}}}{\mathrm{k}_{\mathrm{A}} \cdot \mathrm{A}_{\mathrm{A}}+\mathrm{A}_{\mathrm{R}}+\mathrm{k}_{\mathrm{B}} \cdot \mathrm{A}_{\mathrm{B}}} \\
& \mathrm{W}_{\mathrm{B}}=\frac{\mathrm{k}_{\mathrm{B}} \cdot \mathrm{A}_{\mathrm{B}}}{\mathrm{k}_{\mathrm{A}} \cdot \mathrm{A}_{\mathrm{A}}+\mathrm{A}_{\mathrm{R}}+\mathrm{k}_{\mathrm{B}} \cdot \mathrm{A}_{\mathrm{B}}}
\end{aligned}
$$

In all the calculations the value for $\mathrm{k}_{\mathrm{A}}$ was 0.886 and for $\mathrm{k}_{\mathrm{B}} 2.721$, respectively. All the data processing was carried out with the help of Origin 8.0 SR4 and APD 3.5b software.

\subsection{Diffuse reflectance Spectroscopy (DRS)}

The DRS spectra of all the samples were recorded to determine the sample's UV-VIS light absorption capacity, on a Jasco-V650 diode array, computer controlled (with SpectraManager software) spectrophotometer equipped with an ILV-724 integration sphere. The recorded spectral data was acquired in the $220-800 \mathrm{~nm}$ range, with $0.5 \mathrm{~nm}$ data pitch and 100 
$\mathrm{nm} / \mathrm{min}$ scan speed. When higher resolution of the spectra was needed (usually in the 400-525 $\mathrm{nm}$ ) the data pitch was changed to $0.05 \mathrm{~nm}$ and the scan speed to $50 \mathrm{~nm} / \mathrm{min}$.

\subsection{The specific surface area determination by nitrogen adsorption (BET evaluation method)}

The specific surface area of the catalysts was determined by nitrogen adsorption at $77 \mathrm{~K}$ by a Micrometrics gas adsorption analyzer (Gemini Type 2375). All the samples received a preliminary heat treatment at $100-120^{\circ} \mathrm{C}$ under $10^{-2}$ Torr vacuum for 4 hours to eliminate the trace amount of water present in the samples. The specific surface area was calculated using the BET method.

\subsection{Thermogravimetry and differential thermal analysis (TG-DTA)}

Thermoanalytical measurements (TG-DTA) were carried out on a Mettler-Toledo instrument. The applied sample weight was $5 \mathrm{mg}$ and the heating rate was $60{ }^{\circ} \mathrm{C} / \mathrm{min}$. The unusual heating rate was chosen because in the synthesis of the nanoparticles the calcination was carried out similarly.

In case of the thermogravimetric (TG) measurements the weight change of the sample was followed to give information about the amorphous material's composition by observing weight loss steps (water evaporation, inorganic salt's sublimation, the oxidation of the organic deposits, dehydroxylation of the surface, etc.). From the differential thermal analysis (DTA) we received information regarding the crystal phase change, such as the exothermic anatase-rutile transformation.

\subsection{Scanning and transmission electron microscopy (SEM, TEM)}

SEM-EDX analysis was performed to evaluate the morphology of the amorphous starting material and the obtained well crystallized catalysts on a Hitachi S-4700 Type II cold field emission scanning electron microscope equipped with a Röntec QX2-EDS spectrometer. No conductive coatings were applied on the samples so the fine morphological details could be observed.

Transmission electron microscopic (TEM) studies were performed to characterize the particle size and size distribution and also to observe the morphology of the particles. The TEM 
micrographs were recorded on a Philips CM 10 instrument operating at $100 \mathrm{kV}$ using Formvar coated copper grids. AnalySIS software was used for image processing and particle size determination.

\subsection{X-ray photoelectron spectroscopy (XPS)}

$\mathrm{X}$-ray photoelectron spectra of selected samples were taken with a SPECS instrument equipped with a PHOIBOS 150 MCD 9 hemispherical electron energy analyzer operated in the FAT mode. The excitation source was the $\mathrm{K}_{\alpha}$ radiation of a magnesium anode $(h \cdot v=1253.6 \mathrm{eV})$. The X-ray gun was operated at $180 \mathrm{~W}(12 \mathrm{kV}, 15 \mathrm{~mA})$. The pass energy was set to $20 \mathrm{eV}$, the step size was $25 \mathrm{meV}$, and the collection time in one channel was $150 \mathrm{~ms}$. Typically five scans were added to get a single spectrum.

The C 1s binding energy of adventitious carbon $(285.1 \mathrm{eV})$ was used to calibrate the energy scale. Data acquisition and evaluation was performed using both the manufacturer's (SpecsLab 2) and commercial (CasaXPS, Origin 8.0 SR4) software and before data analysis Xray satellites, originating from the non-monochromatic excitation source, were removed from the spectra.

The data acquisition focused on the detection of Ti $(454-470 \mathrm{eV}), \mathrm{O}(525-536 \mathrm{eV}), \mathrm{N}$ (390 - $410 \mathrm{eV})$ and $\mathrm{C}(275-295 \mathrm{eV})$. These 4 elements were considered to have crucial influence on the surface properties of the obtained nanosized titania.

\subsection{Total organic carbon determinations (TOC)}

Total organic carbon measurements of the catalysts $(10 \mathrm{mg})$ were performed with a Euroglas 1200 TOC instrument. The TOC calibration curve was determined using aqueous solutions of glucose and each determination was reproduced three times. These measurements were executed to evaluate the quantity of the organic residues that are still present at the catalyst's surface, even after calcination.

\subsection{Infrared spectroscopy and Raman (IR)}

Infrared spectra of the catalysts were recorded on two instruments. Bio-Rad Digilab Division FTS-65A/896 FT-IR spectrometer equipped with Harrick's Meridian SplitPea single 
reflectance diamond ATR accessory were used, in the range of $4000-400 \mathrm{~cm}^{-1}$, at $4 \mathrm{~cm}^{-1}$ optical resolution. 256 interferrograms were accumulated providing high signal-to-noise ratio.

Bruker Equinox 55 spectrometer with an integrated FRA 106 Raman module using NdYAG laser (1064 nm) was also used in the determination of IR and RAMAN spectra. The measurements were recorded with a power incident of $300 \mathrm{~mW}$ and a spectral resolution of $1 \mathrm{~cm}^{-}$ ${ }^{1}$. Samples were ground with $\mathrm{KBr}$ pressed into thin pellets (thickness $\sim 0.3 \mathrm{~mm}$ ) and IR spectra were recorded with a spectral resolution of $2 \mathrm{~cm}^{-1}$. Under these conditions, the catalyst's visible light sensitizing groups were followed, such as $-\mathrm{NH}_{2}$ (at $1517 \mathrm{~cm}^{-1}$ ) and long chained hydrocarbons ( $\left.2500 \mathrm{~cm}^{-1}\right)$. The surface OH groups' presence was also monitored at $1535 \mathrm{~cm}^{-1}$. All data were processed using Origin 8.0 SR4 and eXPFit by Dr. Roger Nix a Microsoft Office Excel add-in.

\subsection{High performance liquid chromatography (HPLC)}

The concentration decrease of the chosen pollutant (phenol and monuron) was followed using an Agilent 1100 series HPLC system. This consists of a binary pump; a micro vacuum degasser; a diode array detector $\left(\lambda_{\mathrm{d}}=210 \mathrm{~nm}\right)$; a thermostated column compartment and ChemStation data managing software. The chromatographic system was equipped with Rheodyne Model 7725 injector with a $20 \mu \mathrm{L}$ loop and a Licrospher RP-18 column. The eluent consisted of 5:9 methanol: water $(\mathrm{v} / \mathrm{v})$ mixture for phenol and a 1:1 acetonitrile: water $(\mathrm{v} / \mathrm{v})$ mixture for monuron; and the flow rate in all the cases was $0.8 \mathrm{~mL} / \mathrm{min}$.

\subsection{Photoreactors and the evaluation of the reaction rates}

All the photocatalytic experiments were carried out in a Heraeus photoreactor (Figure 11) equipped with OSRAM Power Star $\mathrm{HCl}$-TC $70 \mathrm{~W} / \mathrm{WDL}$ (in case of visible light driven degradation experiments) or TQ-150 high pressure mercury lamp (for UV photodegradation). 


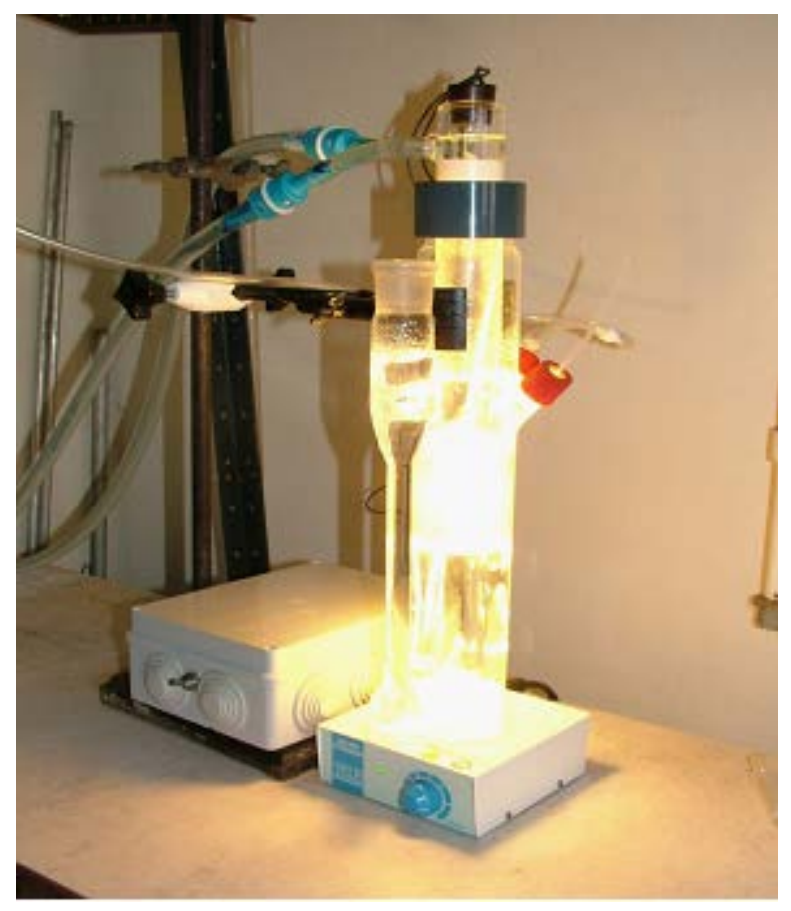

Figure 11 - Heraeus photoreactor system, used in all the photodegradation experiments

Photocatalyst suspensions $(400 \mathrm{~mL})$ containing phenol or monuron $\left(\mathrm{c}_{0}\right.$, phenol or monuron $=0.1$ $\mathrm{mM}, \mathrm{c}_{\mathrm{TiO} 2}=1.0 \mathrm{~g} / \mathrm{L}$ ) were used in all the experiments. In the case of visible light photodegradation $1 \mathrm{M} \mathrm{NaNO}_{2}$ was circulated in the cooling jacket of the lamp to cut off any remaining UV component ( $\lambda>400 \mathrm{~nm}$ ) and to avoid the suspension's overheating (in the UV degradation experiments Milli-Q water was applied). The reactor was continuously purged by air $(40 \mathrm{~L} / \mathrm{h})$ in order to keep a constant concentration of dissolved oxygen during the whole experimental run.

The initial photocatalytic degradation rate of the model compounds, $\left(\mathrm{r}_{0}\right)$ was considered to evaluate the efficiency of the photocatalyst. To determine $r_{0}$, an empirical function was fitted to the experimentally observed data points. Then, $\mathrm{r}_{0}$ was evaluated from the slope of the curve (when, $\mathrm{t}=0$ ).

\subsection{Other instruments used throughout the experiments}

The heat treatment of the amorphous titania was executed in a tubular furnace (Thermolyne 21100, total length $38 \mathrm{~cm}$, quartz tube length $64 \mathrm{~cm}$, tube interior diameter $5.5 \mathrm{~cm}$, quartz tube diameter $4 \mathrm{~cm})$. 


\section{The main objectives of the present $\mathrm{PhD}$ thesis}

As it can be seen from the literature overview presented, the calcination step was considered to be a trivial one. Thus, in the majority of the research papers, related to the present topic (sol-gel made titanias), no attention was given to the calcination parameters, such as the calcination time, atmosphere, furnace type and heating rates.

So, the present thesis investigates and elucidates the above mentioned parameters (focusing mostly on the treatment time) and has the following main/supplementary objectives (keywords for the current research are underlined):

1.) The calcination time as a critical parameter in the synthesis of titania photocatalysts at a given temperature.

a.) The effect of the heat treatment time on the structure and morphology of $\mathrm{TiO}_{2}$

i.) Crystal phase composition and primary particle size.

ii.) Optical properties of the obtained nanomaterials

iii.) Crystallite shape and porosity

iv.) The investigation of the catalysts' surface chemical composition

b.) The photocatalytic activity in the frame of the calcination time

i.) Activity measurements on separate substrates (and compared with reference photocatalysts’ activity)

ii.) The correlation between the catalysts' activity - morpho-structural properties and calcination time

2.) The calcination time's impact on the whole heat treatment temperature scale

a.) The effect of the heat treatment time on the structure and morphology of $\mathrm{TiO}_{2}$

i.) Crystal phase composition and primary particle size

ii.) Optical properties of the obtained nanomaterials

iii.) Advanced surface specie identification

iv.) Determination of the surface chemical composition

b.) The photocatalytic activity in the frame of the calcination time

i.) Activity measurements and the construction of the activity - calcination time calcination temperature diagram 


\section{ii.) The calcination time - surface parameters and activity correlation}

3.) The fast heat treatment's impact on nitrogen doped titanias for visible light driven photocatalysis

a.) The effect of the heat treatment on the structure and morphology of $\mathrm{N}-\mathrm{TiO}_{2}$

i.) Crystal phase composition and primary particle size

ii.) Optical properties of the obtained nanomaterials

iii.) Advanced surface specie identification

b.) The fast heat treatment's impact on the nitrogen incorporation 


\section{The synthesis of the fast heat treated titanias}

$\mathrm{TiO}_{2}$ samples were synthesized by a sol-gel method. $20.0 \mathrm{~mL}$ (to ensure the necessary quantity of base material) of $\mathrm{TiCl}_{4}$ was added dropwise under vigorous stirring into $40.0 \mathrm{~mL}$ of concentrated hydrochloric acid solution. All chemicals were used without further purification. To avoid the overheating of the mixture from exothermic processes, the reaction vessel was cooled on an ice bath with the temperature maintained between $0-5{ }^{\circ} \mathrm{C}$. This mixture was added dropwise under intense stirring into $600.0 \mathrm{~mL}$ of high purity Milli-Q water. The final $\mathrm{pH}$ was below 1.0 and subsequently $10.4 \mathrm{~mL}$ of glacial acetic acid was also added dropwise. The $\mathrm{pH}$ was adjusted with an aqueous solution of ammonia (25\%) until a pH of 8 was obtained. The mixture was left for 2 days at room temperature to complete the hydrolysis. The precipitate was dried at $80^{\circ} \mathrm{C}$ for 24 hours and the resultant white powder was milled.

This amorphous powder ( $30 \mathrm{~g}$ ) was calcinated by heating in a quartz boat placed within a quartz tube in a tubular furnace under still air. A special heat treatment procedure was developed in which the temperature of the amorphous material was raised to the desired calcination temperature in a short time applying high heating rate in three steps (60, 20 and $\left.10^{\circ} \mathrm{C} / \mathrm{min}\right)$. The heating rate was decreased as the temperature reached the threshold to prevent the overheating of the furnace. The studied calcination temperatures were: 400, 500, 550, 600 and $700{ }^{\circ} \mathrm{C}$ with calcination times of 5, 7.5, 10,12, 15, 20, 30, 60, 90, 120 and 180 minutes at the given temperature. The gaseous thermal decomposition by-products were purged from the system by air in the last minute of the calcination procedure. The samples were kept for the pre-determined time at the given oven temperature, then removed from the furnace and left to cool down to room temperature.

The obtained samples were washed and centrifuged in Milli-Q water or in ethanol-water mixture ( $50: 50 \mathrm{v} / \mathrm{v} \%, 0.8 \mathrm{~g}$ product $/ 50 \mathrm{~mL}$ ) three times in order to remove any soluble impurities. The powder was finally redispersed in Milli-Q water and irradiated in a Petri dish with UV irradiation $(\lambda=365 \mathrm{~nm})$ to remove any organic traces from the $\mathrm{TiO}_{2}$ samples.

The samples obtained by applying 5-20 minutes of calcination time were named RHSE (rapid heating short exposure), the samples calcined at 30 and 60 minutes were coded RHME (rapid heating medium exposure); the samples calcined longer than 60 minutes (90, 120 and 180) were coded RHLE ( rapid heating long exposure). Catalysts prepared in a traditional calcination method were called SHLE (slow heating $\left(5^{\circ} \mathrm{C} / \mathrm{min}\right)$ and long exposure (180 minutes)). The name 
of a given sample also indicates the calcination temperature (in ${ }^{\circ} \mathrm{C}$ ) and the calcination time (in minutes) at the given final temperature, separated by hyphen, for example RHSE-600-10. The "w” prefix indicated that all the inorganic salts were washed out before the calcination process.

Two samples were prepared starting from titanium (IV) isopropoxide (TTIP) to highlight the effects of the fast heat treatment on other sol-gel prepared titania. Two solutions were made; the first solution was prepared by adding $5.0 \mathrm{~mL}$ of TTIP to $7.5 \mathrm{~mL}$ of ethanol while the second contained $7.5 \mathrm{~mL}$ of ethanol, $0.75 \mathrm{~mL}$ of Milli-Q water and $85 \mu \mathrm{L}$ of nitric acid (70 \%). This solution was added dropwise to the first one, whilst being vigorously stirred, until a gel was formed. This gel was aged for 7 days and then equally divided into two parts for different heat treatments. The first sample was heated in the conventional method $\left(5^{\circ} \mathrm{C} / \mathrm{min}, 3\right.$ hours at $500{ }^{\circ} \mathrm{C}$ under air flow of $300 \mathrm{~mL} / \mathrm{min}$ ) whilst the second part was treated with the special modified heat treatment $\left(60^{\circ} \mathrm{C} / \mathrm{min}\right.$ until $160{ }^{\circ} \mathrm{C}$, then $20^{\circ} \mathrm{C} / \mathrm{min}$ until $450{ }^{\circ} \mathrm{C}$, and $10^{\circ} \mathrm{C} / \mathrm{min}$ until $500{ }^{\circ} \mathrm{C}$, the heat treatment time at $500{ }^{\circ} \mathrm{C}$ was 10 minutes, in still air). These samples are referred as SG-C (conventional calcination) and SG-S (special calcination), respectively.

Reference sample (to have a direct comparison with a catalyst that has been obtained by sol-gel followed by a traditional calcination) (wSHLE-450-180) was synthesized by a sol-gel synthesis method [4], in which the amorphous sample was washed before calcination and the powder was heated with a slow heating rate $\left(5^{\circ} \mathrm{C} / \mathrm{min}\right)$ and kept at $450{ }^{\circ} \mathrm{C}$ for 3 hours under permanent air flow (300 $\mathrm{mL} / \mathrm{min})$. 


\section{The influence of rapid heat treatment in still air on the photocatalytic activity of titania photocatalysts}

\subsection{Structure and morphology of the obtained nanocatalysts}

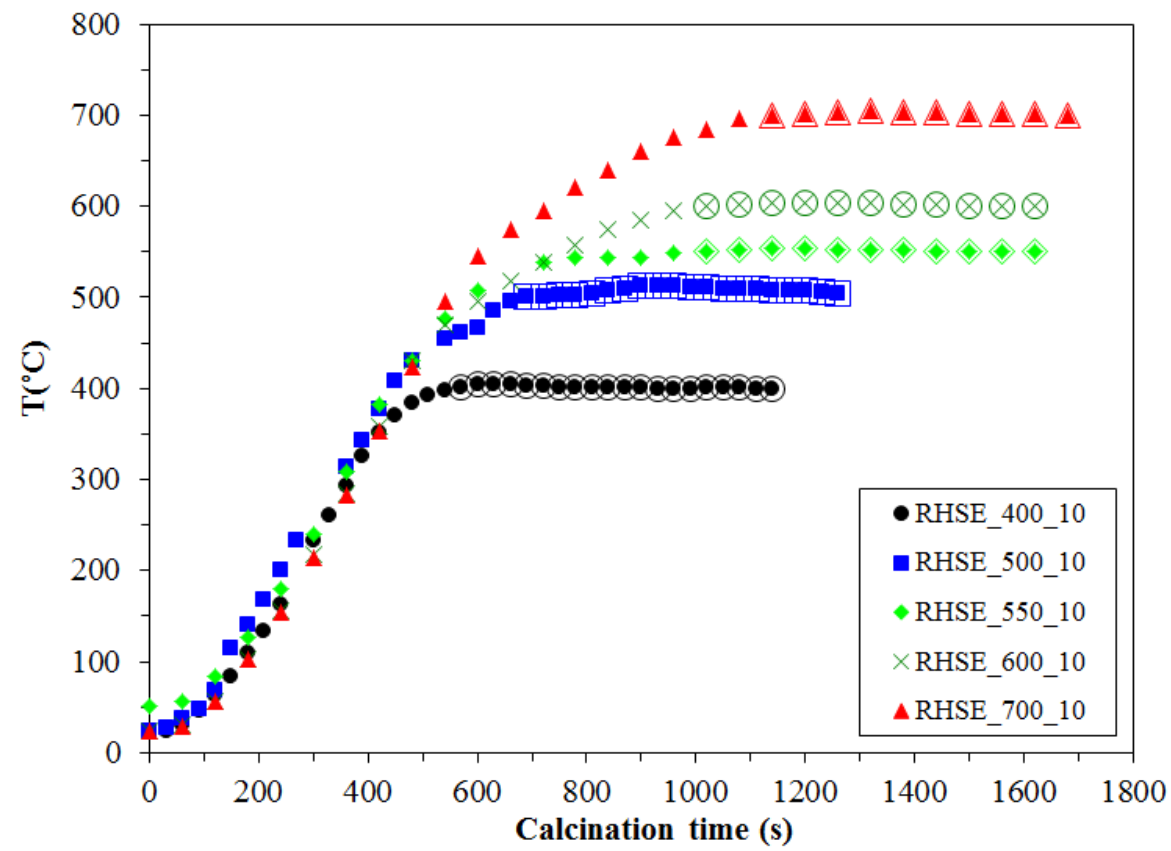

Figure 12 - Temperature profiles during the calcination of RHSE samples between 400 and $700{ }^{\circ} \mathrm{C}$ using 10 minutes as calcination time

Attempting to reproduce several synthesis modes for titania photocatalysts presented in the literature, it was observed that certain synthesis parameters such as the geometry of the furnace and the flow conditions are usually not well described although may have a significant effect on the quality of the product. The majority of the published works uses the conventional heat treatment with a continuous airflow (detailed in the previous sections). Whilst using the newly developed heating temperature profile, it was observed that a permanent airflow causes the synthesized powder to gradually change color along the $\mathrm{x}$-axis of the boat from off-white to yellow. The inhomogeneous color is caused by the airflow transferring gaseous by-products across the quartz boat. 


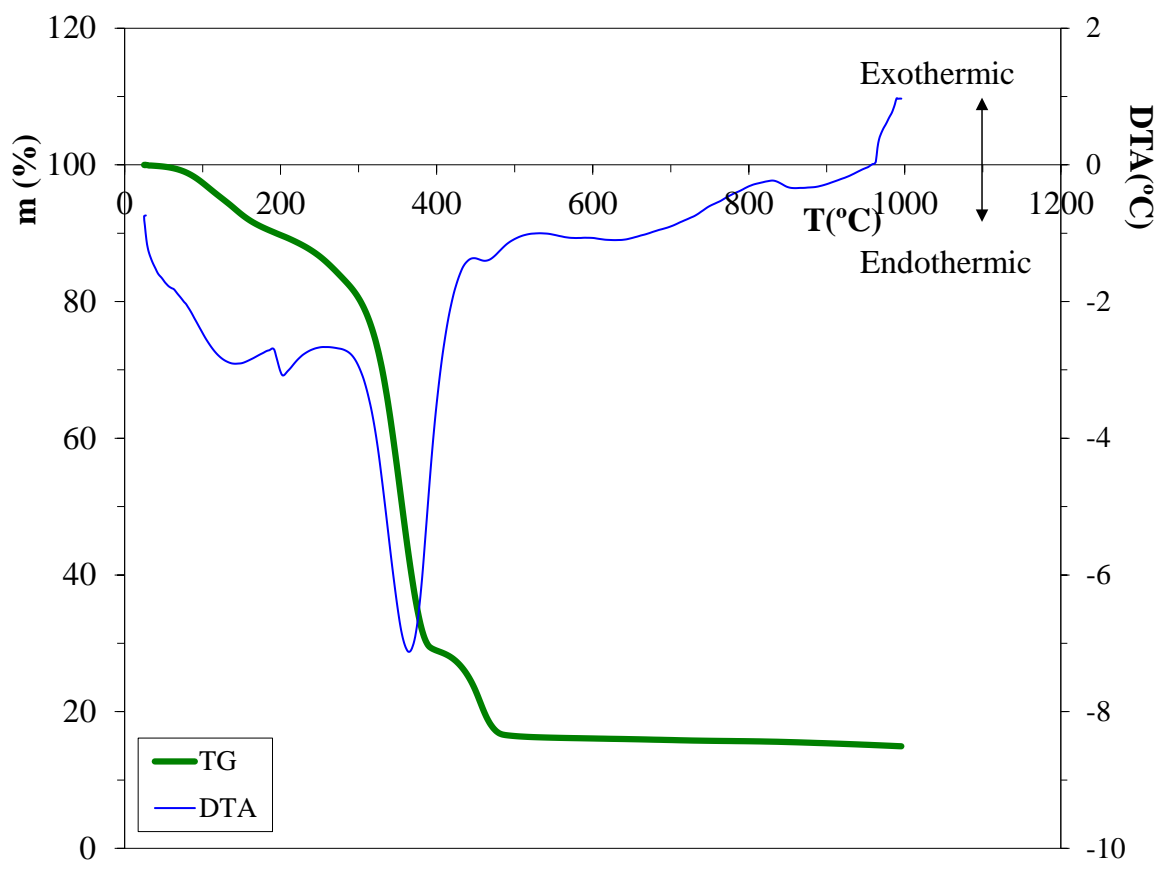

Figure 13 - Thermoanalytical measurements of the amorphous starting material, TG and DTA curves are shown

To minimize this transportation effect, the amorphous material was heated up to the calcination temperature in static air then subjected to intense air purge $(\sim 600 \mathrm{~mL} / \mathrm{min})$ for the last minute of the heat treatment. During the heating step, gaseous by-products are released and diffused to both end of the quartz tube.

Throughout this step the valve after the flow meter is closed. These compounds also form a white deposit on the unheated wall of the quartz tube. In the purge down step, an intense airflow was used to remove these compounds and during this procedure, a significant amount of smoke was released. This method produced a more homogeneous colored sample.

However, there were some small differences in the yellow color of the powder along the $y$-axis and this is most likely due to the convection profile of the gaseous by-products. The applied temperature profiles are shown in Figure 12.

Three heating rate sections can be distinguished: 60,20 and $10{ }^{\circ} \mathrm{C} / \mathrm{min}$. The beginning of the temperature plateau was when the temperature of the furnace reached the desired value and its length was 10 minutes for these experiments. The sample was taken out from the furnace and was left to cool down at room temperature. 
Thermoanalytical measurements of the obtained amorphous starting material were carried out at the heating rate of $60{ }^{\circ} \mathrm{C} / \mathrm{min}$ Figure 13. Considerable weight loss was observed between 25 and $450{ }^{\circ} \mathrm{C}$. This step took only about 7 minutes and consisted of three main weight loss steps placed at $25-200,200-380$ and $380-500{ }^{\circ} \mathrm{C}$. The first is most likely due to the loss of adsorbed and structural water as the sample contained ammonium acetate, which is very hygroscopic. The other two steps involved the decomposition of ammonium chloride and ammonium acetate and the titanium (IV) oxide-hydroxide transformation to amorphous $\mathrm{TiO}_{2}$. All these steps are endothermic. The crystallization of the sample took place between $420-550{ }^{\circ} \mathrm{C}$ (small exothermic, overlapped peak), which was followed by a small exothermic peak indicating the anatase-rutile transformation at $650-900{ }^{\circ} \mathrm{C}$ [115].

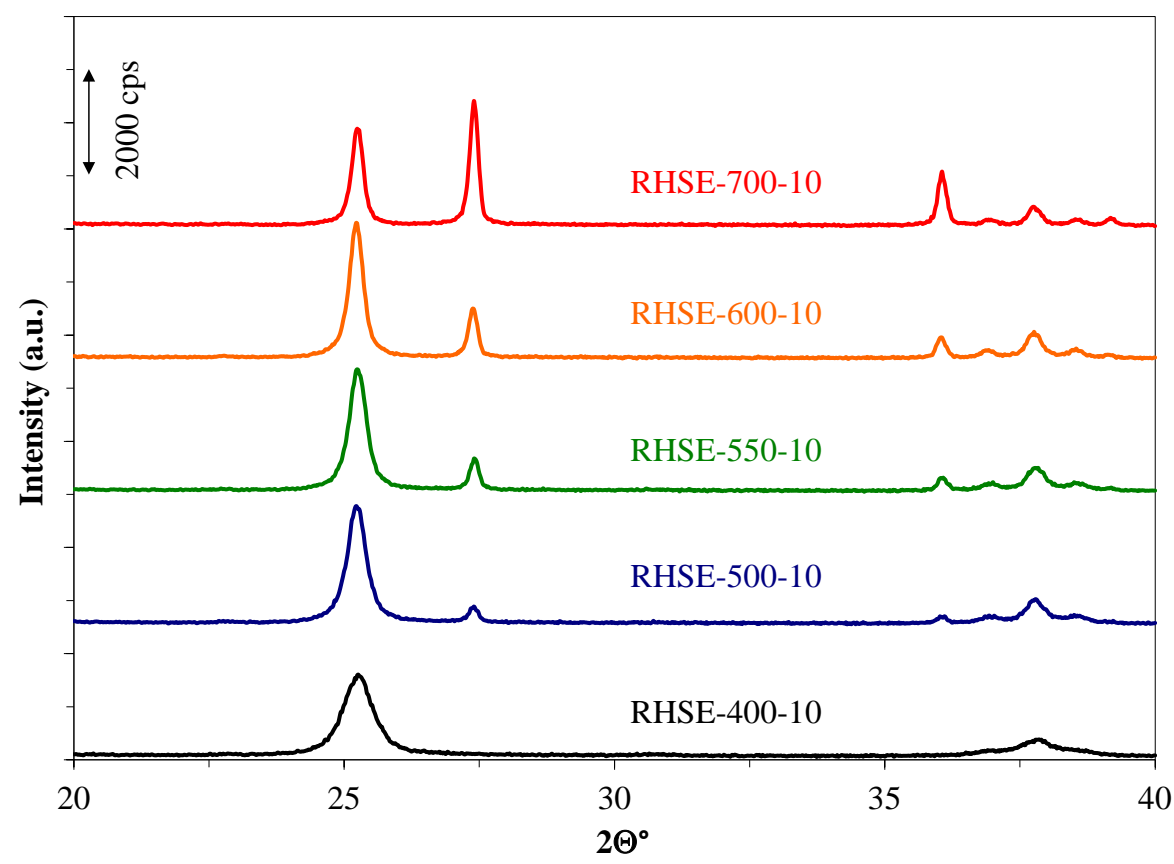

Figure 14 - XRD patterns of samples treated for 10 minutes at different temperatures in the rapid heating-up procedure $\left(400-700^{\circ} \mathrm{C}\right)$

The majority of the papers describe the calcination as procedures lasting between 1-5 hours without any mentioned reason. The effects of short heating cycle could have only been studied by applying the fastest possible heating rate otherwise the heating up step would take too long (typical heating rates $2-5{ }^{\circ} \mathrm{C} / \mathrm{min}$ ). The newly developed method involves three different heating rate periods, which makes possible to approach the end-point without exceeding the calcination temperature, with an accuracy of the set point of $\pm 2{ }^{\circ} \mathrm{C}$. 


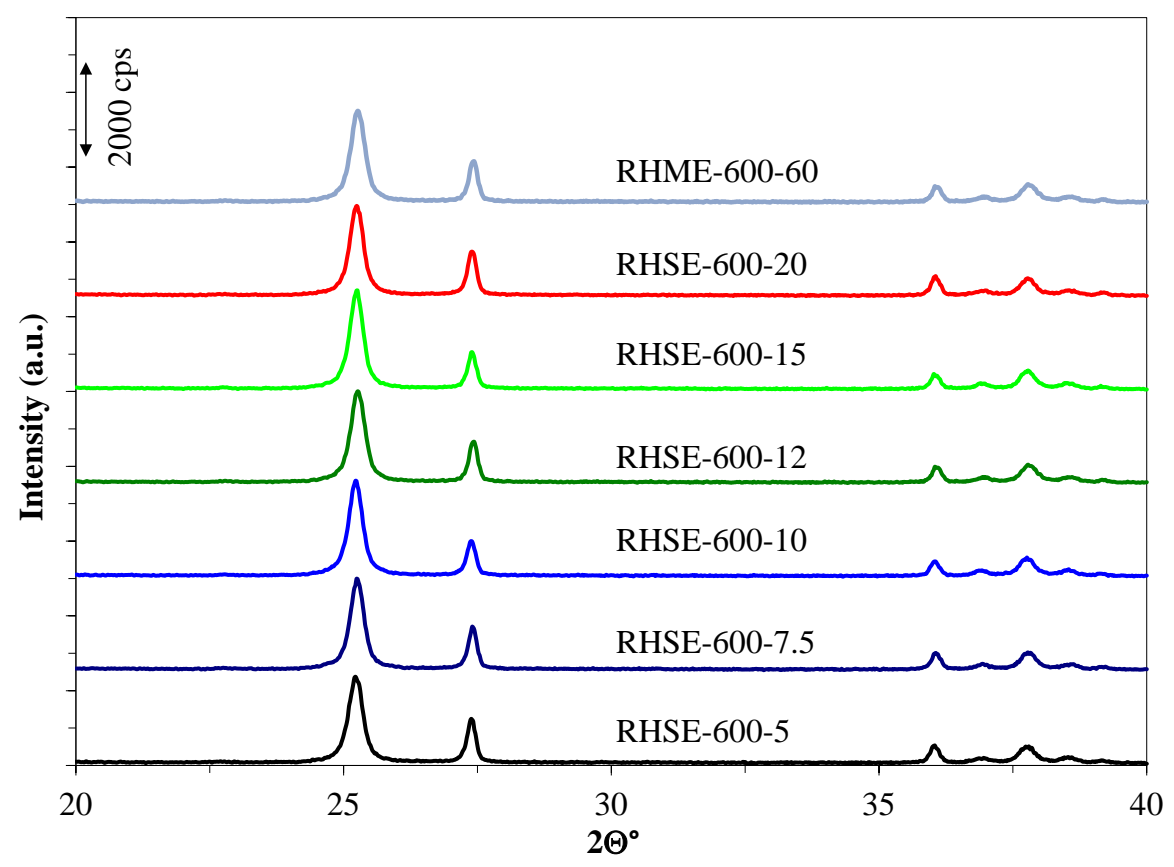

Figure 15 - XRD patterns of samples prepared at $600{ }^{\circ} \mathrm{C}$ calcinated for different times between 5 and 20 minutes, and 60 minutes respectively

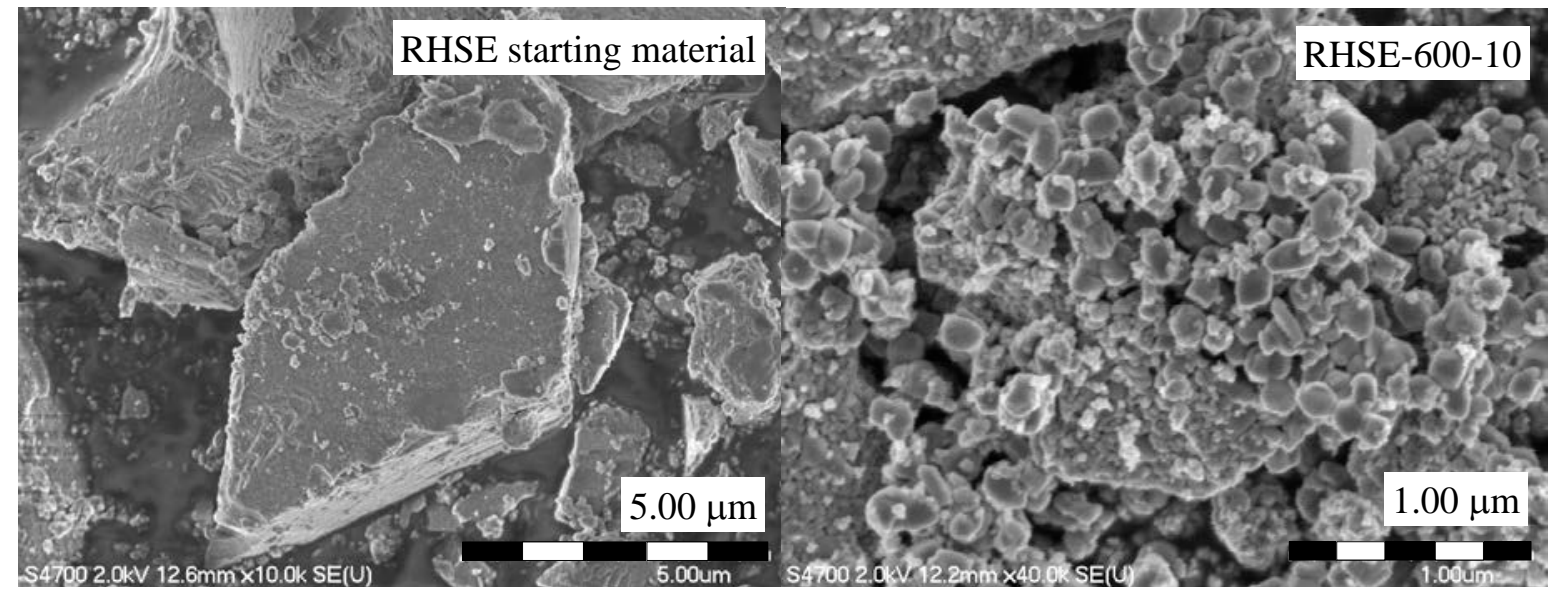

Figure 16 - SEM images: amorphous starting material (left); b, RHSE-600-10 sample (right)

Figure 14 shows the effects of calcination temperature (400, 500, 550, 600 and $700{ }^{\circ} \mathrm{C}$ ), using 10 minutes of calcination time, on the XRD patterns of the resulting sample, whilst Table 2, Appendices summarizes the main temperature depending morpho-structural characteristics of these samples.

The peak at $25.3^{\circ}(2 \Theta)$ shows that sample calcinated at $400{ }^{\circ} \mathrm{C}$ solely consists of anatase nanoparticles. By increasing the temperature up to $500{ }^{\circ} \mathrm{C}$, the rutile phase appears, whilst between 600 and $700{ }^{\circ} \mathrm{C}$, the rutile content increased from $17.5 \mathrm{wt} \%$ to $48.7 \mathrm{wt} \%$. The particle 
diameter for both phases, indicated by the sharpening of the diffraction peaks, increases in conjunction with the temperature rising. The average diameter of anatase nanoparticles increases from 15 to $54 \mathrm{~nm}$. Rutile particles diameters are between 90-100 nm, which are initially larger than the anatase particles. Caution should be taken when analyzing larger particle size (>50 nm) from line broadening as equipment inaccuracies may become significant.

The preliminary experiments revealed that the best photocatalytic activity was for the sample prepared at $600{ }^{\circ} \mathrm{C}$ so the effect of calcination time was investigated using samples which were maintained at $600{ }^{\circ} \mathrm{C}$ for $5,7.5,10,12,15,20,30,60,90$ and 120 minutes. The XRD patterns are similar for all the samples (Figure 15) and Table 3, Appendices lists the main parameters The anatase content varied somewhat between 76 and $82 \mathrm{wt} \%$ and the particle diameter was almost constant for these samples ( $\mathrm{D}=38-42 \mathrm{~nm})$.

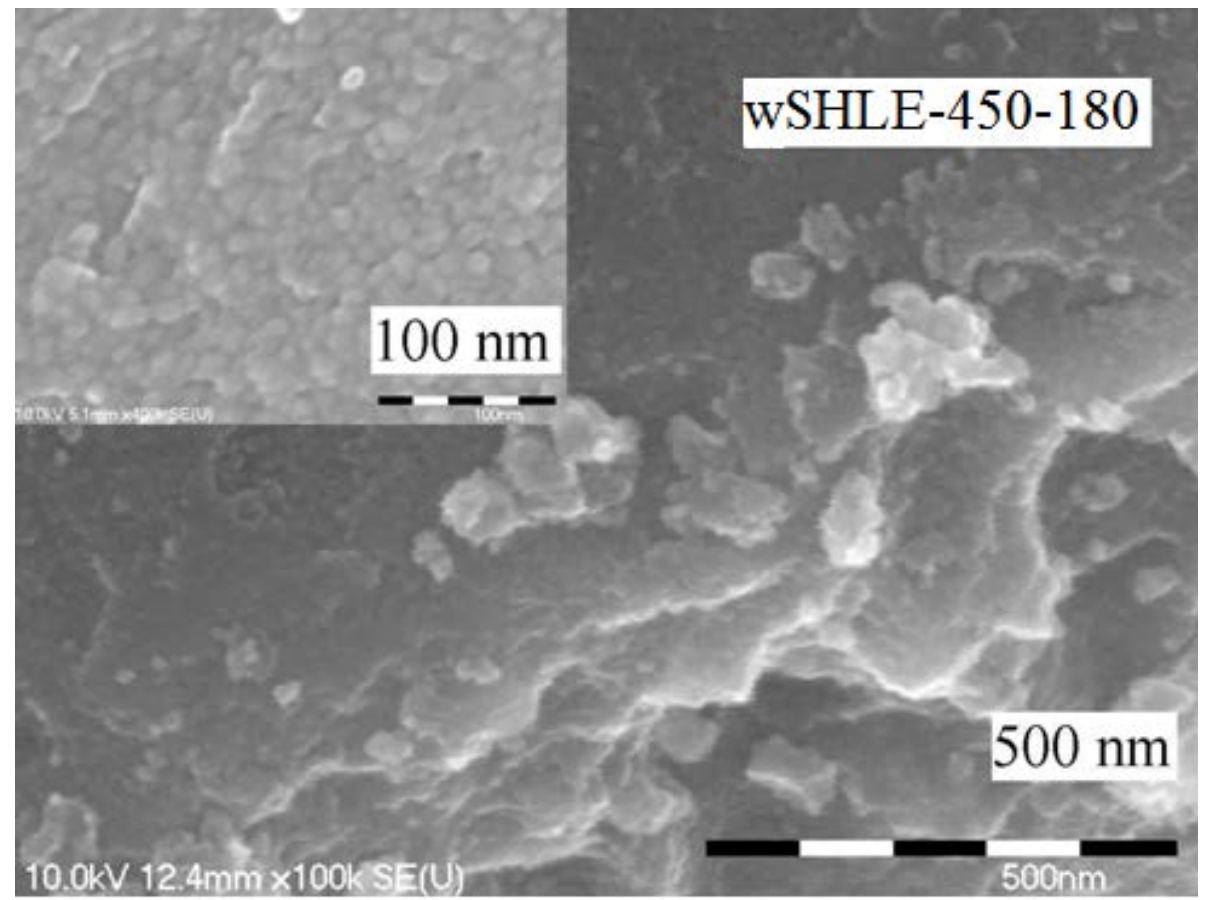

Figure 17 - SEM image of wSHLE-450-180 sample

Figure 16, show that the amorphous sample has an interesting lamellar structure whilst the calcinated samples are totally different. In these samples, the ordered structure has disappeared and various sized crystallites were formed. SEM images of RHSE-600-10 sample (Figure 16) show that the aggregates contain both very small $(\mathrm{D}=10-30 \mathrm{~nm})$ and large particles $(\mathrm{D}=100-150 \mathrm{~nm})$. The morphology of the larger particles is polyhedral. The presence of nanoparticles in the diameter range of $10-30 \mathrm{~nm}$ is confirmed also by TEM analysis. 
The particle diameter of the wSHLE-450-180 sample was determined to be about 10-20 nm by SEM investigations (Figure 17) that is in good agreement with the average diameter value estimated from its XRD pattern $\left(D_{\mathrm{XRD}}=16.7 \mathrm{~nm}\right)$.

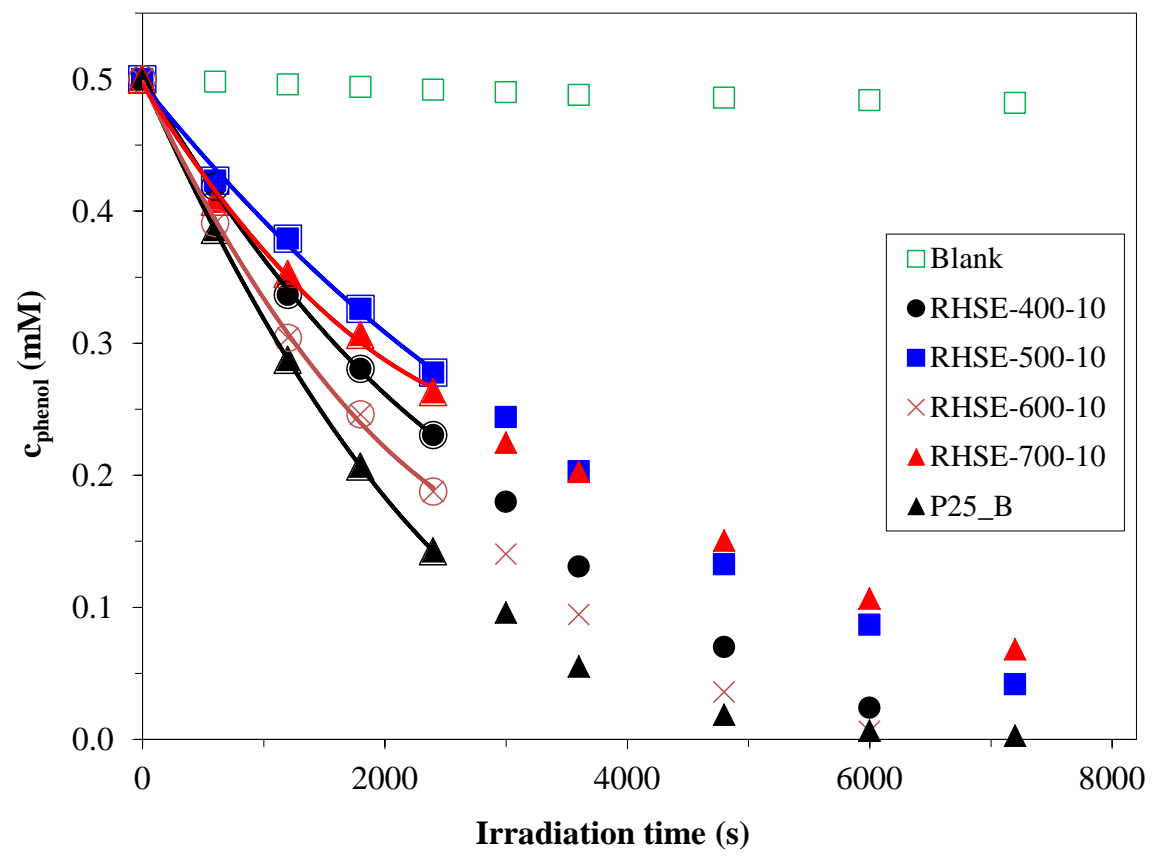

Figure 18 - Photocatalytic decay curves of phenol measured under UV irradiation for series RHSE at different temperatures

Two samples prepared by the conventional thermal treatments were also further investigated (wSHLE-450-180 and SHLE-600-180). The phase composition and the particle size of SHLE-600-180 were similar to that determined for RHSE-600-10 and RHLE-600-180 samples (see Table 2, Appendices). This implies that the main structural characteristics are determined by the calcination temperature and not by the calcination time and heating rate.

\subsection{Photocatalytic performance of the specially calcinated photocatalysts}

Figure 18 and Figure 19, show the decay curves of the most important samples for phenol photodegradation. P25 (A - it is known as simply Degussa P25 and B - the new Evonik Industries' P25, the differences between the two commercial materials are described in Table 2 and Table 3 from Appendices) references were also tested under the same conditions and blank experiment was also carried out for UV irradiation without photocatalyst (6 \% phenol decomposition within 2 hours). The first five data points were used for the determination of the 
slope of the fitted curve and by this the value of $r_{0}$ (all the obtained values are summarized in Table 2 and Table 3 from Appendices). These $\mathrm{r}_{0}$ values elucidate that the calcination method of the photocatalyst has a strong influence on its photocatalytic performance.

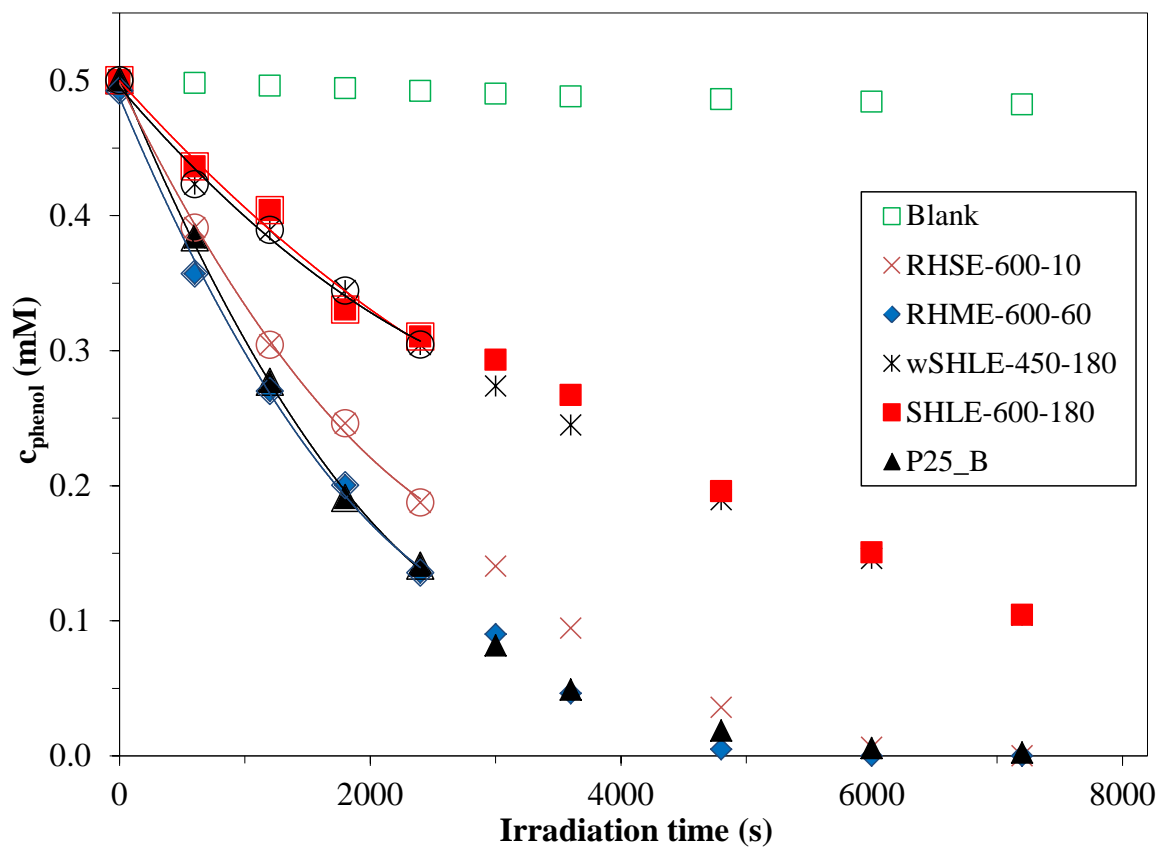

Figure 19 - Photocatalytic decay curves of phenol measured under UV irradiation for RHSE, RHME, SHLE, wSHLE samples

Despite the similar levels of anatase content and similar particle sizes, samples RHSE600-10 and RHME-600-60 have approximately twice as high activity as the samples calcined in the conventional method (SHLE-600-180, wSHLE-450-180 for $\mathrm{r}_{0}$ values see Table 2 and Table 3 from Appendices).

The washing of the amorphous samples eliminates all the inorganic salts before calcinations, and causes a dramatic activity decrease. Table 2, Appendices shows that the activity dropped by $\sim 50 \%$ in comparison with wRHSE-600-10 and RHSE-600-10, and this means that these inorganic salts should be present during the rapid crystallization process. The wSHLE-450180 and SHLE-600-180 samples exhibited similarly low performance, meaning that conventional long heat treatment could cause similarly low activity even if the amorphous starting material was not purified by washing. 


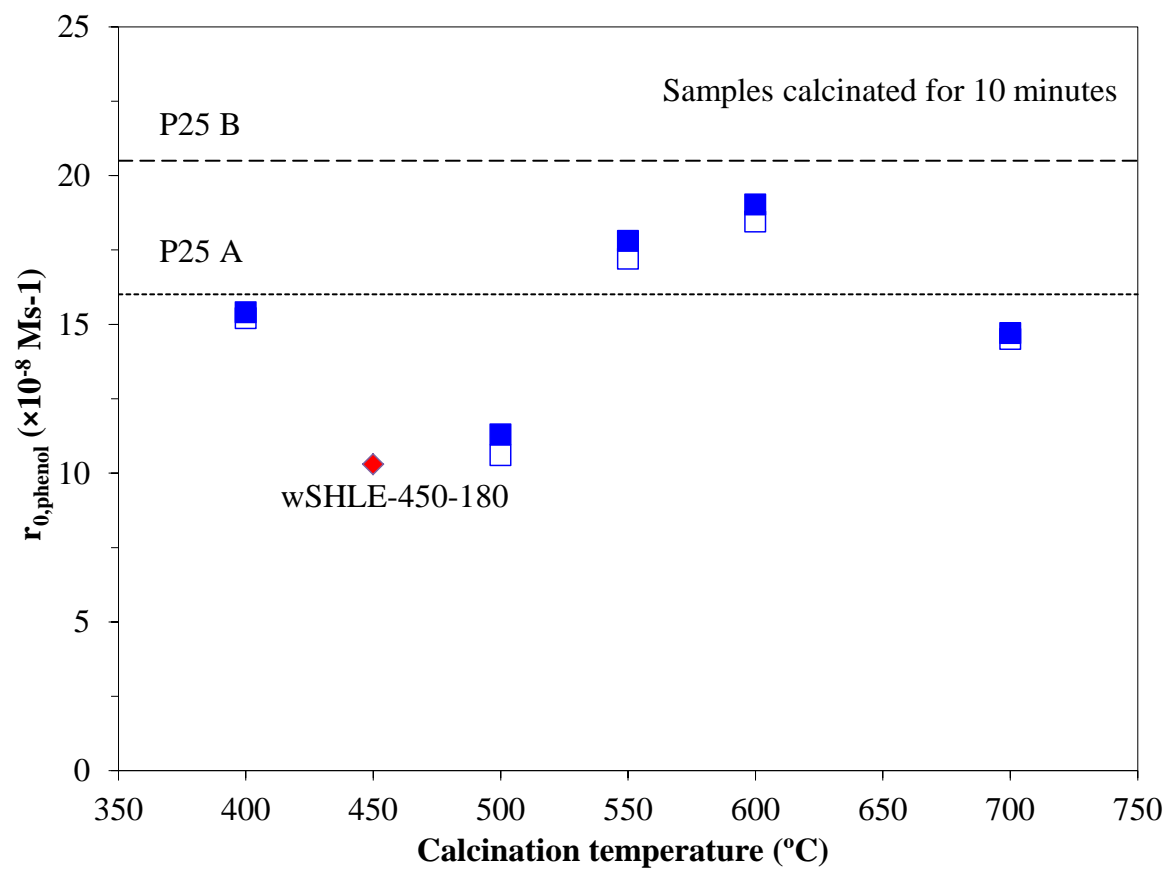

Figure 20 - The calcination temperature dependence of the initial photocatalytic decomposition rate of phenol

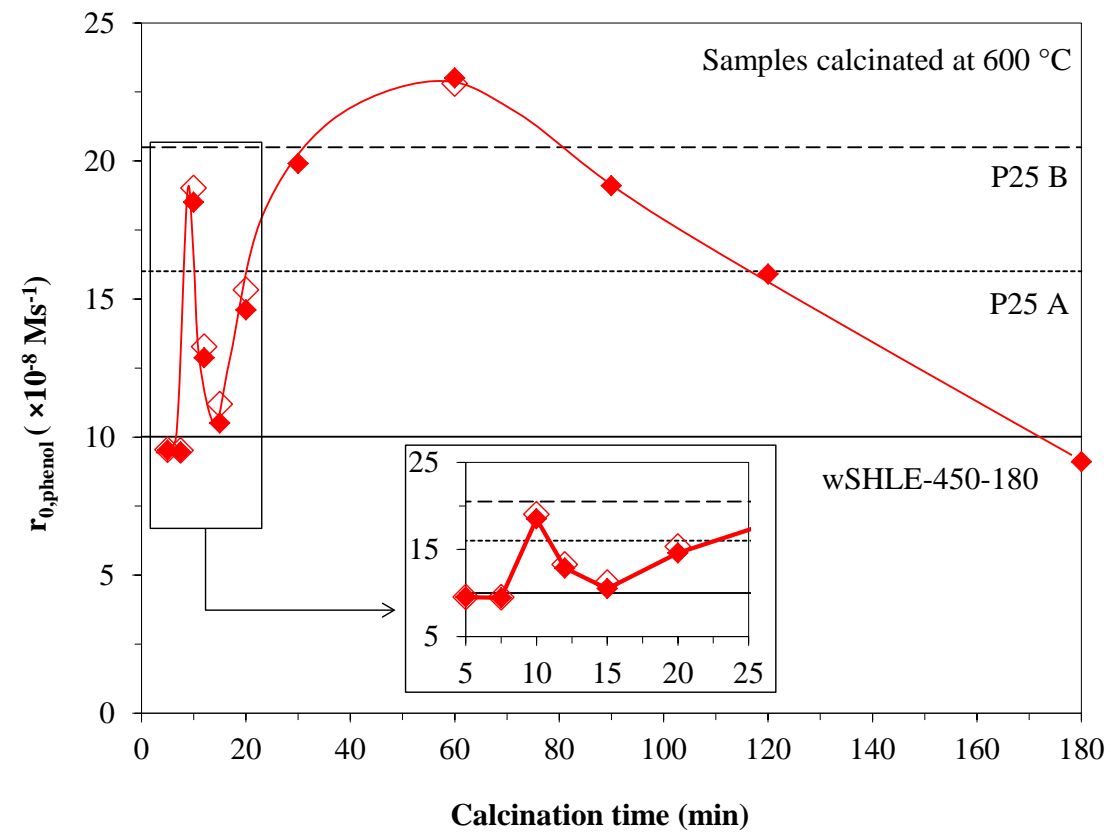

Figure 21 - The calcination time dependence of $r_{0, \text { phenol }}$ of samples prepared at $600^{\circ} \mathrm{C}$

Figure 20 indicates that the highest reaction rate was found when 10 minutes of calcination time was applied at $600{ }^{\circ} \mathrm{C}$ (sample RHSE-600-10). This sample is highly active, with an activity between P25 A and B. The $\mathrm{r}_{0}$, phenol value of wSHLE-450-180 sample is also indicated 
by a single point (this sample was obtained using similar synthesis parameters presented by $X u$ and co-workers [4]). Empty symbols indicate the results with reproduced samples. In all experiments, the reproducibility for $\mathrm{r}_{0 \text {, phenol }}$ is approximately $\pm 5 \%$.

Figure 21 shows the activity of samples calcinated at $600{ }^{\circ} \mathrm{C}$ for different times. Increasing the calcination time from 5 to 10 minutes, results in a sample (RHSE-600-10) that is twice active than the samples synthesized in the conventional method. The properties of sample RHSE-600-10 ( $\mathrm{a}_{\text {BET }}^{\mathrm{S}}=20 \mathrm{~m}^{2} / \mathrm{g} ; 80: 20$ anatase to rutile weight ratio) are very similar to those of the best flame made titanium dioxide samples previously reported by our research group [48]. However, applying longer heat treatment times (30, 60, 90, 120 and 180 minutes) a secondary activity maximum was determined at 60 minutes of calcination (Figure 21). Its material properties are nearly identical with the characteristics of the RHSE-600-10 sample (same anatase/rutile content, same particle size). The photocatalytic activity of the best performing catalyst (RHME-600-60) was almost three times higher than the samples obtained by conventional method applying calcination at $600{ }^{\circ} \mathrm{C}$ for 3 hours $\left(r_{0, \text { phenol }}=23.0\right.$ versus $8.2 \times 10^{-8}$ $\mathrm{M} / \mathrm{s})$.

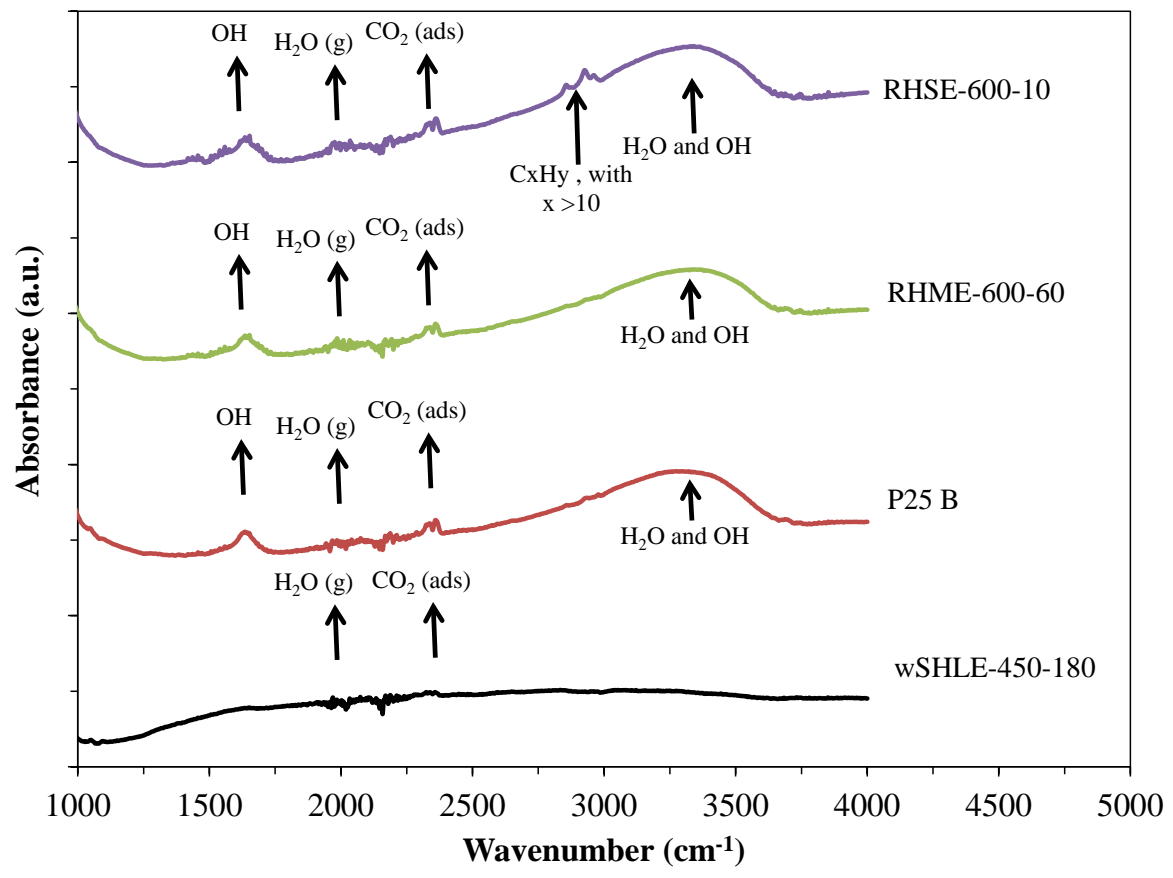

Figure 22 - IR spectra of wSHLE-450-180, P25 B, RHSE-600-10 and RHME-600-

60 samples 
Two activity maxima were found for the time series, namely at 10 and 60 minutes of calcination, RHSE-600-10 and RHSE-600-60 samples, respectively. It is very difficult to explain the high phenol decomposition rates for these two samples based only on XRD results. The factors which may be responsible for the fast decomposition rates could include better surface quality due to higher surface $\mathrm{OH}$ group density and/or the presence of light absorption sensitizers, like surface organics or additional inorganic groups.

Figure 22 shows the IR spectra for three highly active samples (P25 B, RHSE-600-10, and RHME-600-60) and the traditionally calcinated wSHLE-450-180 sample. The highly active photocatalysts all have very similar surface $\mathrm{OH}$ group absorption bands at $1635 \mathrm{~cm}^{-1}$ whilst there is no corresponding absorption for the wSHLE-450-180 sample. The loss of surface OH groups in the traditionally calcined material, which is assumed to occur during long time calcination, could be one of the main reasons for the low UV activity.

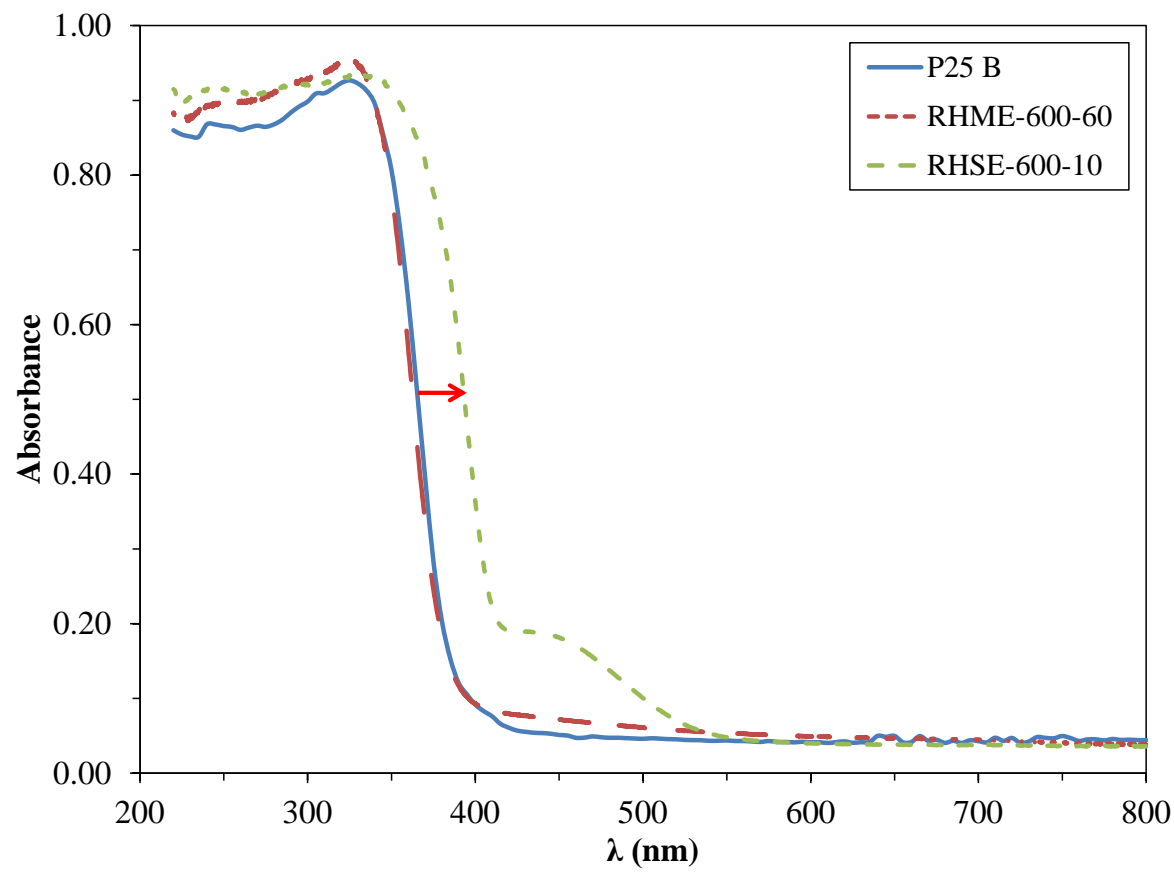

Figure 23 - DRS spectra of P25 B sample, RHSE-600-10 and RHME-600-60 samples

The spectrum of RHSE-600-10 sample shows several small peaks at $\sim 2870 \mathrm{~cm}^{-1}$ whilst the RHME-600-60 sample lacks this feature. These absorptions arise from long hydrocarbons chains and this means that after a short heat treatment time, carbonaceous species (-C-C -) still could exist on the catalyst's surface [116]. These species may cause a small red shift and a visible 
light absorption in the 420-530 nm range in the DRS spectra of the catalysts and may be the origin of its pale yellow colour (Figure 23). This shift and extra absorption could sensitize the photocatalyst to be excited over a broader spectral range of the irradiation. Although this positive effect could increase the photocatalytic activity, too much organic impurities remaining on the surface are obviously disadvantageous for photocatalytic purposes. Longer calcination times cause the thermal decomposition of these organic species, possibly forming first an amorphous carbon layer on the nanocrystals (activity local minimum at RHSE-600-20) and finally a virtually carbon-free clean surface. Although the influence of nitrogen incorporation in the samples treated at $600{ }^{\circ} \mathrm{C}$ cannot be excluded, nitrogen doping was not confirmed by XPS technique.

Figure 21 clearly shows that the samples obtained using longer calcination times (30-120 minutes) have higher activity than those calcined for very short times (5-15 minutes). The only exception is the sample treated for 10 minutes with its unexpectedly high activity probably due to the sensitization of the photocatalyst. Long heat treatment times (120-180 minutes) cause a considerable activity decrease.

TOC measurements were also performed on the P25 B, wSHLE-450-180, RHSE-600-10 and RHME-600-60 samples. P25 B contained only trace amounts of carbon - 0.05 wt\% (including adsorbed $\mathrm{CO}_{2}$ and organic compounds from the air). As expected, sample RHSE-60010 contained significantly higher amount of carbon (0.28 wt\%) than the RHME-600-60 sample (0.16 wt\%). It should be emphasized that similarly like in the case of P25 B, organic carbon is partially adsorbed from ambient air on our samples and this portion is not related to the impurities from the synthesis but strongly could depend on the specific surface area of our samples (20-60 $\left.\mathrm{m}^{2} / \mathrm{g}\right)$. The RHME-600-60 sample is more active than the RHSE-600-10 sample with the sensitized surface, because the active sites are not covered with organic residues. The wSHLE-450-180 sample contained 0.24 wt\% carbon very likely due to its higher specific surface area $\left(60 \mathrm{~m}^{2} / \mathrm{g}\right)$ and lower calcination temperature at which the rate of thermal oxidation is obviously lower.

It was noticed that the materials calcinated for shorter times are very hydrophilic, demonstrated by the sedimentation experiments conducted in aqueous solution of phenol under identical conditions to the photocatalytic experiments $\left(\mathrm{c}_{\mathrm{phenol}}=0.5 \mathrm{mM}, \mathrm{c}_{\mathrm{TiO} 2}=1.0 \mathrm{~g} / \mathrm{L}\right)$ with the samples calcined for different times (5-20, 180 minutes and P25 B). The sedimentation of these particles was monitored in test tubes at fixed time intervals. 
Figure 24 shows the image of these suspensions after $1.5 \mathrm{~h}$ of sedimentation. Suspensions containing particles from RHSE series and P25B $\mathrm{TiO}_{2}$ are more stable than the SHLE-600-180 sample suspension. The supernatant is more transparent in this later case and there is a sediment layer in the bottom of the tube. Some sedimentation was noticed in the case of RHSE-600-15 sample also. The best photocatalyst (RHME-600-60) showed similar aggregation behavior like the RHSE-600-10 sample.

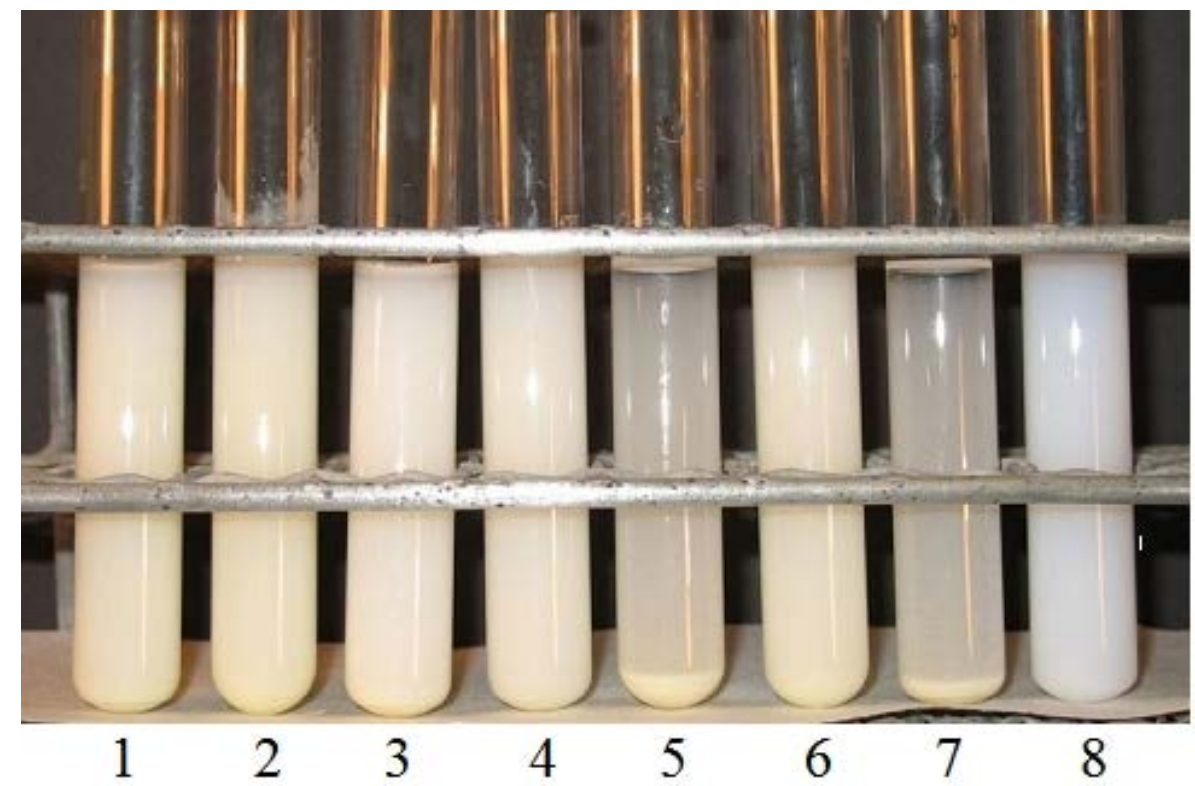

Figure 24 - Particle sedimentation experiments in photocatalyst suspensions after 1.5 hours settling; RHSE calcination time series (1-6: RHSE-600-05, 7.5, 10, 12, 15, 20); SHLE-600-180 sample (7) and P25 B (8); $\mathrm{c}_{0, \text { phenol }}=0.5 \mathrm{mM}, \mathrm{c}_{\mathrm{TiO} 2}=1.0 \mathrm{~g} / \mathrm{L}$

As can be seen in this experiment, good hydrophilicity possibly contributes to the high activity of these samples. However, our results suggest that other factors are also important in photocatalytic performance. This is usually the case for ill-adsorbing substrates, such as phenol.

Photocatalytic decomposition rate of monuron, that is a pesticide, was measured to ensure that the observed activity enhancement is true for other substrate as well. The decay curves for this experiment are presented in Figure 25. Virtually the same activity trend was obtained as in the case of phenol degradation. RHME sample was able to reach comparable initial decomposition rate as P25 B for monuron ( 90 \%). 


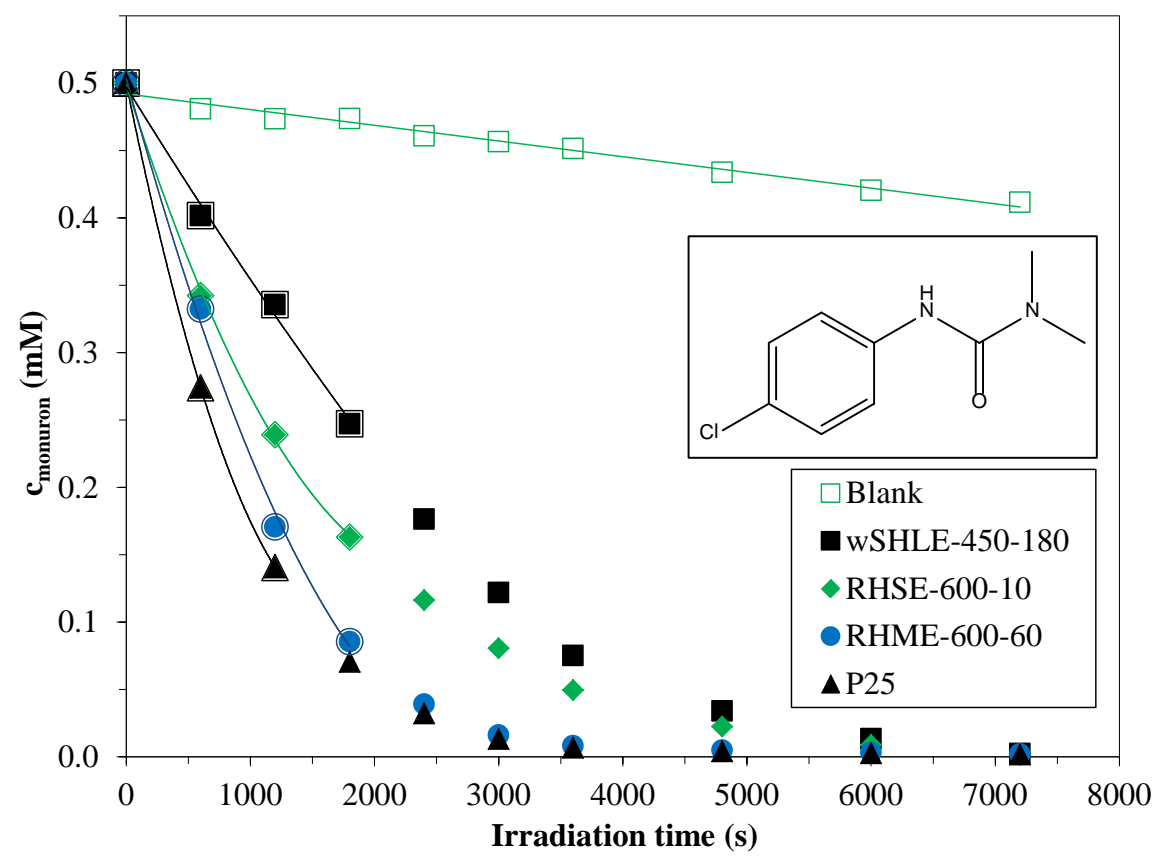

Figure 25 - Photocatalytic decay curves of monuron measured under UV irradiation for selected samples
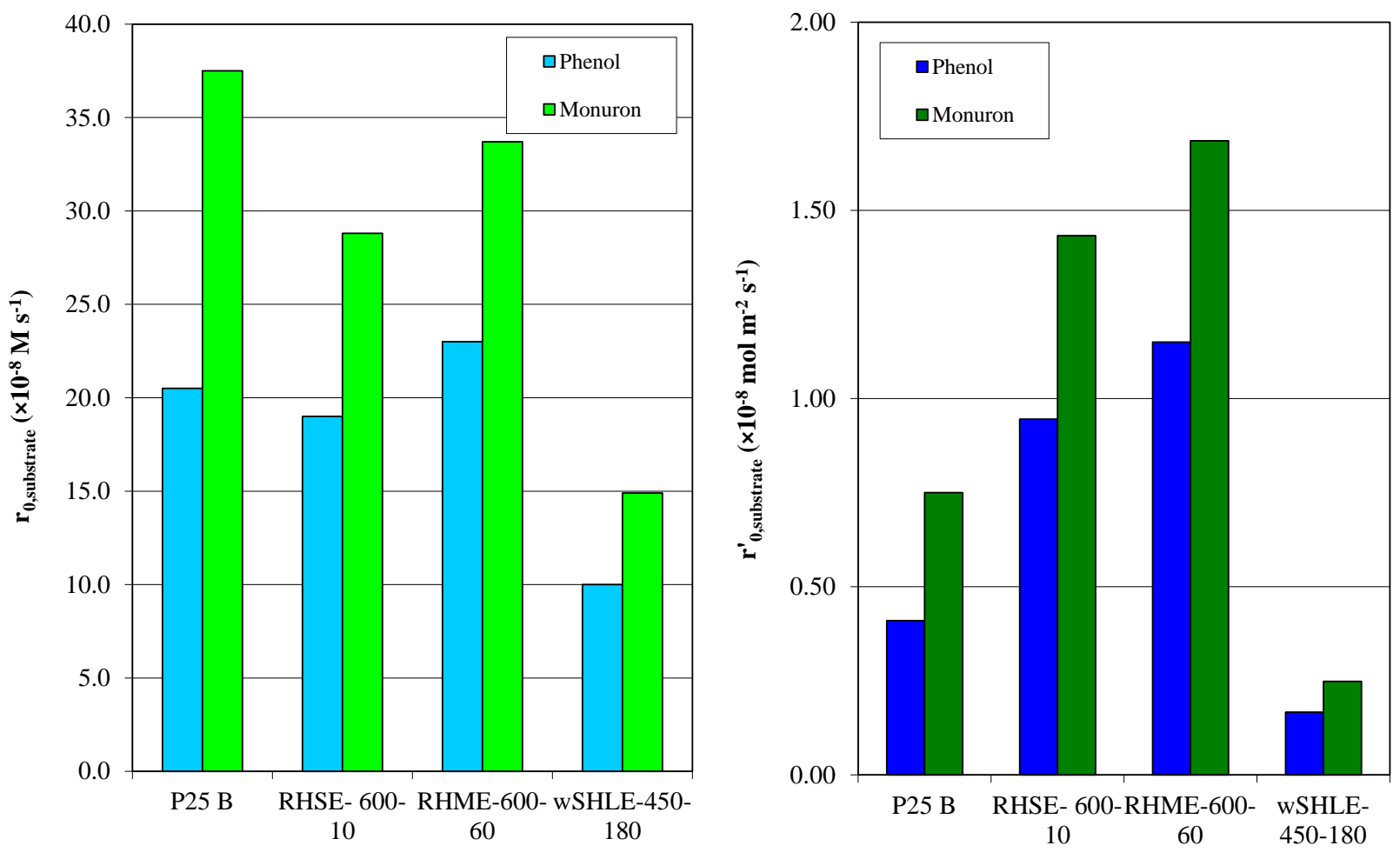

Figure 26 - Initial decomposition rate of phenol and monuron (left) and specific degradation rate of phenol and monuron (right) determined on the selected most interesting samples, such as P25 B reference photocatalyst,

RHSE-600-10, RHME-600-60 and wSHLE-450-180 samples 
Our previous studies revealed that the adsorption affinity of the substrate significantly alters its photocatalytic decomposition mechanism and consequently the rate of the decomposition as well [10]. It was concluded that in the case of salicylic acid, the stronger adsorption caused slower decomposition rate on $\mathrm{P} 25 \mathrm{TiO}_{2}$ at lower pH value because the adsorption of oxygen was probably hindered by competitive adsorption [10]. However, the decomposition of adsorbed salicylic acid could be faster on high specific surface area catalysts via direct oxidation reacting with the holes. Monuron is comparable with phenol as it poorly adsorbs on titanium dioxide, and has similar adsorption characteristics and the main photocatalytic oxidation routes.

Because P25 B has significantly higher BET surface area ( $\left.\sim 50 \mathrm{~m}^{2} / \mathrm{g}\right)$ compared to RHSE600-10 ( $\left.20 \mathrm{~m}^{2} / \mathrm{g}\right)$ and RHME-600-60 ( $\left.20 \mathrm{~m}^{2} / \mathrm{g}\right)$ samples, the specific reaction rate ( $\left.\mathrm{r}^{\prime}{ }_{0}\right)$ values should also be compared for both substrates (expressed in $\mathrm{mol} \mathrm{m}^{-2} \mathrm{~s}^{-1}$, [48]). Figure 26, shows the comparison of the initial reaction rates and the specific reaction rates for phenol and monuron. As it can be seen from Figure 26, the specific reaction rate values of the RHME-600-60 and RHSE600-10 samples were 1.9-2.8 times higher than that values determined for P25 B.

XPS spectra were taken for the following samples: P25 B, RHSE-600-10, RHME-600-60 and wSHLE-450-180. The binding energy of the Ti $2 \mathrm{p}_{3 / 2}$ orbital was measured $458.9 \mathrm{eV}$ which is characteristic of $\mathrm{Ti}^{4+}$ in $\mathrm{TiO}_{2}$. The $\mathrm{Ti} 2 \mathrm{p}_{1 / 2}$ peak was detected at $464.6 \mathrm{eV}$. The presence of nitrogen was not confirmed by this technique for any of the samples mentioned above.

Figure 27, shows the O 1s XPS spectra of these samples which could be deconvoluted into minimum two peaks in all cases. The most intense peak located at $530.2 \mathrm{eV}$ is due to lattice oxygen; the peak $531.8 \mathrm{eV}$ reflects the existence of surface $\mathrm{OH}$ groups [117] and there is a third, least intense component, in the case of RHSE-600-10 sample, that is located at $533.2 \mathrm{eV}$ and is possibly due to water. Figure 27 a, is very similar to the spectrum obtained for P25 B (Figure 27 $b$,). As the shoulder feature at $531.8 \mathrm{eV}$ was similar for the RHSE-600-10 sample, it could be concluded that the $\mathrm{OH}$ density in these samples must be comparable. This has implications for the hydrophilicity of the samples as the wSHLE-450-180 sample showed less pronounced shoulder belonging to the surface $\mathrm{OH}$ groups (Figure $27 d$,). 

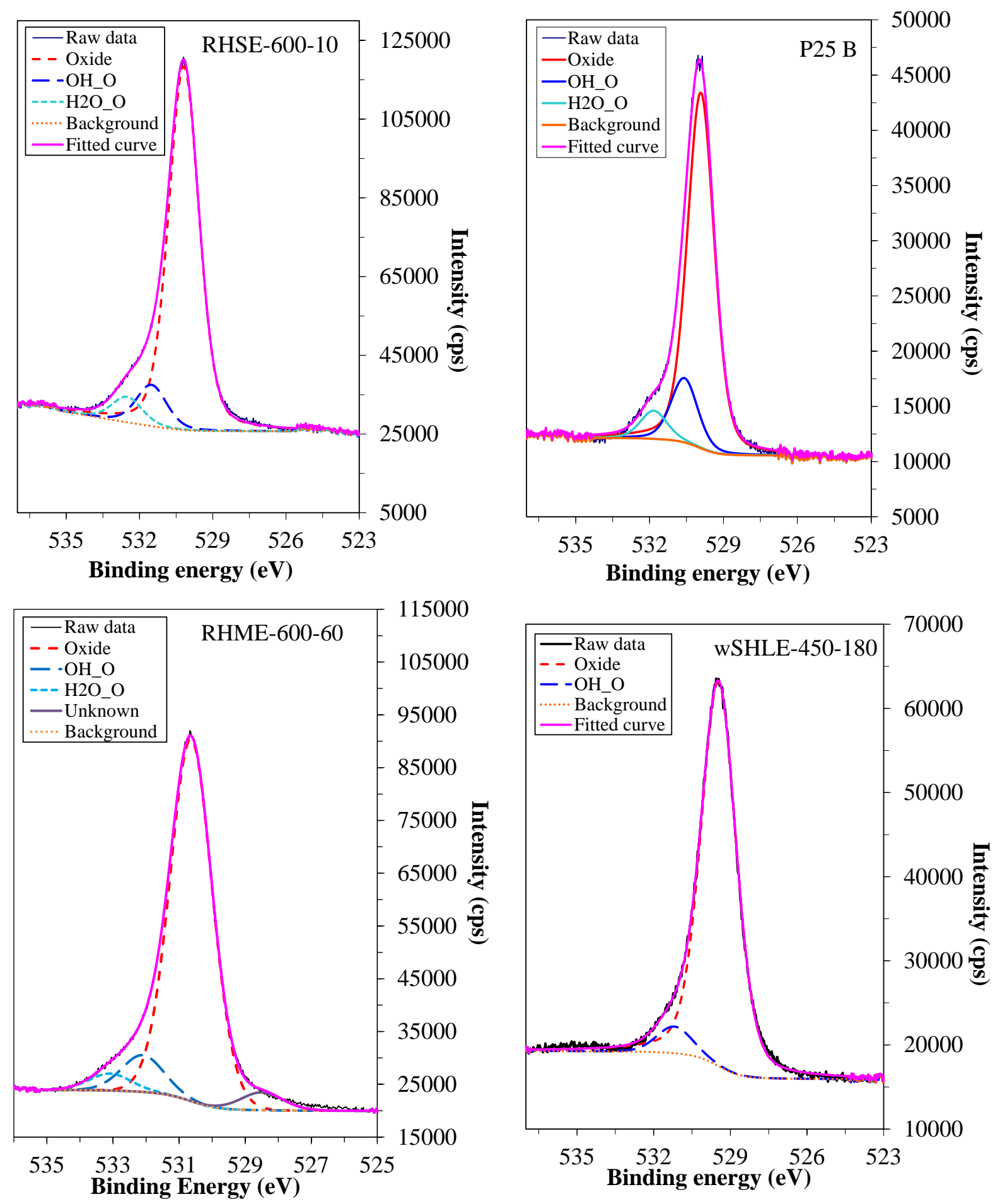

Figure 27 - O 1s XPS spectra of a, P25 B b, RHSE-600-10 c, wSHLE-450-180 and d, RHME-600-60 
Interestingly, an additional shoulder was noticed at $527.5 \mathrm{eV}$ for the RHME-600-60 sample with the highest UV activity (Figure $27 d$,). For the best performing photocatalysts prepared by our flame hydrolysis method, this unidentified peak with low intensity was also observed [118]. It was assumed that the high activity of these samples could be somehow correlated with the presence of this special oxygen form on the crystal surface.

These results suggest that during the newly developed heating method a protective atmosphere against dehydroxylation process is formed from the rapidly subliming ammonium salts. This influence is not significant when: i) the sample is slowly heated; ii) the furnace is continuously purged by air during the calcination; iii) a long treatment time is applied or iv) the sample is washed before calcination.

SG-C (conventionally heat treated) and SG-S (heat treated with the special calcination profile) samples were tested under the same conditions as the RHSE and SHLE samples and the SG-S sample was 1.76 times more active than the SG-C sample (for phenol degradation $9.7 \times 10^{-8}$ vs. $5.5 \times 10^{-8} \mathrm{M} / \mathrm{s}$, respectively). The synthesis of these photocatalysts did not involve any addition of ammonia therefore it can be concluded that some of the beneficial effects of rapid heat treatment could exist for other sol-gel prepared photocatalysts (details regarding the synthesis procedure of these materials can be found in section 5).

The synthesis of visible light sensitive materials could also be efficiently modified by the rapid heat treatment method. Our experimental results (for details see section 9), which will be discussed in a separate section of the thesis, revealed that the highest VIS activity is found under different synthesis parameters, especially at lower calcination temperatures that result in smaller particles. Our observations are in good agreement with the conclusions of Ryu and Choi [119]. Optimizing the synthesis conditions of nitrogen doped titania samples, resulted in high photocatalytic activity under visible light. The best performing sample calcinated at $400{ }^{\circ} \mathrm{C}$ for 10 minutes was about twice as active as the sample prepared with the conventional method (for details see section 9).

The aggregation of particles synthesized by the new calcination method was less pronounced and this may be a significant factor in the increased photocatalytic activity. The extended absorption of near-UV light of these materials also could have improved their UV photocatalytic performance. The observed photocatalytic activity depends on the light absorption properties, the surface purity and hydrophilicity as well. 
As we have seen in this section very high activities can be achieved at $600{ }^{\circ} \mathrm{C}$, using fast heating up step and short/medium calcination time (10, 60 minutes). This result showed that the calcination time is a critical parameter in the design of highly active photocatalysts. Thus, it would be interesting to study these activity variations (with the calcination time) for other calcination temperatures and to investigate more deeply the surface quality change during the calcination procedure. 


\section{Dynamic changes on the surface during the calcination of rapid heat treated $\mathrm{TiO}_{2}$}

\subsection{Characterization of the photocatalysts ${ }^{1}$}
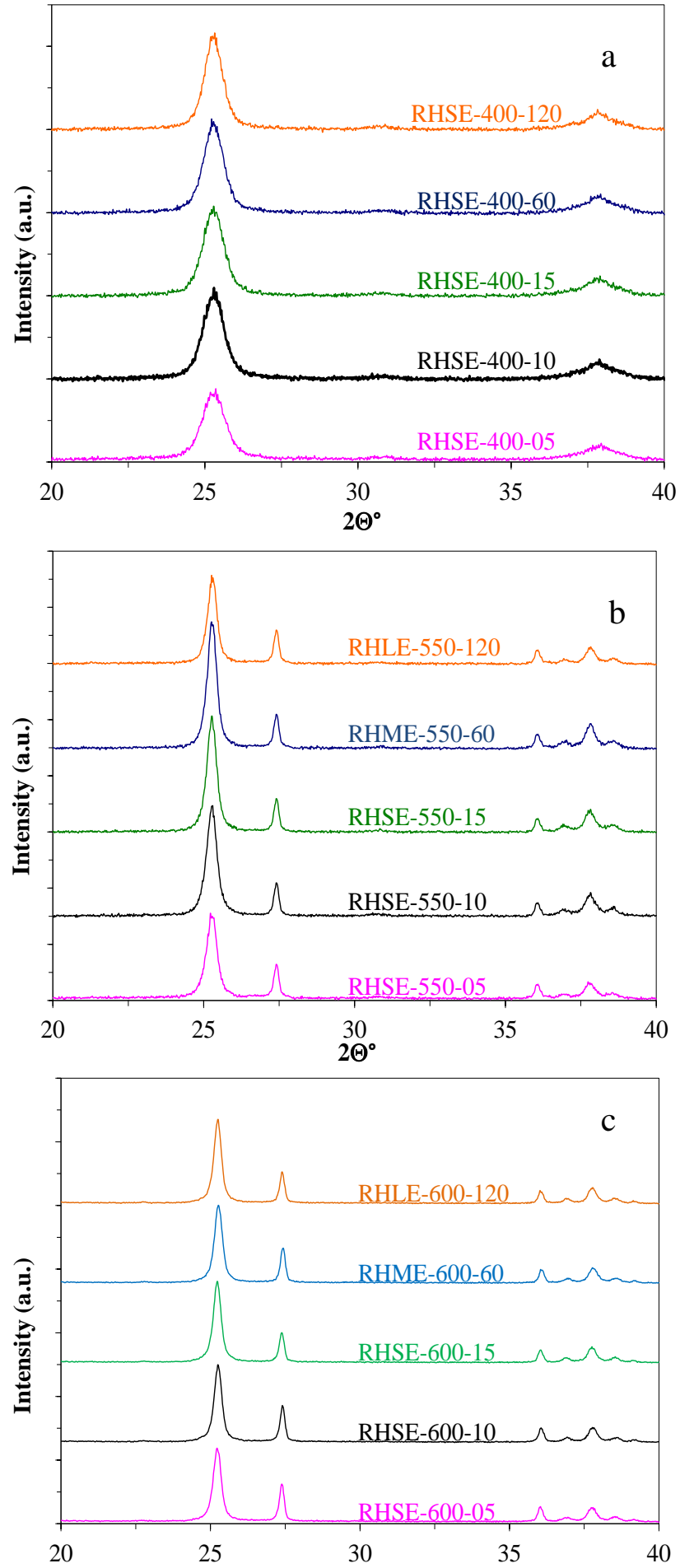

Figure 28 - XRD pattern of samples treated at (a) $400{ }^{\circ} \mathrm{C}$, (b) $550{ }^{\circ} \mathrm{C}$ and (c) $600{ }^{\circ} \mathrm{C}$

\footnotetext{
${ }^{1}$ Please note that only the representative samples are discussed in the present section.
} 
The first step in the characterization of the obtained materials was to determine their crystal phase composition. Based on the XRD patterns (Figure $28 a, b, c$ ), the following crystal phases were identified: anatase, rutile and brookite. Anatase was present in all samples in different amounts, depending on the heat treatment temperature: $100 \mathrm{wt} \%$ in the samples treated at $400{ }^{\circ} \mathrm{C}$, 84-88 wt\% in the samples treated at $550{ }^{\circ} \mathrm{C}$ and $78-82 \mathrm{wt} \%$ in the samples calcined at $600{ }^{\circ} \mathrm{C}$ (Table 4, Appendices; Figure $28 a, b, c$ ). As the heat treatment temperature increases so does the rutile's ratio in the samples. The presence of brookite was negligible (below $1 \mathrm{wt} \%$ ) in the samples obtained at 400 and $550{ }^{\circ} \mathrm{C}$ and totally absent from the materials calcined at $600{ }^{\circ} \mathrm{C}$. As expected, the calculated primary particle size also increased in conjunction with the heat treatment temperature. At $400{ }^{\circ} \mathrm{C}$ the anatase particle's size was $12.6 \mathrm{~nm}$. At $550{ }^{\circ} \mathrm{C}$ this value reached $26.6 \mathrm{~nm}$ and finally $41.4 \mathrm{~nm}$ at $600{ }^{\circ} \mathrm{C}$.

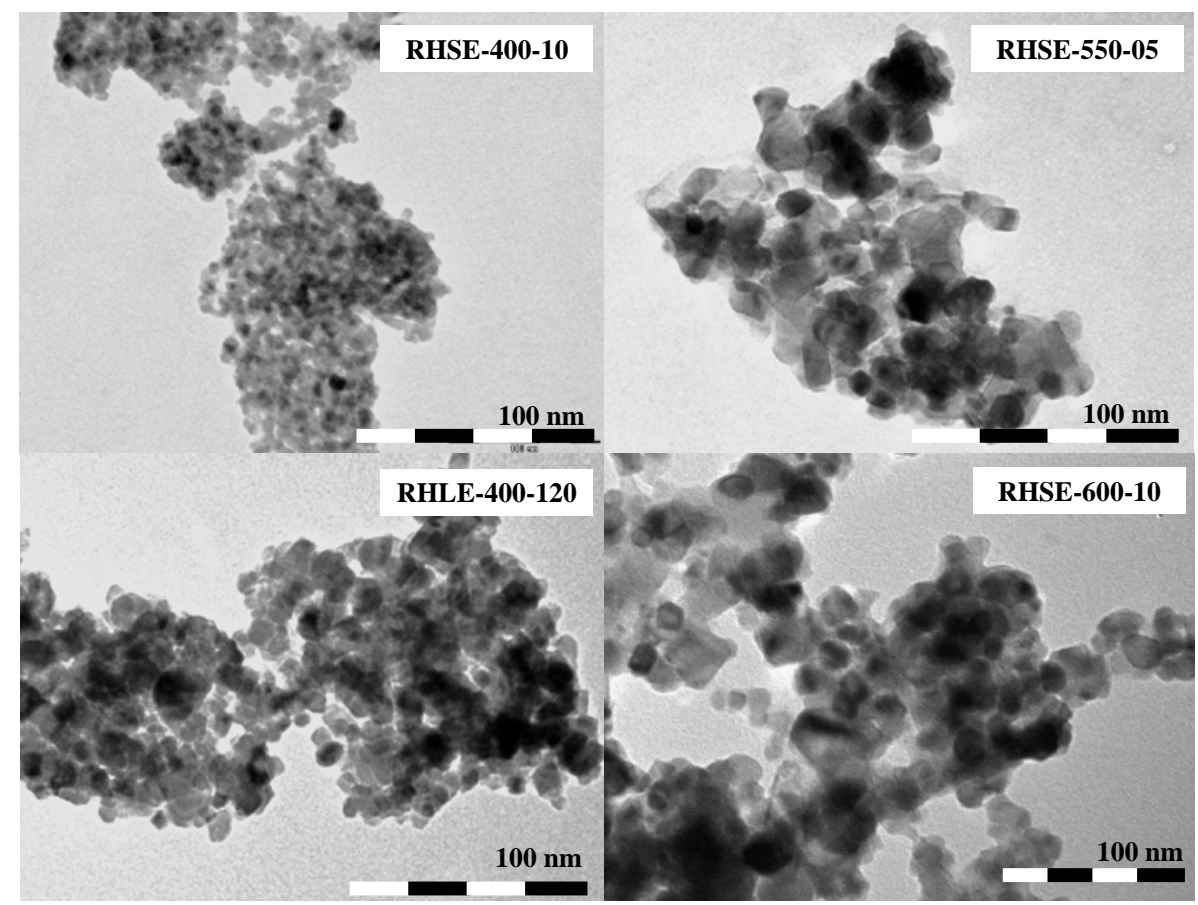

Figure 29 - TEM micrograph of samples RHSE-400-10, RHLE-400-120, RHSE-550-05 and RHSE-600-10

The diameter of rutile particles was between 90-100 nm, which is considerably larger than that determined for anatase particles (Table 4, Appendices). Caution should be taken when analyzing larger particle size ( $>50 \mathrm{~nm})$ from line broadening as equipment inaccuracies may become significant 

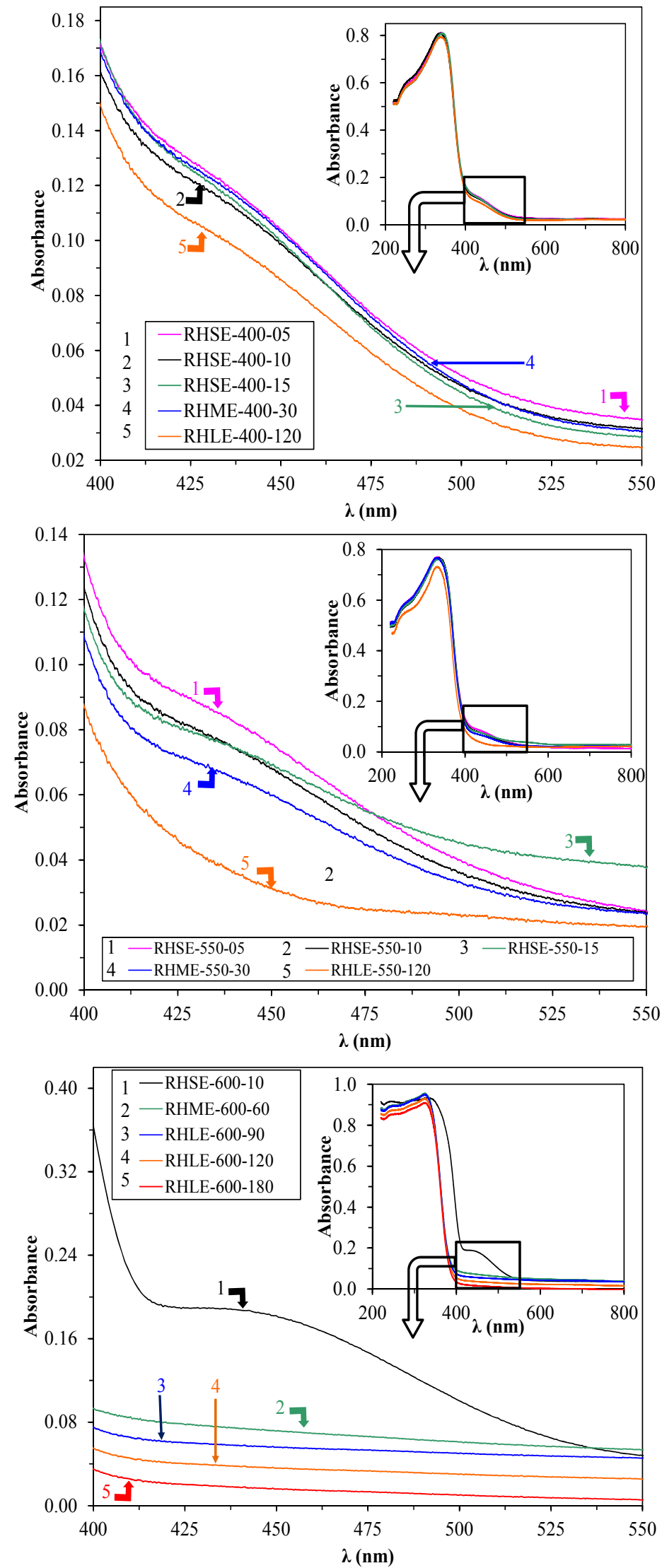

Figure 30 - DRS spectra of samples treated at (a) $400{ }^{\circ} \mathrm{C}$, (b) $550{ }^{\circ} \mathrm{C}$ and (c) $600{ }^{\circ} \mathrm{C}$ 
The particle size calculated from XRD is in good agreement with the value determined by TEM imaging (see Figure 29). The DRS spectra of the representative samples were recorded in order to evaluate the importance of the light absorption in the photocatalytic performance of the samples. The majority of the materials calcined at 400,550 and $600{ }^{\circ} \mathrm{C}$ showed an absorption shoulder from 400 to $525 \mathrm{~nm}$. As Figure $30 a, b$, and $c$ shows, the light absorption of the photocatalysts decreases as the calcination time gets longer.

The small primary particle size may point out possible visible light active catalysts, as showed by Ryu and Choi [119] the DRS spectra could give some hints about possible doping [120] or sensitizing [121]. However the particle size, crystal phase composition and visible light absorption were unable to explain the observed photocatalytic activities (Figure 31), thus a detailed study about the surface of these materials by other methods (such as IR spectroscopy and XPS) were needed.

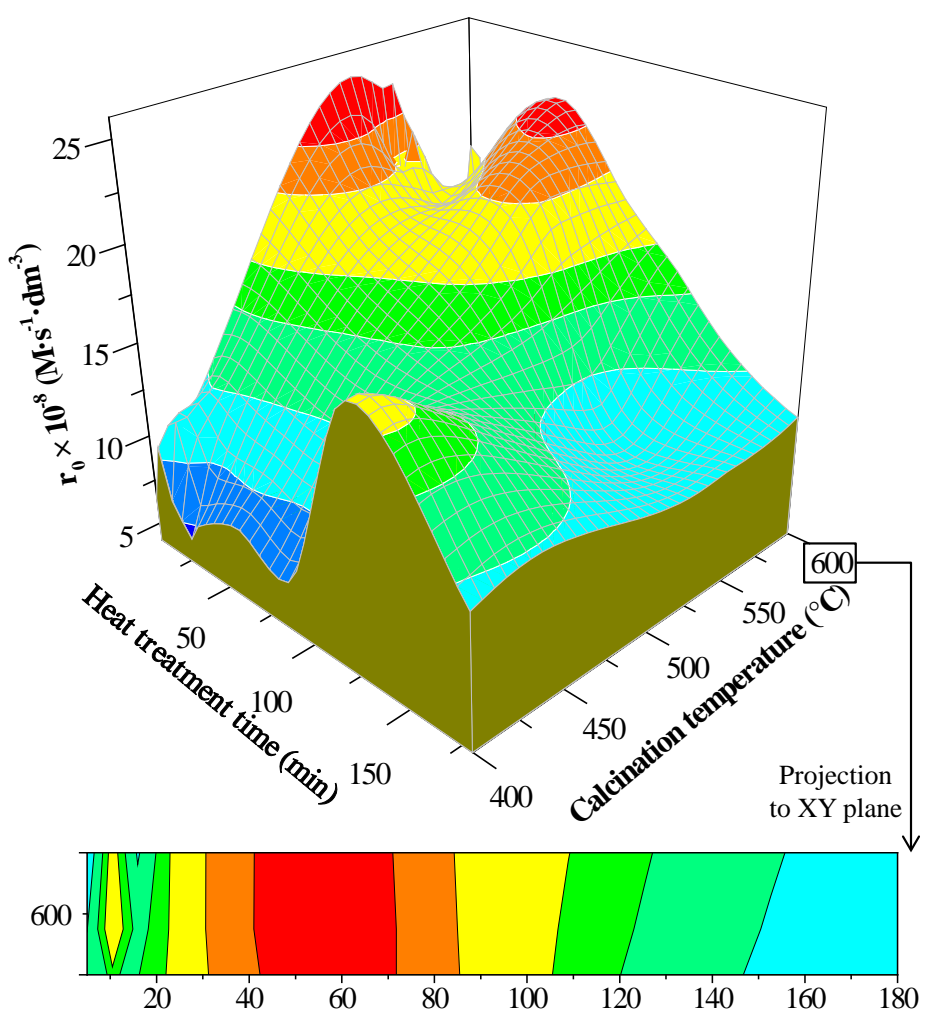

Figure 31 - The optimization of the photocatalytic activity of the titania samples as function of the heat treatment time and temperature. A separate projection was attached to reveal the maximum at $600^{\circ} \mathrm{C}$ and 10 minutes of calcination otherwise covered in the original surface plot 


\subsection{Correlations observed between the surface quality, bulk properties and the achieved photocatalytic performance}

\subsubsection{Samples heat treated at $400{ }^{\circ} \mathrm{C}$}

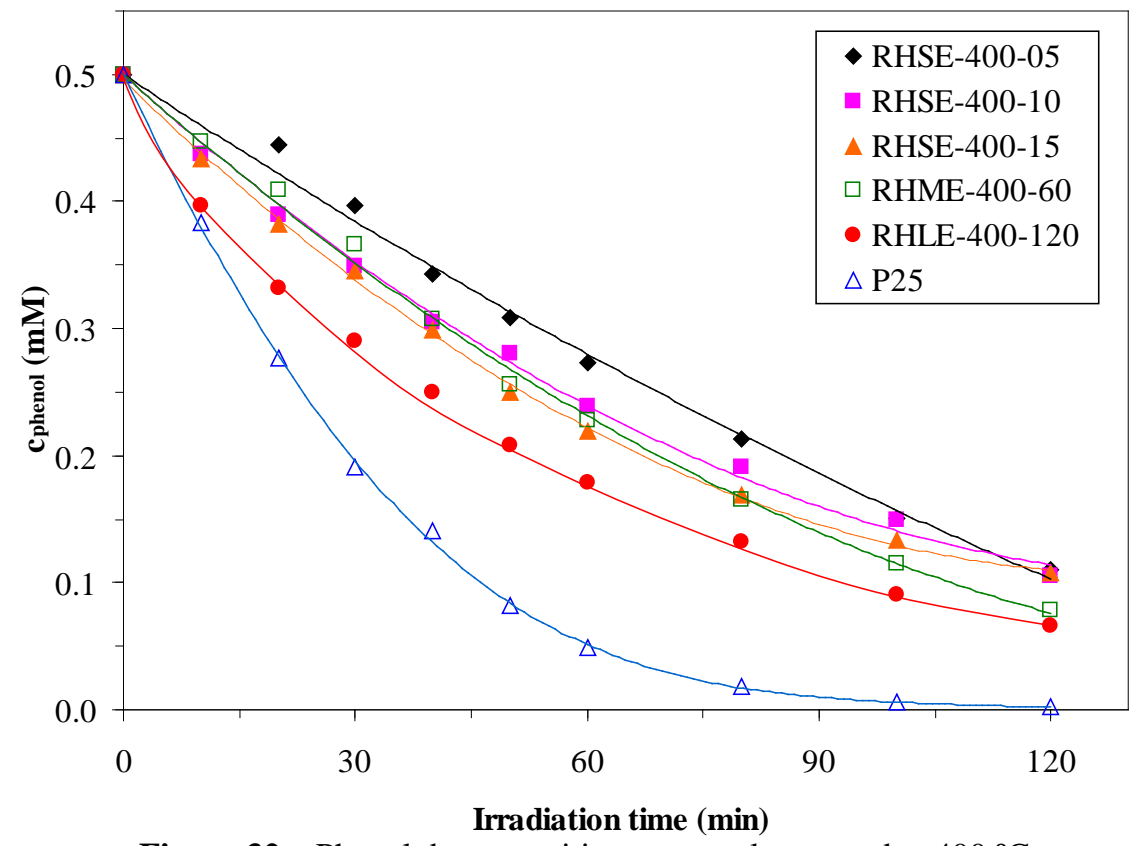

Figure 32 - Phenol decomposition on samples treated at $400{ }^{\circ} \mathrm{C}$

The phenol degradation rates observed for these catalysts were below the degradation rate measured with P25 B (later on, P25) $\left(20.5 \times 10^{-8} \mathrm{M} / \mathrm{s}\right)$. The best performing catalyst was obtained at 120 minutes of calcination while the samples treated for 5 up to 60 minutes were the least active from this series (Figure 31 and Figure 32). All the materials in this series (except RHLE400-120 and RHLE-400-180 sample) were unable to exceed the performance of the sol-gel reference sample, wSHLE-450-180. These experimental data can raise the following questions:

i.) What causes the low activity at shorter calcination times?

ii.) What is the reason for the activity maximum at 120 minutes of calcination? 


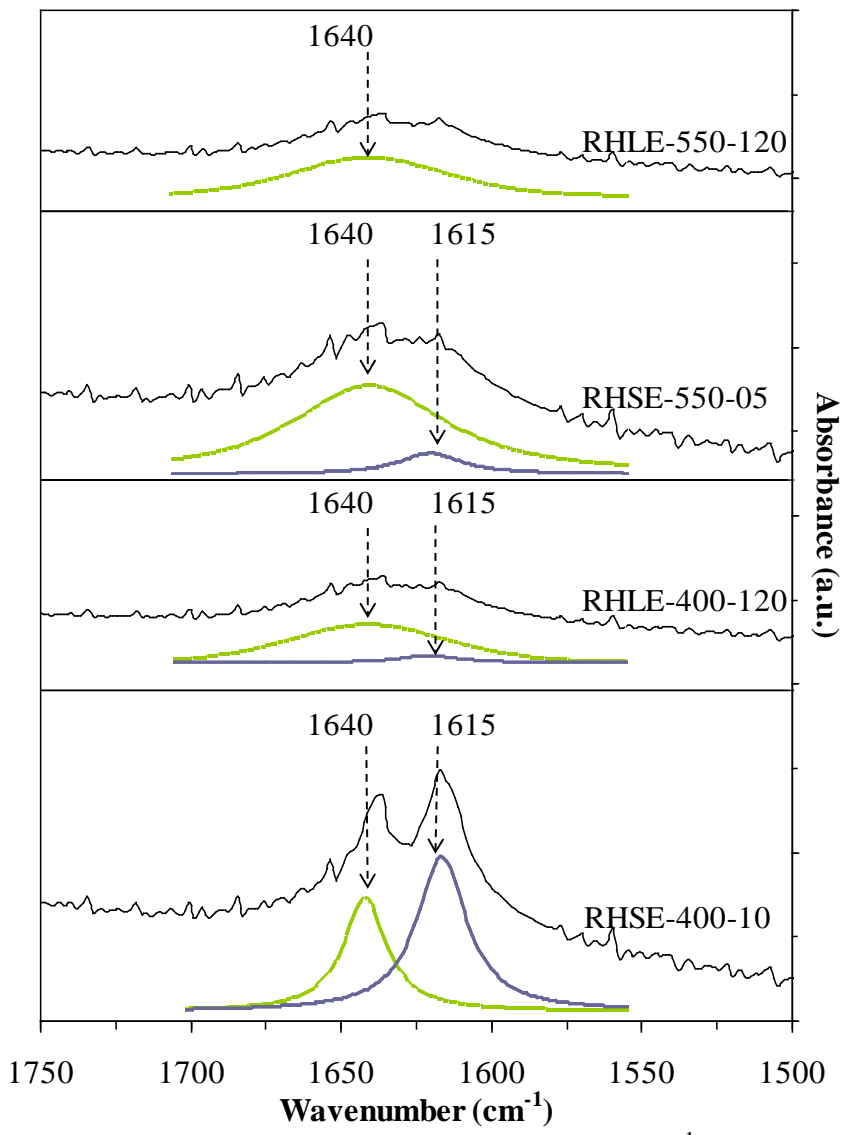

Figure 33 - IR spectra (region $1500-1750 \mathrm{~cm}^{-1}$ ) of sample RHSE-400-05, RHLE-400-120, RHSE-550-05 and RHLE-550120
It was concluded that all samples from the $400{ }^{\circ} \mathrm{C}$ series have practically the same phase composition, primary particle size (Figure 28 a; Table 4, Appendices) and the same specific surface area. We also observed that while the heat treatment time increases the absorbance at 425-475 $\mathrm{nm}$ decreases (Figure 30 a). This obviously means that the surface quality of the catalyst is slowly changing with the heat treatment time.

$$
\text { Surprisingly, the X-ray }
$$
photoelectron spectra showed that no changes could be determined in the type of nitrogen incorporation (O-Ti-N, interstitial type, [122]) and its concentration for the samples in this series ( 1.0 \pm 0.1 at \%). Similarly no changes were observed in the $\mathrm{Ti}$ : $\mathrm{O}$ ratio. The carbon deposits detected on the surface decreased slowly throughout the calcination time (5 min to $180 \mathrm{~min}$ ) indicating a very slow surface purification which could explain the higher UV activity at longer calcination times.

At very short treatment times (5-10 minutes), 7 at\% of all oxygen forms in the surface layer can be found as surface OH-groups and the remaining part exists as oxide. However, after 120 minutes of calcination this value decreases to $\sim 6$ at\%, so a slight dehydroxylation can be observed. This observation suggests that the samples treated for longer times should exhibit slightly lower phenol degradation rates as we have previously found [11], thus further examination is needed to explain the activity maximum at 120 minutes. 


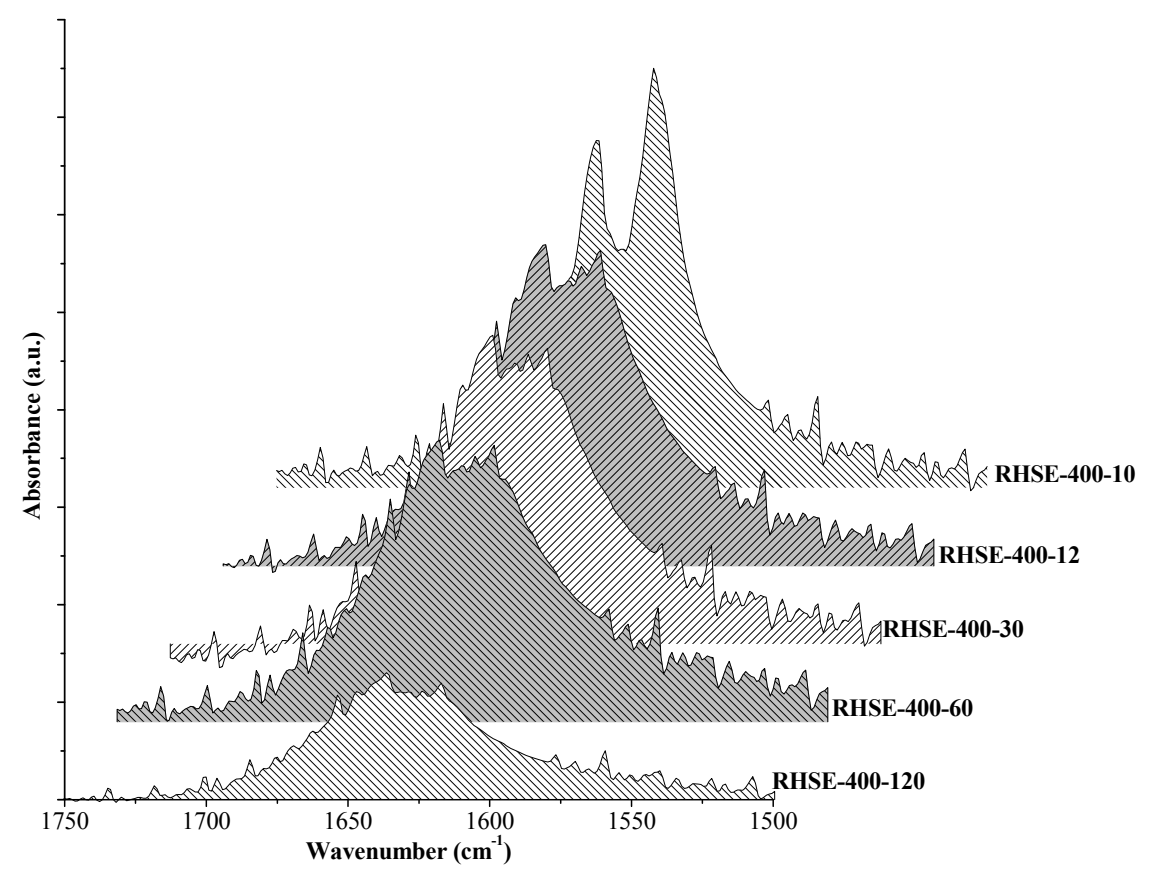

Figure 34 - IR spectra of several selected samples calcined at $400{ }^{\circ} \mathrm{C}$ (region 1500 $\left.-1750 \mathrm{~cm}^{-1}\right)$

A possible reason for this can be found in the IR spectra of these materials. In Figure 33 is clearly visible that two overlapped absorption bands were detected in the RHSE-400-05 sample. After peak deconvolution the two bands are clearly visible. The first one at $1615 \mathrm{~cm}^{-1}$ can be identified as $-\mathrm{NH}_{2}$ and the band at $1635-1640 \mathrm{~cm}^{-1}$ corresponds indirectly to the surface OH-groups [123]. The presence of $\mathrm{NH}_{2}$-group is not surprising at all, if we consider that our samples contained a substantial quantity of ammonium salts. As the calcination time increases these bands ratio changes with their intensity. At short and medium calcination (5-60 minutes) times the $\mathrm{NH}_{2}$ and $\mathrm{OH}$ bands are both intense. At long calcination times the first band nearly disappears, the second one becomes wider and less intense (Figure 34). This observation confirms the surface dehydroxylation observed from the XPS spectra. The OH band vanishes (as in the case of wSHLE-450-180 in Figure 35) from the sample treated at 180 minutes (RHLE400-180), which could explain the observed lower UV activity (compared to the sample RHLE400-120).

However, the presence of the surface anchored $\mathrm{NH}_{2}$-groups could be important, because it is possible, that the low activity of the samples calcined at shorter times can be attributed to pure 


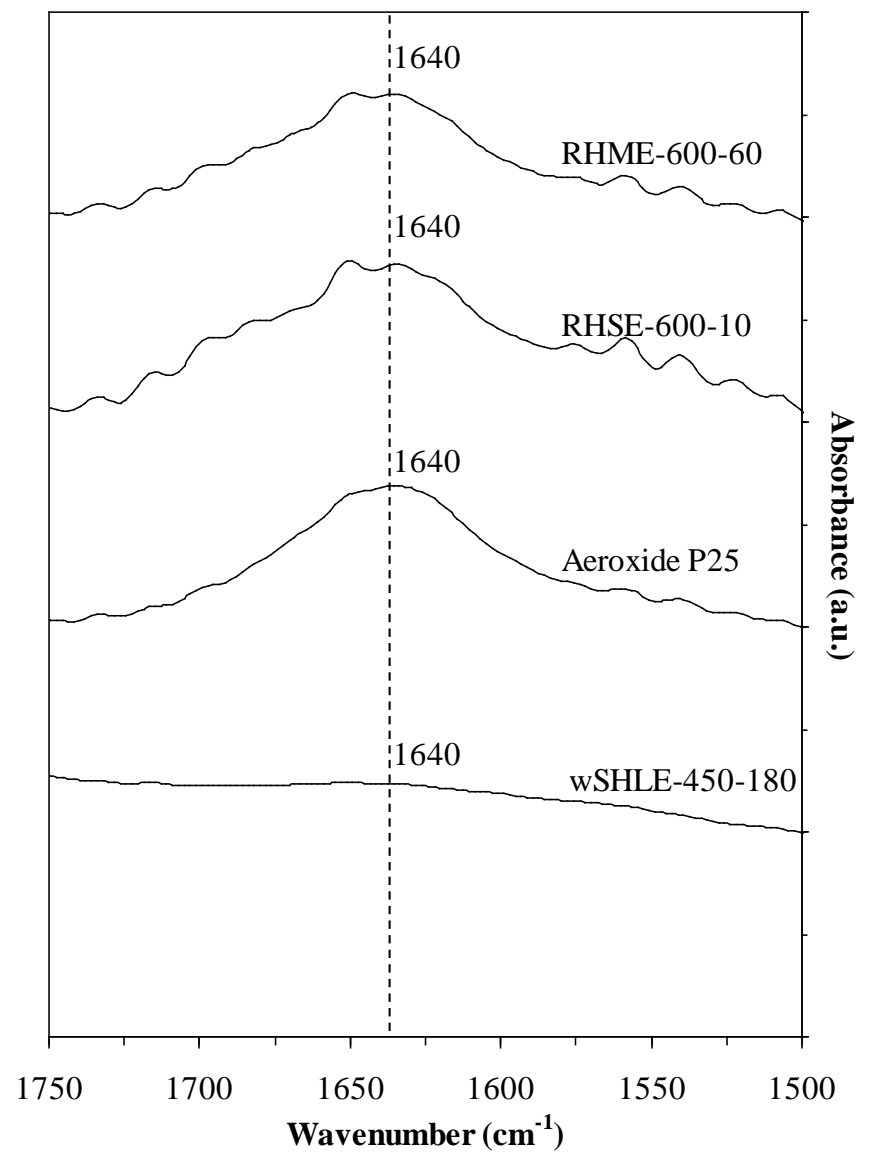

Figure 35 - IR spectra of sample wSHLE-450-180, P25, RHSE-600-10 and RHME-600-60 (region $1500-1750 \mathrm{~cm}^{-1}$ ) visible light activity (here the $\mathrm{NH}_{2}$-group can act as a sensitizer [96]). This hypothesis needs further investigations based on experiments carried out under visible light.

Very interesting bands were observed at $2854 \mathrm{~cm}^{-1}$ and $2924 \mathrm{~cm}^{-1}$ (Figure 36). These bands can be assigned to long chained hydrocarbons (similar to those observed by Lettmann et al. [116]). Their presence indicates that the surface of all investigated catalysts in this series is covered by organics (organic residues.)

The intensity of these bands decreases throughout the calcination series as the heat treatment time increases, in parallel with the intensity of the $\mathrm{NH}_{2}$ and $\mathrm{OH}$ bands and the UV-VIS absorption. Unfortunately, no obvious

correlation was found between these bands and the measured photocatalytic activity in this series.
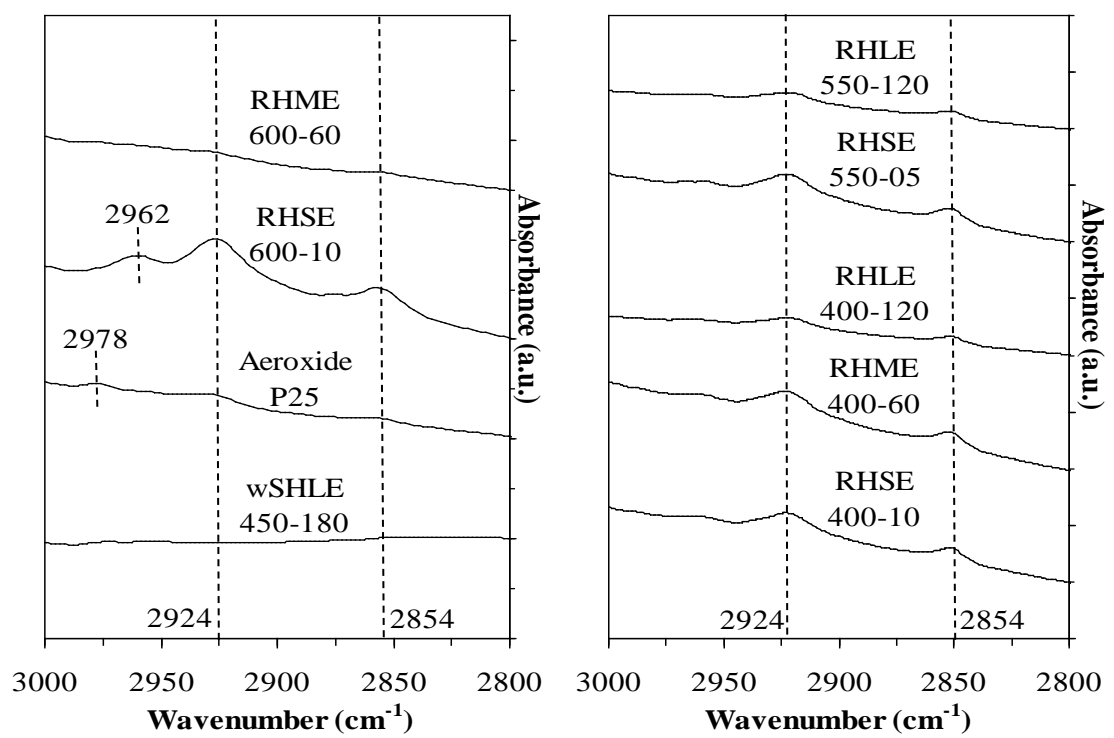

Figure 36 - IR spectra of the most significant samples (region $2800-3000 \mathrm{~cm}^{-1}$ ) 


\subsubsection{Samples heat treated at $550{ }^{\circ} \mathrm{C}$}

The phenol degradation rates measured for these samples were slightly below the P25‘s degradation rate, except for one (Figure 31 and Figure 37). The best performing catalyst was obtained at 5 minutes of heat treatment and exceeded by 5\% the activity of P25. All the materials were performing better than the sol-gel reference sample (wSHLE-450-180), except RHLE-550180. This fact confirms the assumption that for high UV photocatalytic performance, higher calcination temperatures are recommended. The following points should be clarified:

i.) The unusually high activity for sample RHSE-550-05;

ii.) The significant activity decrease observed in this series (from $\sim 25 \times 10^{-8} \mathrm{M} / \mathrm{s}$, sample RHSE-550-05 to 9×10-8 M/s ,sample RHLE-550-180).

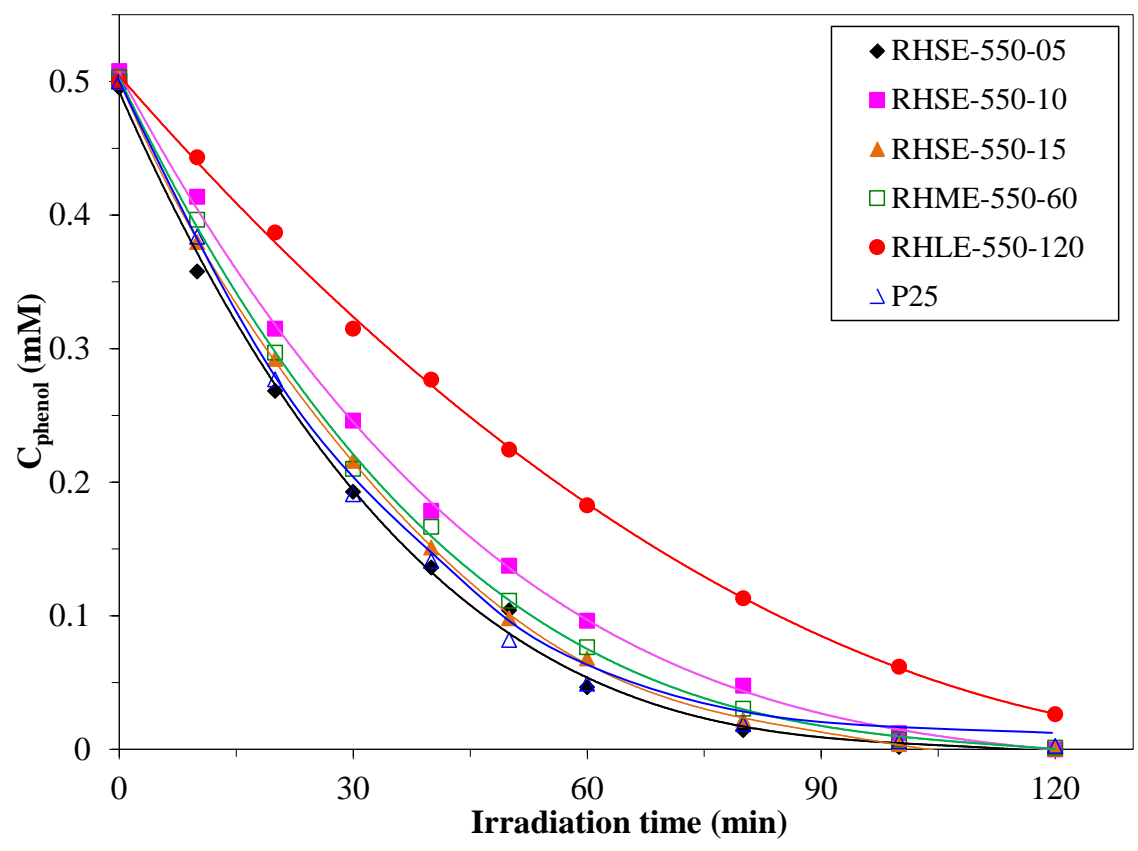

Figure 37 - Phenol decomposition on the catalysts treated at $550{ }^{\circ} \mathrm{C}$

All the materials in the $550{ }^{\circ} \mathrm{C}$ series have practically the same phase composition, primary particle size (Figure 28 b; Table 4, Appendices) and same specific surface area (same behavior was observed for the samples treated at lower temperatures, see the previous section). It was also noticed that while the heat treatment time increases the considerable absorbance at 425$475 \mathrm{~nm}$ decreases (Figure $30 \mathrm{~b}$ ) - as it was similarly found for the series of samples treated at $400{ }^{\circ} \mathrm{C}$. This obviously means that the surface quality of the catalyst is slowly changing throughout the heat treatment time. 


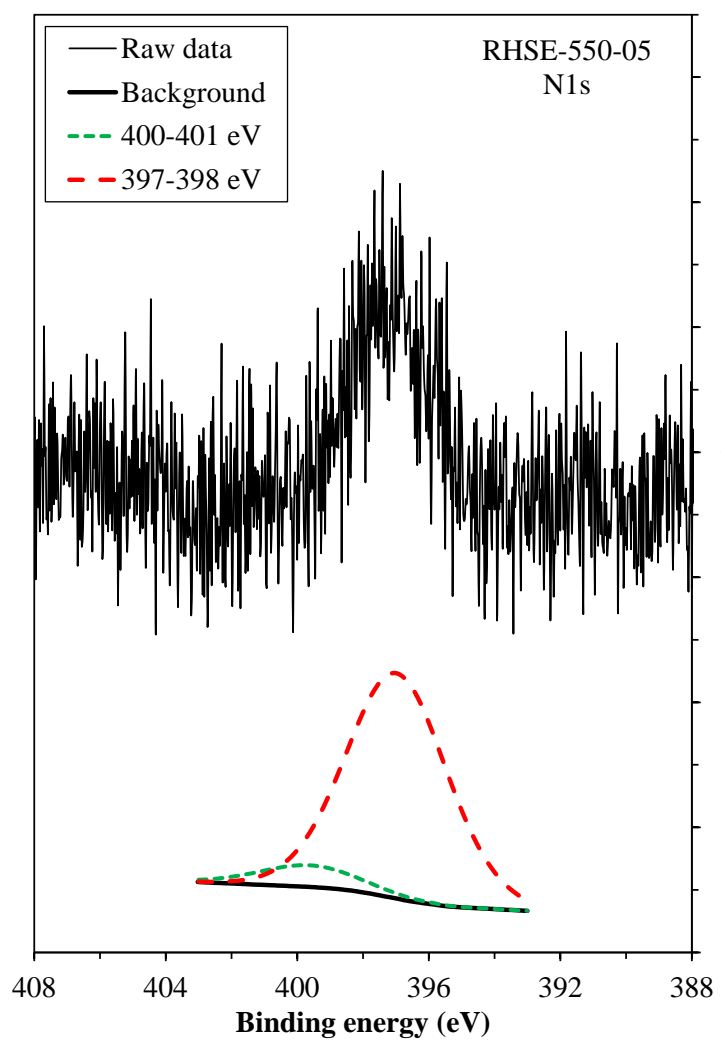

Figure 38 - XPS N1s signal for sample RHSE-550-05

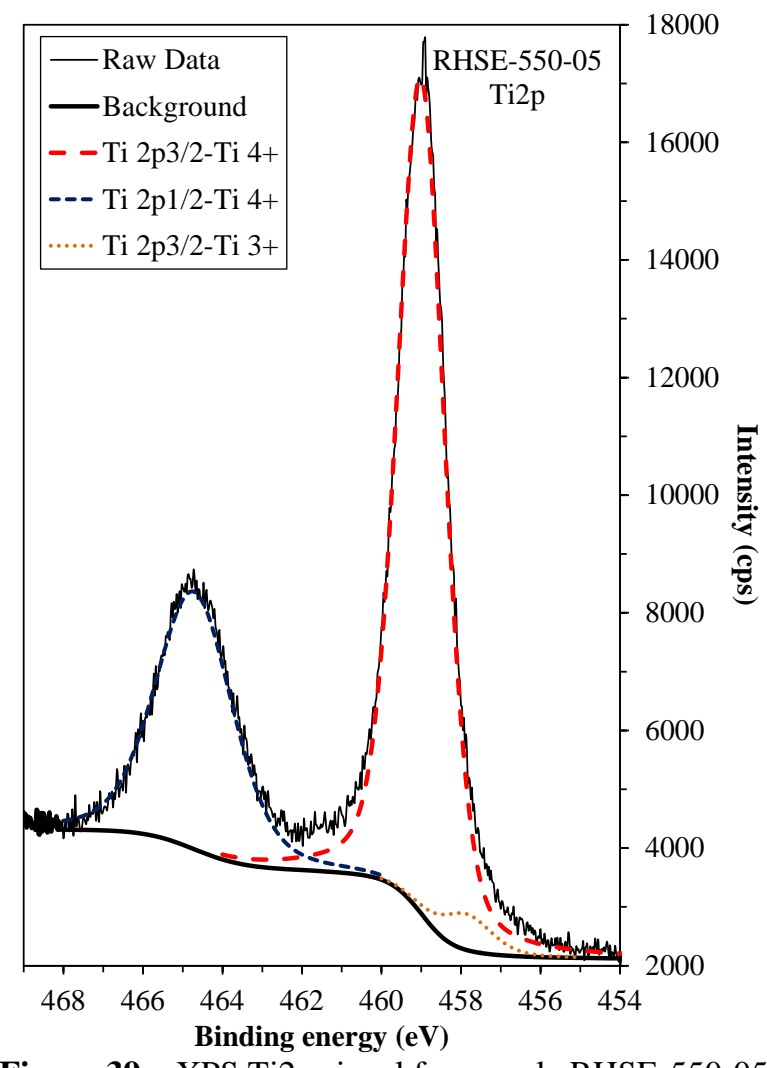

Figure 39 - XPS Ti2p signal for sample RHSE-550-05
It is rather unusual for a sample treated only for 5 minutes to have such high photocatalytic activity (Figure 37). One of the possible answers is offered by the XPS spectra. The total amount of nitrogen measured in this sample was 1.2 at \%. First of all the substitutional nitrogen type was detected [124] (88 at\% from the total nitrogen) along with a small amount of interstitial nitrogen (12 at\% from the total nitrogen) (Figure 38). The formation of the substitutional nitrogen is favored when the crystallization occurs under oxygen poor conditions [124], like in our case. Surprisingly, it disappears in the samples calcined for longer times, at this temperature, and only a small amount of interstitial nitrogen remains ( 0.7 at\%). As the calcination time extends, the nitrogen leaves the substitutional position possibly as elemental nitrogen or a rearrangement occurs resulting interstitial incorporation.

Furthermore at, $\sim 458 \mathrm{eV}$ a small amount of $\mathrm{Ti}^{3+}$ ( 1 at $\%$ from the total titanium, 0.02 at $\%$ from the atomic total) was detected (Figure 39) concomitantly with an unidentified oxygen type at $~ 528 \mathrm{eV}$ (5.7 at\% from the total oxygen and 1.7 at\% from the atomic total, see Figure 40). These two species disappear simultaneously as the calcination time advances. It is very important to elucidate the relationship between $\mathrm{Ti}^{3+}$ and the unknown oxygen type. In order to 


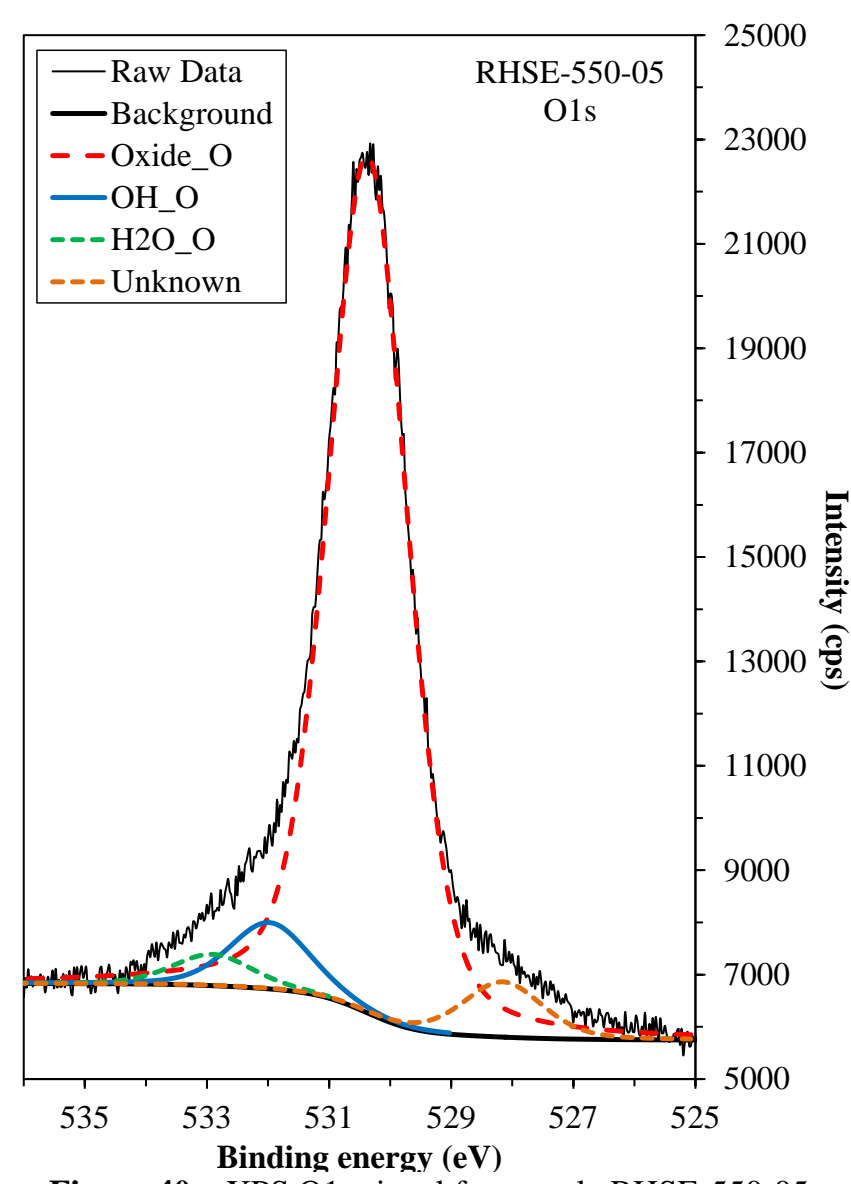

Figure 40 - XPS O1s signal for sample RHSE-550-05 clarify this question properly we should consider the followings:

i.) Yang et al. [125] predicted in their work that along $\mathrm{Ti}^{3+}$ sites a change in the oxygen types should occur in their $\mathrm{TiO}_{2-\mathrm{x}-\mathrm{y}} \mathrm{N}_{\mathrm{x}} \mathrm{C}_{\mathrm{y}}$ films;

ii.) If $\mathrm{Ti}^{3+}$ is present in a given system (in our case in the $\mathrm{TiO}_{2}$ crystal), than a change in the oxygen photoelectron spectra towards lower binding energies is observable [126];

iii.) The formation of oxygen vacancies is favored by substitutional nitrogen doping [39];

iv.) The presence of $\mathrm{Ti}^{3+}$ is simultaneous with the existence of oxygen vacancies [124].

Based upon the listed points it becomes clear that the substitutional nitrogen doping is related to the presence of $\mathrm{Ti}^{3+}$ and oxygen defects which were indirectly observed via the presence of the lower binding energy type of oxygen. This could have a major impact on the measured photocatalytic activity as we observed in our previous work [118]. In that paper we noticed in our flame made titania samples the same oxygen type ( 3 at $\%$ from the oxygen total), especially in the highly active samples. In the low activity catalysts no such oxygen type was detected. However, in the best materials no $\mathrm{Ti}^{3+}$ was detected concomitantly with the lower binding energy type of oxygen, possibly because of its low concentration, below the detection level, or their accumulation in the deeper layers.

The IR spectra of these samples reveal important information and changes compared to the samples treated at lower temperatures. The $\mathrm{NH}_{2}$ band is still visible in the RHSE-550-05 sample at $1615 \mathrm{~cm}^{-1}$ (Figure 33), but is significantly weaker than in the samples calcined at 400 ${ }^{\circ} \mathrm{C}$. The $\mathrm{OH}$ band at $1635 \mathrm{~cm}^{-1}$ becomes dominant in this series. 
In the RHLE-550-120 sample the $\mathrm{NH}_{2}$ signal is missing, thus we can affirm that no more ammonia residues could be found on the surface. This is indirectly observable also from the DRS spectra (Figure $28 b$ ). The activity decrease throughout the series can be explained by the surface dehydroxylation and the continuous decrease of the light absorbance in the 425-475 nm range.

The carbon content remained low in all the samples in this series. The bands at $2854 \mathrm{~cm}^{-1}$ and $2924 \mathrm{~cm}^{-1}$ indicate that the long chained hydrocarbons are constantly present at the catalyst's surface (Figure 36). Their intensity decrease is accompanied by the absorbance decrease in the DRS spectra, the disappearance of the $\mathrm{NH}_{2}$-band and the intensity decrease of $\mathrm{OH}$ band.

\subsubsection{Samples treated at $600{ }^{\circ} \mathrm{C}$}

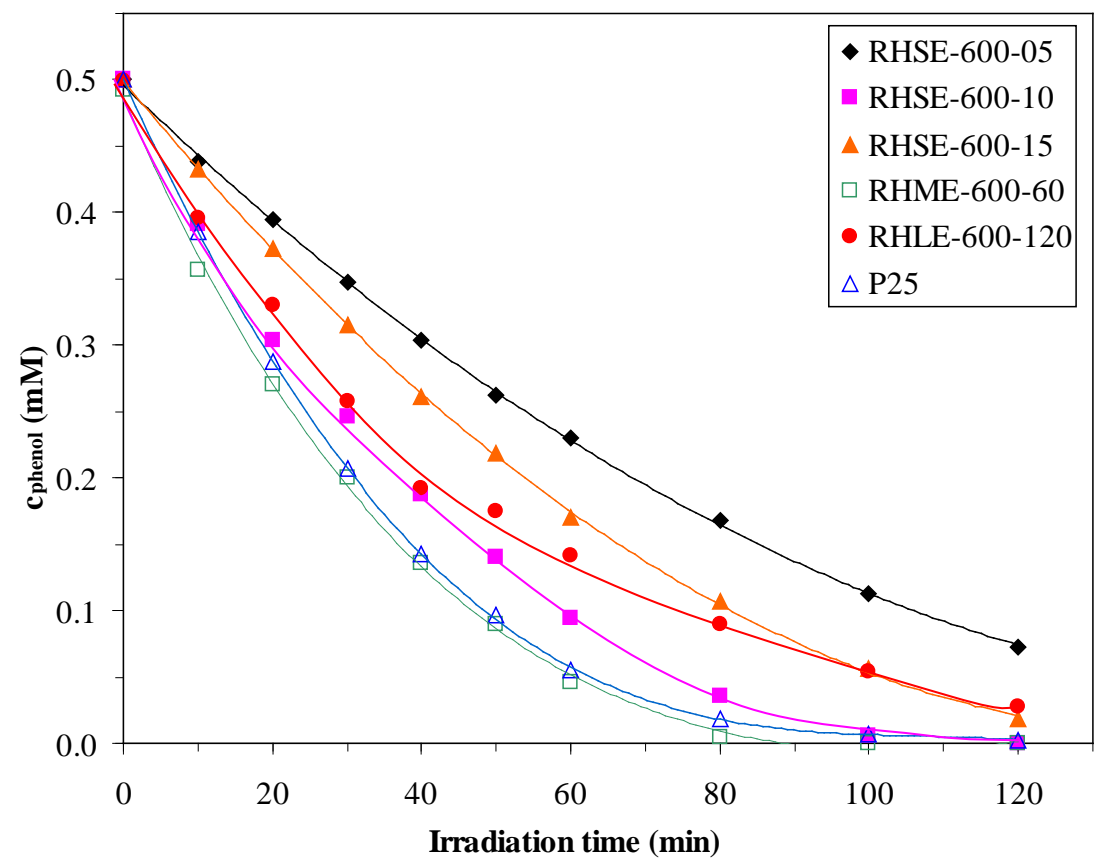

Figure 41 - Phenol decomposition on samples treated at $600{ }^{\circ} \mathrm{C}$

The phenol degradation rates measured for these samples were between $50 \%$ (sample RHLE-600-180) and 115 \% (sample RHME-600-60) of P25's degradation rate, except for sample RHSE-600-180. Another activity maximum (90 \% of P25's activity) was observed at 10 minutes of calcination (sample RHSE-600-10) (Figure 31 and Figure 41). All the materials were performing better than the sol-gel reference sample (wSHLE-450-180). Some interesting observations could be made related to: 


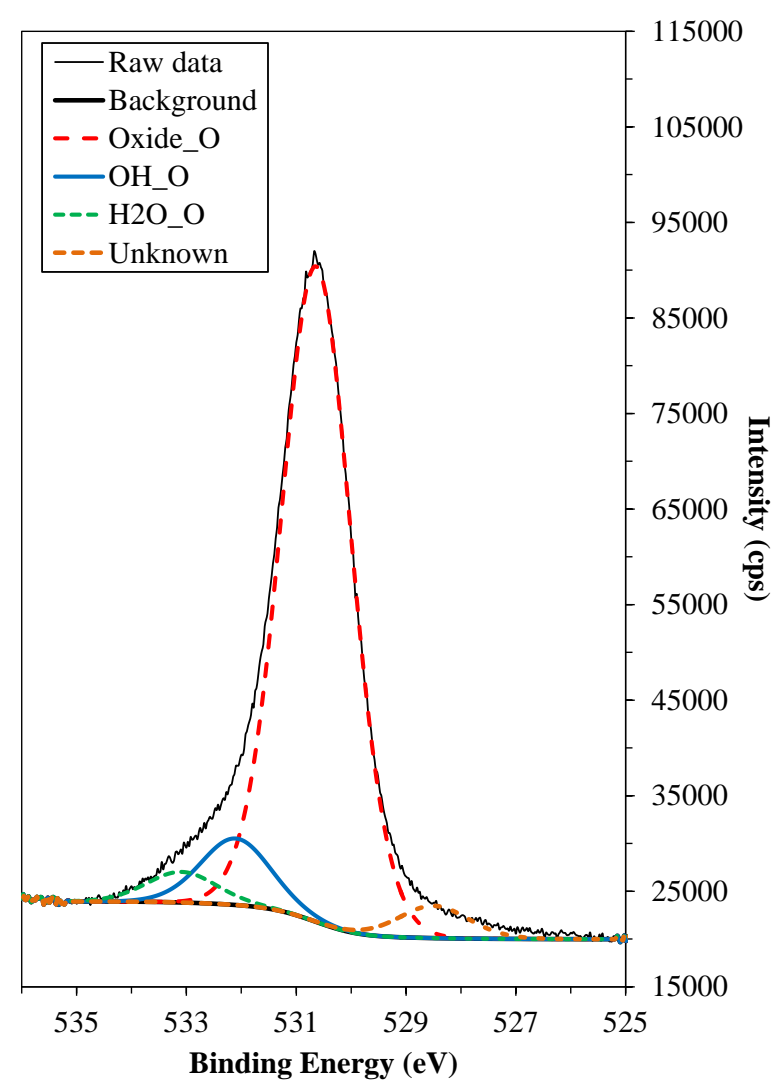

Figure 42 - XPS O1s signal for sample RHME-600-60

i.) The high activity of the samples RHSE-600-10 and RHME-600-60;

ii.) The reason for the high activity for the sample RHSE-600-10.

We observed that all the samples from the $600{ }^{\circ} \mathrm{C}$ series have similar phase composition, primary particle size (Table 4, Appendices) and specific surface area (similar behavior was observed for the samples treated at lower temperatures, see the previous two sections). As in the previous two cases, we observed the fact that while the heat treatment time increases the considerable absorbance at 425-475 nm decreases (Figure $28 c$ ).

The XPS spectra of the catalysts in this series showed that no nitrogen incorporation occurred, thus we can affirm that nitrogen doping is nearly impossible at this temperature. However, the same unknown oxygen type was observed at $~ 528 \mathrm{eV}$ (Figure 42) in the highly active samples. In the materials treated for longer times this special oxygen type is missing. The observed concentration of this type of oxygen in sample RHME-600-60 was 2.6 at \% from the oxygen total (compared to the 5.7 at\% in sample RHSE-550-05). The same quantity was found in sample RHSE-600-10. We did not observe any $\mathrm{Ti}^{3+}$ sites, probably due to their low concentration. Also a slight dehydroxylation was observed in this series (as in the case of the samples calcined at lower temperatures). Based upon the O1s XPS spectra of the samples, the two activity maxima cannot be explained.

Figure 35 shows the IR spectra for three highly active catalysts (P25, RHSE-600-10, and RHME-600-60) and the sol-gel reference, sample wSHLE-450-180. The highly active photocatalysts all have very similar surface $\mathrm{OH}$-group absorption bands at $1635 \mathrm{~cm}^{-1}$, whilst there is no corresponding absorption for the wSHLE-450-180 sample. No $\mathrm{NH}_{2}$ bands were observed in 
the materials of this series. The loss of surface OH-groups in the traditionally calcined material, which is assumed to occur during long time calcination, could be one of the main reasons for the low UV activity.

The spectrum of RHSE-600-10 sample shows several small bands at $\sim 2870 \mathrm{~cm}^{-1}$ whilst the RHME-600-60 sample lacks this feature (Figure 36). These absorptions arise from long hydrocarbons chains and this means that after a short calcination time, carbonaceous species (-CC-) still could remain on the catalyst's surface, similarly to the materials calcined at lower temperatures (Figure 36) [116]. These species may cause a small red shift and a visible light absorption in the $420-530 \mathrm{~nm}$ range in the DRS spectra of the catalysts and may be the origin of the yellow color of RHSE-600-10 sample (Figure 28 c). This shift and extra absorption could sensitize the photocatalyst to be excited over a broader spectral range of the irradiation. In fact at this temperature an additional absorption band appears in the 2800-3000 $\mathrm{cm}^{-1}$ region at 2962 $\mathrm{cm}^{-1}$, which could be the reason for the successful sensitization.

Although this effect could increase the photocatalytic activity, too much organic impurities remaining on the surface are obviously disadvantageous for photocatalytic purposes. Longer calcination times cause the thermal decomposition of these organic species, possibly forming first an amorphous carbon layer on the nanocrystals (minimum local activity at RHSE600-20) and finally giving a virtually carbon-free clean surface as in case of sample RHME-60060.

Figure 31 clearly shows that the samples obtained using longer calcination times (30-120 minutes) have higher activity than those calcined for very short times (5-15 minutes). The only exception is the sample treated for 10 minutes with its unexpectedly high activity probably due to the sensitization of the photocatalyst. Long heat treatment times (120-180 minutes) can cause a drastic activity decrease.

As it can be seen, until now the thesis deals with fast heat treated titanias applied under UV irradiation. Unfortunately, these materials were nearly inactive under visible light. Thus, the next problem that needs to be solved is the synthesis of visible light active materials. 


\section{The synthesis of the fast heat treated nitrogen doped titanias}

$\mathrm{N}$-doped $\mathrm{TiO}_{2}$ samples were synthesized by the following sol-gel method. Glacial acetic acid $(a \mathrm{~mL})$ was added dropwise under vigorous stirring to $\mathrm{HNO}_{3}(70 \%, b \mathrm{~mL})$. The $a$ and $b$ values were summarized in Table 5, Appendices together with the molar ratios of these acids to the titanium precursor. The mixture was cooled down and kept at $5{ }^{\circ} \mathrm{C}$ in an ice bath. $\mathrm{TiCl}_{4}(5$ $\mathrm{mL}$ ) was slowly added to the acidic media to avoid overheating. During the hydrolysis, $\mathrm{NO}_{2}$ was released from the system and the color of the dispersion turned brownish-orange (the measured $\mathrm{pH}$ was below 1.0 for all the dispersions).

The dispersion was stirred for 1 hour and subsequently added to $100 \mathrm{~mL}$ of double distilled water. Aqueous solution of $\mathrm{NH}_{3}(25 \%)$ was used to precipitate the amorphous titania and the $\mathrm{pH}$ value was adjusted to $\sim 8-9$. To drive the hydrolysis to completion, the slurry was kept at room temperature overnight. A yellowish-white powder was obtained by drying the amorphous precipitate at $80^{\circ} \mathrm{C}$ for 24 hours.

The amorphous sample was calcined in a muffle furnace (Carbolite ELF 11/6 (201)) to obtain crystalline $\mathrm{TiO}_{2}$. The applied heating rate was $60{ }^{\circ} \mathrm{C} / \mathrm{min}$ and the samples were calcined for 10 minutes at 400,500 and $600{ }^{\circ} \mathrm{C}$. Then, the samples were taken out and cooled to room temperature. The catalysts treated at different temperature were labeled $\mathbf{N x}-\mathbf{A y}-\mathbf{T}$ ( $\boldsymbol{N}$ and $\boldsymbol{A}$ from nitric acid and acetic acid respectively, and $\mathbf{T}$ represent the heat treatment temperature; $x$ is $\mathrm{HNO}_{3}$ : $\mathrm{TiCl}_{4}$ molar ratio and $y$ represents $\mathrm{CH}_{3} \mathrm{COOH}$ : $\mathrm{TiCl}_{4}$ molar ratio).

The samples were washed with double distilled water, and received 3 hours of UV (365

$\mathrm{nm}$ ) treatment to remove all possible organic impurities. The obtained samples were dried at 80 ${ }^{\circ} \mathrm{C}$. All the catalysts obtained were reproduced to gain higher accuracy for the conclusions. 


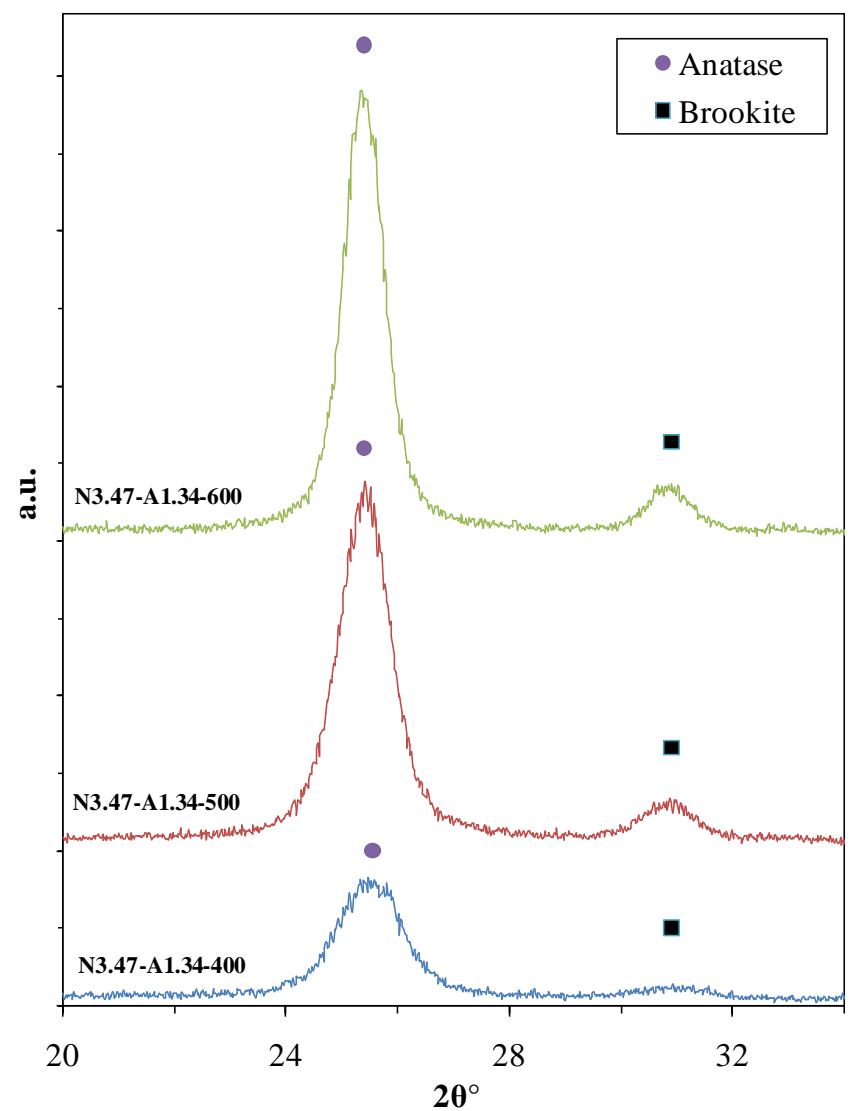

Figure 43 - XRD patterns for the N3.47-A0.67 series
9. Nitrogen doped titania photocatalysts properties made by rapid calcination

\subsection{XRD, BET, and Raman results}

The initial step of the photocatalysts evaluation consists in the determination of the phase composition and the average primary catalyst particle size. Anatase (91-100 wt\%) and brookite (0-9 wt\%) were the main crystal phases, identified by XRD, within the synthesized catalysts (see Table 6, Appendices and Figure 43). No rutile formation was detected. Colón and coworkers found similar hindering of the rutile phase formation by pre-treating the amorphous material with oxo acids (nitric, sulfuric and phosphoric acid) before calcination [69].

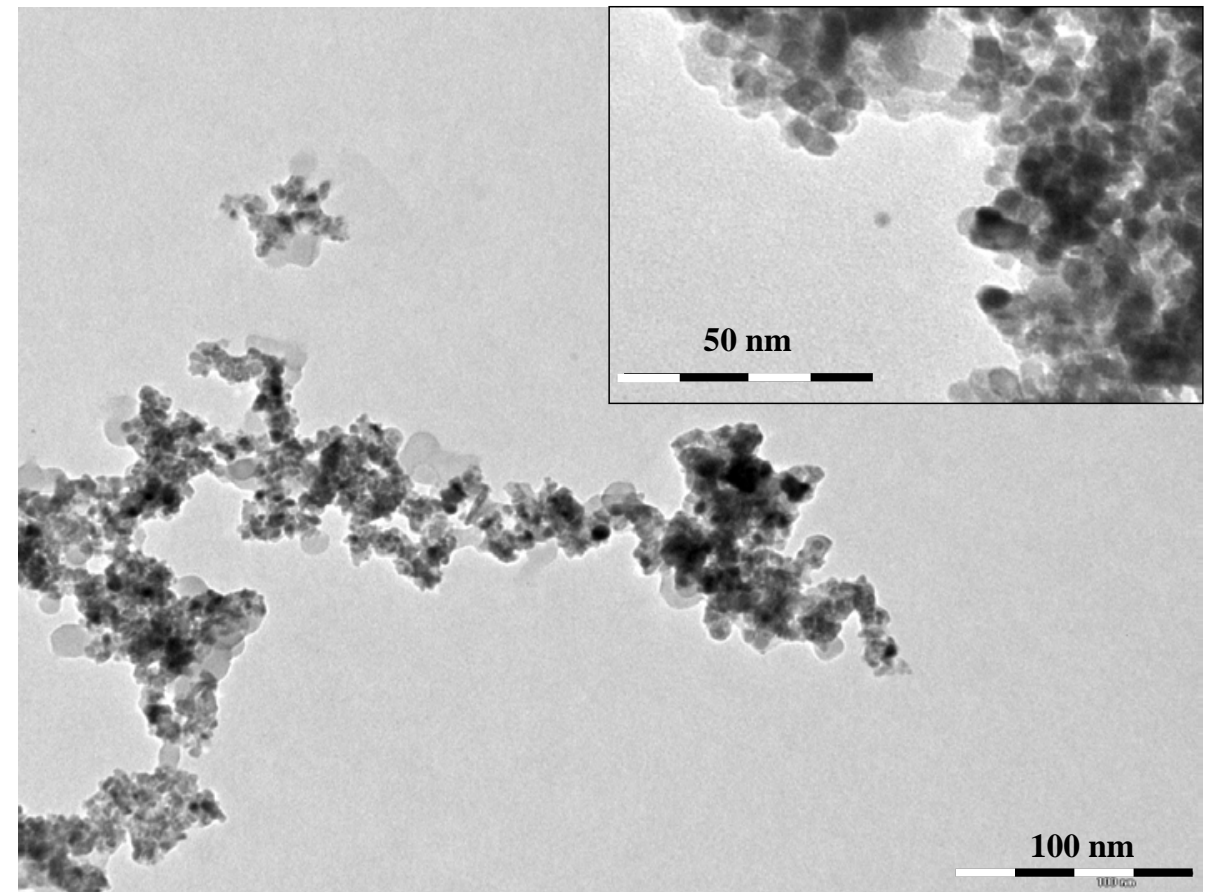

Figure 44 - TEM image of sample N3.47-A0.67-400 
The present synthesis conditions are favorable for identifying the effects that brookite nanoparticles have on the visible light photocatalytic activity as the rutile phase (band gap 3.0 $\mathrm{eV}$ ) absorbs light up to $410 \mathrm{~nm}$. Examination of the crystallites size (Table 6, Appendices) of these nanomaterials shows that particle sizes for each crystal phase are rather small $(6-15 \mathrm{~nm})$. According to Ryu and Choi [119], these materials are very likely suitable for visible light photocatalysis.

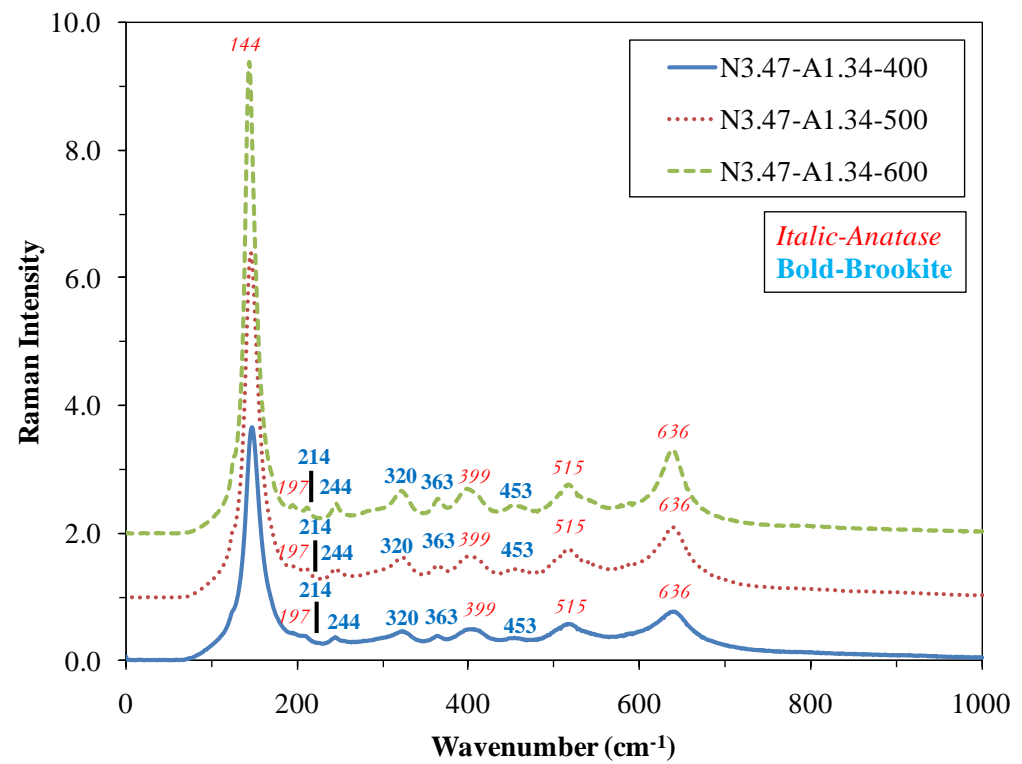

Figure 45 - Raman spectra of N3.47-A1.34 series

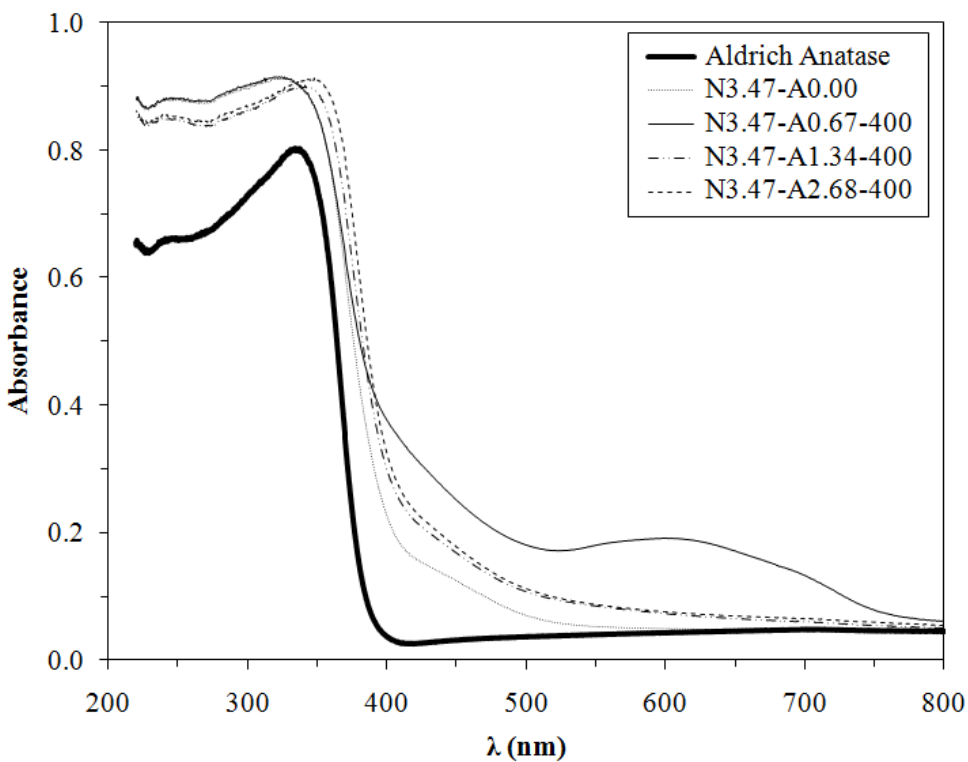

Figure 46 - DR spectra of the acetic acid series treated at $400{ }^{\circ} \mathrm{C}$ (acetic $\mathrm{acid} / \mathrm{TiCl}_{4}$ molar ratio increases as follows N3.47-A0.00-400, N3.47-

A0.67-400, N3.47-A1.34-400, N3.47-A2.68-400) 
The TEM images (Figure 44) and the relatively high BET specific surface area values of the non-porous structured samples $\left(100-155 \mathrm{~m}^{2} / \mathrm{g}\right)$ confirmed the particle size calculated from the XRD data (Table 7, Appendices). Figure 45 shows the Raman spectra of the N3.47-A1.34 amorphous material calcined at different temperatures. The following bands were identified corresponding to the anatase structure: $144 \mathrm{~cm}^{-1}$ (strong band, overlapping the brookite band at $128 \mathrm{~cm}^{-1}$ ), $197 \mathrm{~cm}^{-1}, 399 \mathrm{~cm}^{-1}, 515 \mathrm{~cm}^{-1}$, and $636 \mathrm{~cm}^{-1}$. For the brookite phase, the following bands were found: $128 \mathrm{~cm}^{-1}$ (covered by the anatase band at $144 \mathrm{~cm}^{-1}$ ) as a shoulder, $214 \mathrm{~cm}^{-1}$, $244 \mathrm{~cm}^{-1}, 320 \mathrm{~cm}^{-1}, 363 \mathrm{~cm}^{-1}, 453 \mathrm{~cm}^{-1}$ and $639 \mathrm{~cm}^{-1}$ (this last band is unfortunately covered by the anatase band at $636 \mathrm{~cm}^{-1}$ and can be observed only from the nonsymmetrical distribution of the signal). Similar distribution of the bands was observed by $\mathrm{Hu}$ and coworkers [127]. These results confirm the phase composition determined by XRD (see Table 6, Appendices). 


\subsection{The influence of acids on the phase composition and light absorption of rapid heat treated N-doped titanias}

In this work, two acids (nitric and acetic acid) were used in the hydrolyzing media in order to investigate the effect that $\mathrm{pH}$ controlling acids have during the hydrolysis [128]. Hydrochloric acid is also present in the system as it is formed during the titanium precursor hydrolysis. To evaluate the difference between systems with oxo-acids and non-oxo-acids, a sample was synthesized with hydrochloric acid instead of nitric acid (N0.00-A1.34-400 sample). The sample N0.00-A1.34 (Table 6, Appendices) contained only anatase meaning that the presence of nitric acid could determine brookite phase formation. This was also observed by Hao and Zhang [67]. If the acetic acid is absent from the system (N3.47-A0.00 series) the brookite formation still occurs meaning that the presence of this acid is not critical for this crystal phase presence. However, Figure 46 shows that the visible light absorbance varies with the molar ratio of acetic acid within the system and Figure 47 shows that the brookite particle size and corresponding visible light absorbance has a maximum exactly at the same acetic acid/ $\mathrm{TiCl}_{4}$ molar ratio (0.67, N3.47-A0.67-400).

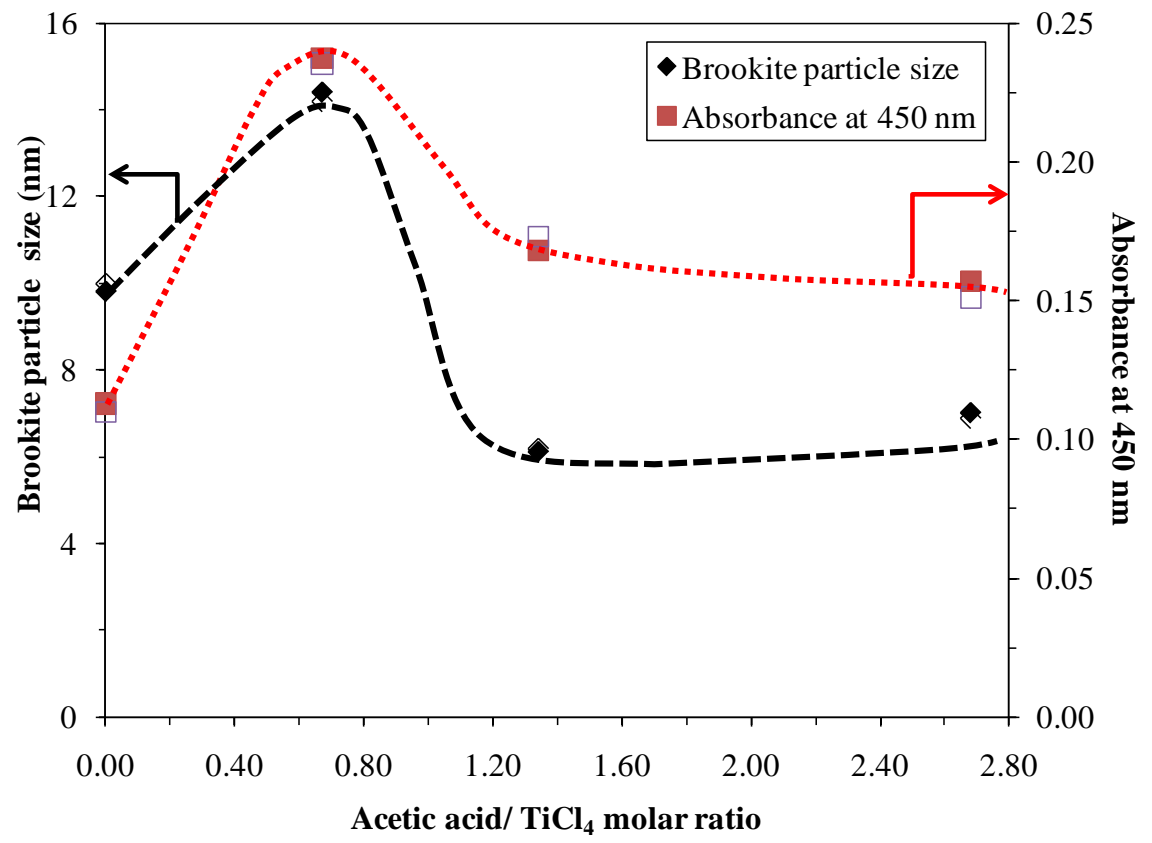

Figure 47 - Correlation between the brookite particle size and visible light absorption with the applied acetic acid/ $\mathrm{TiCl}_{4}$ molar ratio (the empty symbols represents the values obtained for reproduced catalysts)

Visible light absorption is a prerequisite for obtaining a highly visible light active photocatalyst but high levels of absorption may not be linked with an effective catalytic activity. 
In our preliminary studies, it was observed that strong visible light absorption of nitrogen doped $\mathrm{TiO}_{2}$ photocatalysts (using urea as nitrogen precursor) did not correlate with a high level of activity under visible light. In this study the nitrogen content of the samples (0.8-1.1 at\%; $\pm 15 \%$ error) determined by elemental analysis was found to be independent from the applied acids/ titania precursor molar ratio and from the used acids concentration.

\subsection{The influence of the calcination temperature on the structural and photocatalytical properties of the prepared photocatalysts}

The amorphous samples (excluding N0.00-A1.34) was separately calcined for 10 minutes) using 3 different final temperatures $\left(400,500\right.$ and $600{ }^{\circ} \mathrm{C}$ ) with a heating rate of 60 ${ }^{\circ} \mathrm{C} / \mathrm{min}$. The XRD patterns for every series showed that the crystal phase content was unaffected by this treatment, but for the majority of the samples, the anatase crystallite size increased with the final heat treatment temperature (Figure 43; Table 6, Appendices). Also, the photocatalytic activity was reduced with an increase in the final heat treatment temperature (Table 8, Appendices). This supports the claims that efficient visible light active photocatalysts can be made mostly at low crystallization temperature.

\subsection{Correlation between the brookite particle size and visible light photocatalytic activity}
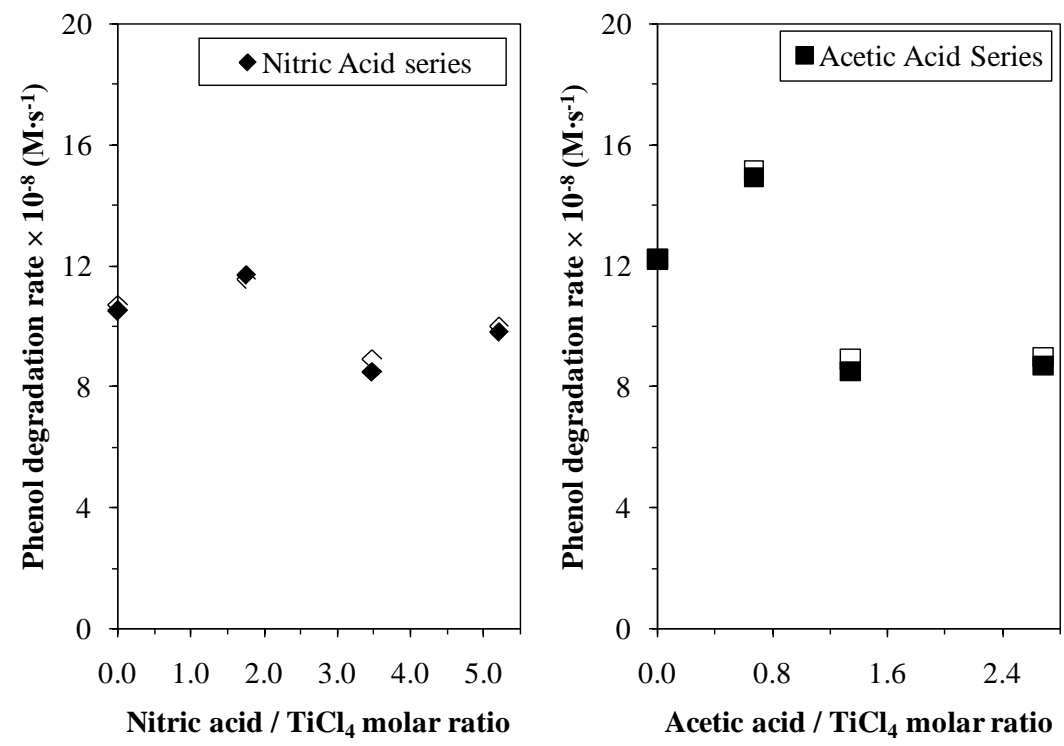

Figure 48 - Correlation between the phenol degradation rate and the applied acetic acid and nitric acid molar ratio in the hydrolysis process (the empty symbols represents the rate values obtained with the reproduced catalysts) 
Figure 48 shows that there was no correlation between the photocatalytic properties and the applied nitric acid/TiCl ${ }_{4}$ molar ratio. The photocatalytic activity of the obtained samples is maximized with a large acetic acid/ $\mathrm{TiCl}_{4}$ molar ratio such as 0.67 (Figure 48). This trend mirrors the previous observation regarding the visible light absorption and for the brookite particle size (Figure 47). It is not yet clear how the brookite phase influences the visible light activity. We have also observed that the phenol degradation rate increases in correlation with the brookite particle size (Figure 49) but no dependences were found with the anatase content and particle size, which is virtually constant in all samples.

There is evidence in the literature that the particle size strongly influences the band gap of the semiconductor [129]. The general trend is that as the particle size increases, the band gap of the semiconductor material decreases to a certain minimum. The observed increase in brookite particle size $(\mathrm{D}=6-15 \mathrm{~nm})$ correlates with a reduction in the band gap and thus enables electron transfer between the two crystal phases. The brookite phase may also function as a local electron/hole reservoir and probably hinders the recombination process for large particles (10-15 $\mathrm{nm})$. This may be the origin for the maximum photocatalytic activity of the N3.47-A0.67-400 sample (Figure 49 and Table 6, Appendices).

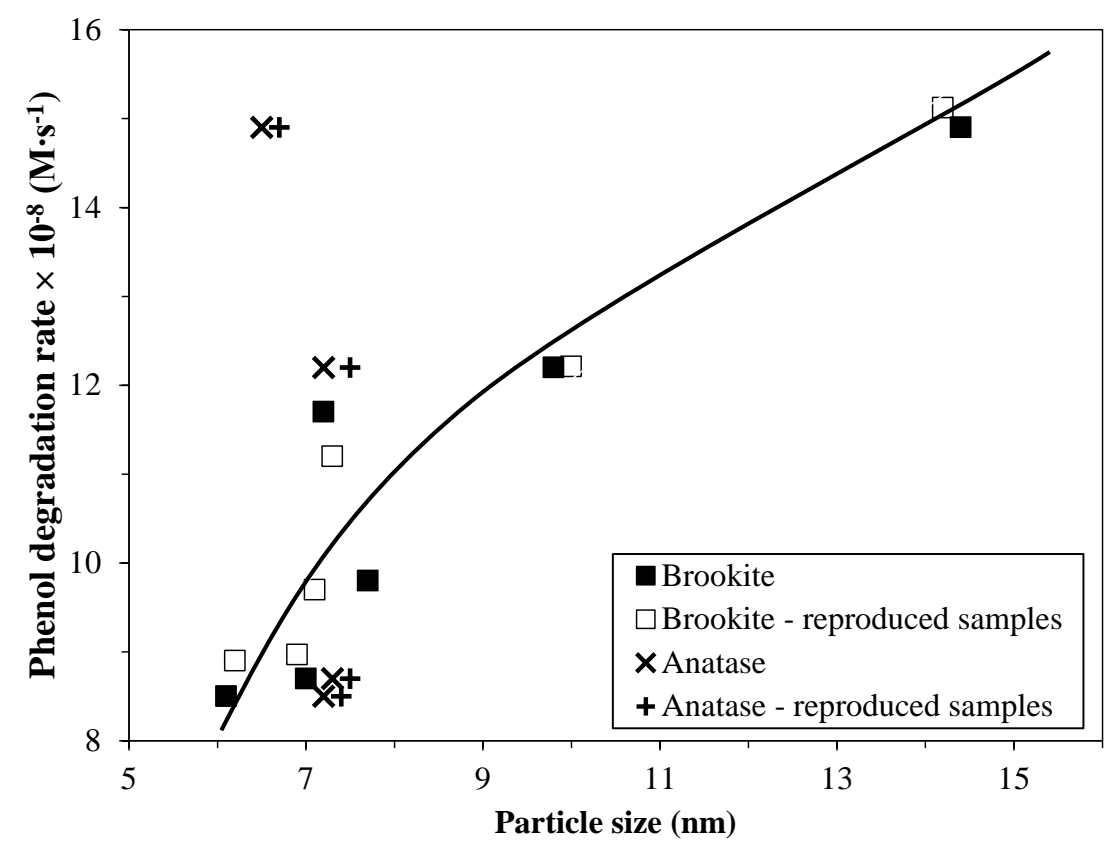

Figure 49 - Correlation between the brookite primary particle size and phenol degradation rate; (the empty symbols represents results with the reproduced catalysts) 


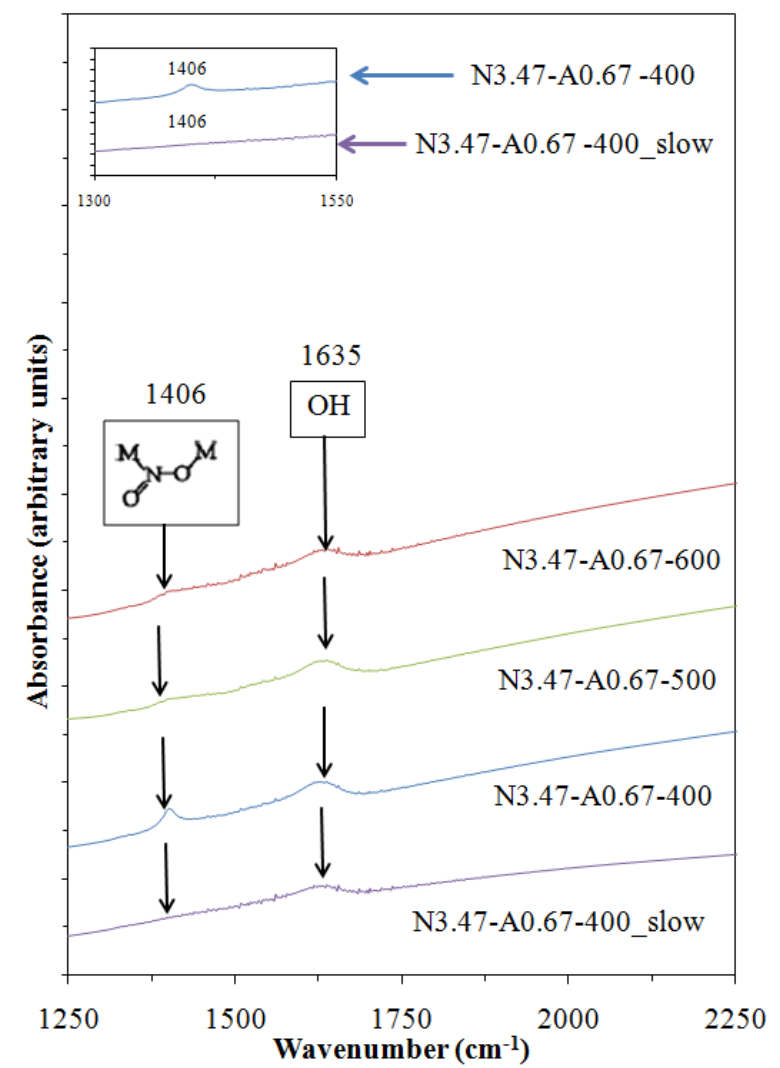

Figure 50 - IR spectra of N3.47-A0.67 series including N3.47-A0.67 -400_slow sample
9.5. Comparison between traditionally calcined samples and fast heat treated samples

The N3.47-A0.67-400 sample was traditionally calcinated using a low heating rate $\quad\left(5{ }^{\circ} \mathrm{C} / \mathrm{min}\right)$ (N3.47-A0.67-400_slow sample) to highlight the effects of the fast calcinations. The XRD pattern of the obtained samples showed that the anatase and brookite content and the crystallite size did not depend on the calcination method (Table 6, Appendices).

Samples prepared using the fast heat treatment, have a characteristic IR absorption band at $1406 \mathrm{~cm}^{-1}$ (N3.47-A0.67-400 sample, Figure 50). This band corresponds to bridged nitro species [130] and is suspected to arise from the amorphous material synthesis process, which uses a nitric acid precursor.

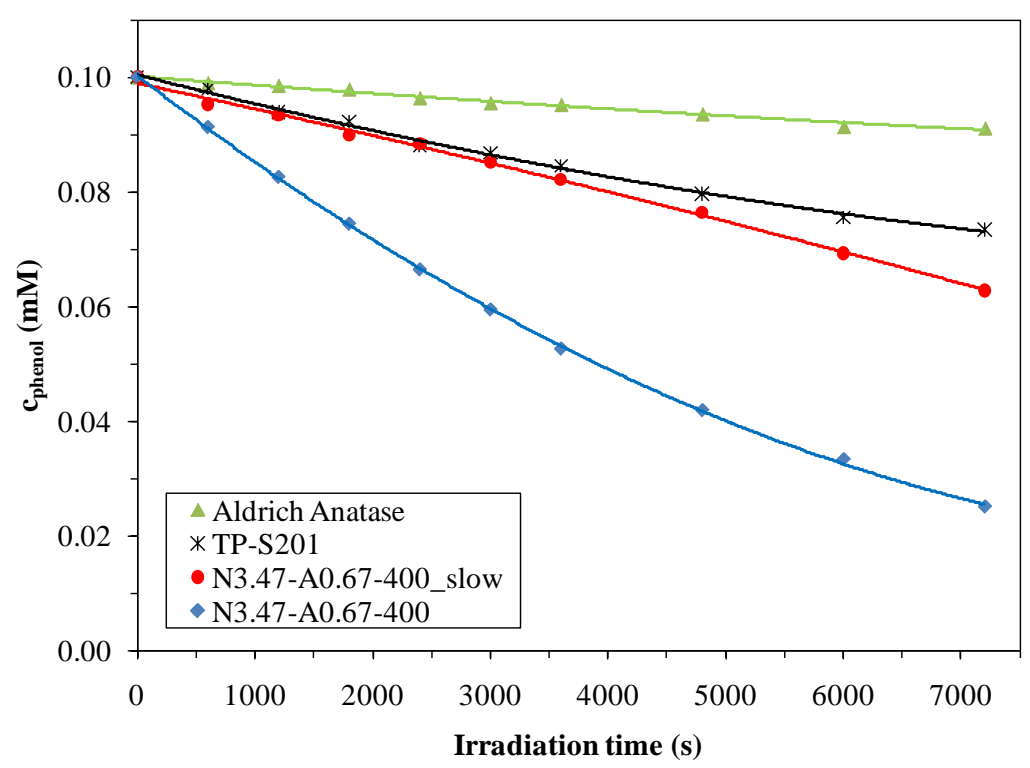

Figure 51 - Phenol degradation for the N3.47-A0.67-400, Reference Catalyst (TP-S201), Aldrich Anatase and N3.47-A0.67 -400_slow samples 
Very weak IR absorption for these bridging nitro species was also detected for the samples treated at higher temperature (Figure 50) synthesized at higher temperatures (treatment time 10 minutes at $500,600^{\circ} \mathrm{C}$ ). However, the IR spectrum for the slowly heated sample (N3.47A0.67-400_slow) does not show absorption arising from a bridging nitro group. This difference is ascribed to the decomposition of and subsequent desorption of the bridged nitro groups, phenomena facilitated by the long exposure to high temperature. This partially explains why N3.47-A0.67-400 sample can absorb more visible light in the 400-800 nm wavelength range.

This can be one of the reasons why the activity of the fast heat treated sample is higher compared to the traditionally calcined sample, and is much higher than that of a commercially available nitrogen doped visible light active photocatalyst (TP-S201 produced by Sumitomo Chemicals Ltd, see Figure 51).
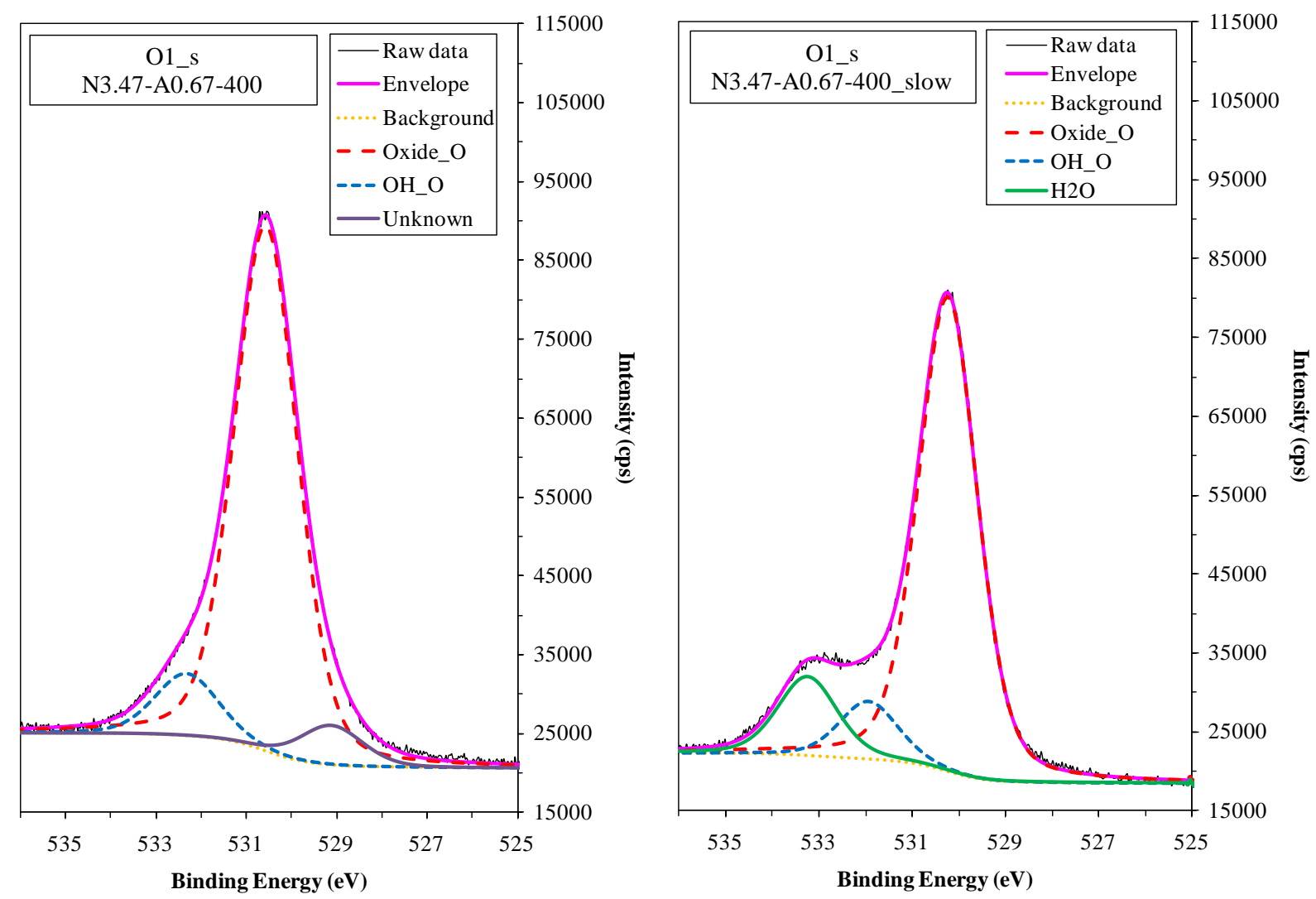

Figure 52 - O1s XP spectra of N3.47-A0.67-400 sample (left) O1s XP spectra of N3.47-

A0.67-400_slow sample (right)

Figure 52 shows the O 1s XP spectrum of the N3.47-A0.67-400 sample with a small peak at $532.5 \mathrm{eV}$ correlating to surface $\mathrm{OH}$ groups [117]. This $\mathrm{OH}$ peak is present also in the N3.47- 
A0.67-400_slow sample XP spectra but with a greater relative peak area when compared to the peak of the fast heat treated sample. This difference between the surface $\mathrm{OH}$ densities can be seen also in the IR spectra at $1635 \mathrm{~cm}^{-1}$ (Figure 50). This means that a long heat treatment favors the dehydroxylation of the photocatalyst surface. A relatively strong adsorbed water signal is observed at $533.5 \mathrm{eV}$ for the traditionally calcined sample. A peak at $529.1 \mathrm{eV}$ could not be identified from literature values of oxygen types. This peak was also observed in the XPS spectra of other UV active titania samples made by flame and other fast heat methods [131].

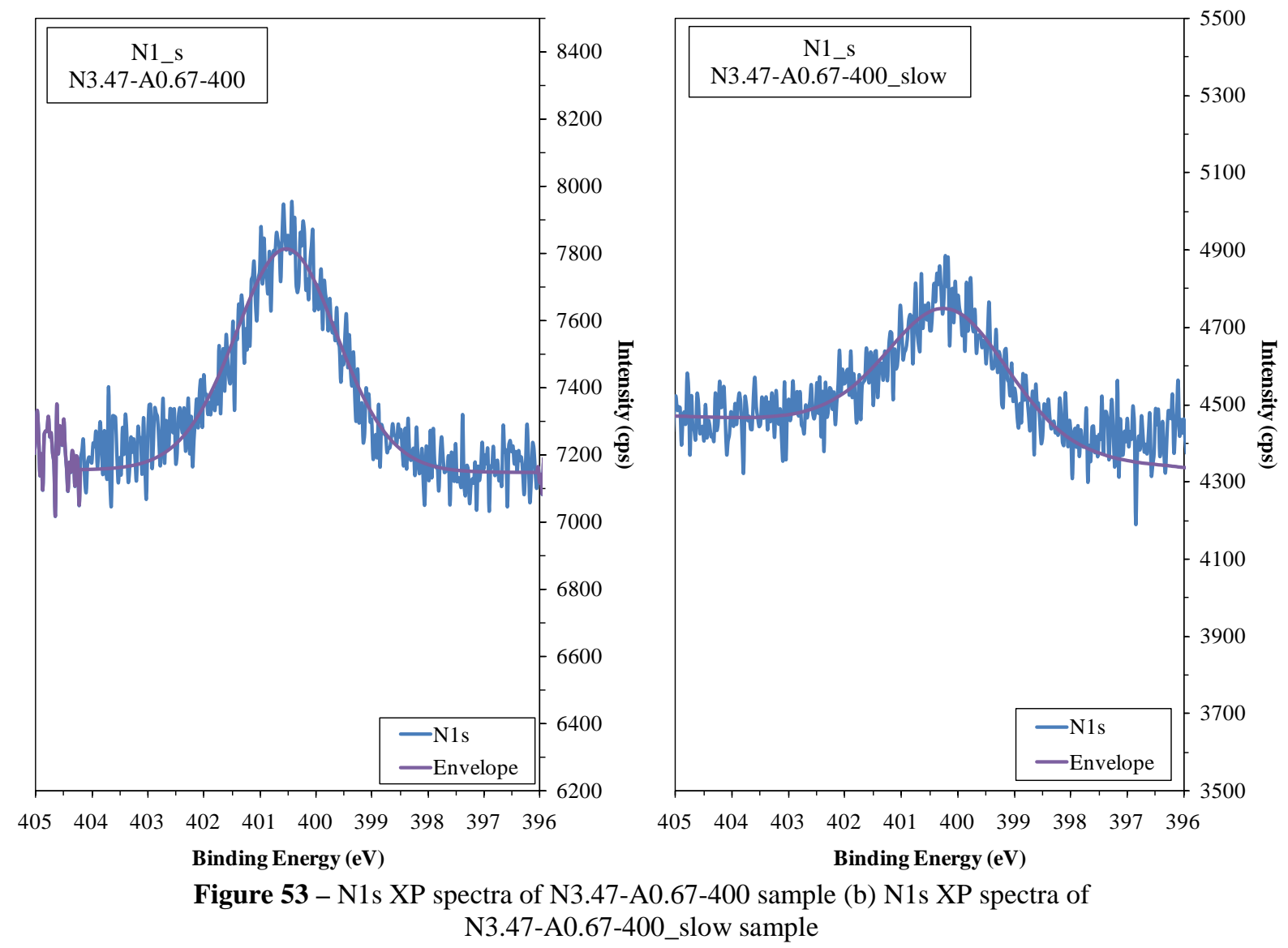

The N1s XP (Figure 53) signal of O-Ti-N type nitrogen was also found by Senthilnathan et al. [122]. The signal position is independent from the calcination time. The nitrogen content calculated from the XPS data is 1.32 at\% for N3.47-A0.67-400 sample and 1.23 at\% for the N3.47-A0.67-400_slow sample. This means that the substitutional form of nitrogen is more stable than the bridged nitro species, which is only present at the surface and can be eliminated by longer heat treatment times. 


\section{Conclusions}

The literature regarding sol-gel prepared titanias, treated the calcination as a standard procedure without seriously considering its complex influence on the photocatalytic properties on the obtained nanomaterials. It is well known how the temperature can modify the primary particle size and phase composition but no meticulous study was published regarding the influence of the calcination time.

We have successfully shown that in a temperature series, throughout the calcination times several surface parameters change continuously, like: the presence of $\mathrm{NH}_{2}$-group at lower temperatures, the influence of the long chained hydrocarbons, the dehydroxylation phenomena, the nitrogen incorporation, the evolution of the light absorption of the samples, etc. Several evidences were brought up to support the role of each surface parameter.

It was proven that very active catalysts can be made with just 5 (RHSE-550-05 sample) or 10 (RHSE-600-10 sample) minutes of calcination and experimental data were collected to explain their unusual properties. However, in some cases (RHME-600-60 and RHLE-400-120 samples) due to the longer calcination time a surface purification occurs and a photoactivity increase was observed. We demonstrated that at low calcination temperature, because of the surface coverage with organic residues/carbon deposits, only low UV activity can be obtained.

The samples treated at higher temperatures (above $500^{\circ} \mathrm{C}$ ) were more active than the solgel reference wSHLE-450-180 sample and only a few samples, such as RHSE-550-05 and RHME-600-60 exceeded the performance of the well-known P25 titanium dioxide (and obtained comparable reaction rates in the case of monuron degradation).

Two main synthesis aspects influencing the activity of the fast heat-treated nitrogen doped titania photocatalysts were studied in details. The importance of the hydrolysis media was proven by varying the concentration of acetic and nitric acid. The presence of the nitric acid was crucial for the formation of the brookite phase and there were no other correlations between the nitric acid concentration and the resulting catalyst properties. However, the acetic acid had a major impact on the structural parameters of the catalysts, particularly the brookite particle size and visible light absorbance. These two parameters are closely related to the visible light driven photocatalytic properties of the titania powders. It was shown that the size of brookite particle is very important even when there was low level of brookite content. The anatase particle size was independent of these experimental conditions. 
These studies show that the catalyst's resulting morphology, structure and photocatalytic properties are dependent on the calcination time. Significant difference was observed in the photocatalytic activity of the two differently calcined materials, with the fast heat treated samples performing the best for phenol degradation under visible light irradiation. This result originates from the combined effects of higher concentration of incorporated nitrogen, the lack of dehydroxylation and the beneficial presence of the bridged nitro group. This photocatalyst was nearly twice as active as the traditionally calcined catalyst. 


\section{References}

[1] A. Fujishima, K. Honda, Nature 238 (1972) 37-38.

[2] Q. Zhang, W. Fan, L. Gao, Appl. Catal., B 76 (2007) 168-173.

[3] M. Qamar, M. A. Gondal, Z. H. Yamani, Catal. Commun. 10 (2009) 1980-1984.

[4] J. Xu, W. Dai, J. Li, Y. Cao, H. Li, H. He, K. Fan, Catal. Commun. 9 (2008) 146-152.

[5] C. Adán, A. Bahamonde, M. Fernández-García, A. Martínez-Arias, Appl. Catal., B 72 (2007) 11-17.

[6] T. A. Kandiel, R. Dillert, A. Feldhoff, D. W. Bahnemann, J. Phys. Chem. C 114 (2010) 4909-4915.

[7] K. Kakiuchi, E. Hosono, H. Imai, T. Kimura, S. Fujihara, J. Cryst. Growth 293 (2006) 541-545.

[8] R. Buonsanti, V. Grillo, E. Carlino, C. Giannini, T. Kipp, R. Cingolani, P. D. Cozzoli, J. Am. Chem. Soc. 130 (2008) 11223-11233.

[9] D. Dambournet, I. Belharouak, J. W. Ma, K. Amine, J. Mater. Chem. 21 (2011) 30853090.

[10] Z. Ambrus, K. Mogyorósi, Á. Szalai, T. Alapi, K. Demeter, A. Dombi, P. Sipos, Appl. Catal., A 340 (2008) 153-161.

[11] Z. Pap, V. Danciu, Z. Cegléd, Á. Kukovecz, A. Oszkó, A. Dombi, K. Mogyorósi, Appl. Catal., B 101 (2011) 461-470.

[12] S. Cassaignon, M. Koelsch, J. Jolivet, J. Phys. Chem. Solids 68 (2007) 695-700.

[13] H. Wang, Y. Wu, B.-Q. Xu, Appl. Catal., B 59 (2005) 139-146.

[14] E. Hosono, S. Fujihara, H. Lmai, I. Honma, I. Masaki, H. S. Zhou, ACS Nano 1 (2007) 273-278.

[15] N. H. Hong, W. Prellier, J. Sakai, A. Hassini, Appl. Phys. Lett. 84 (2004) 2850-2852.

[16] Y. Huang, W. K. Ho, Z. H. Ai, X. A. Song, L. Z. Zhang, S. C. Lee, Appl. Catal., B 89 (2009) 398-405.

[17] J. Carbajo, C. Adán, A. Rey, A. Martínez-Arias, A. Bahamonde, Appl. Catal., B 102 (2011) 85-93.

[18] P. Vijayan, C. Mahendiran, C. Suresh, K. Shanthi, Catal. Today 141 (2009) 220-224.

[19] X. Fan, X. Chen, S. Zhu, Z. Li, T. Yu, J. Ye, Z. Zou, J. Mol. Catal. A: Chem. 284 (2008) 155-160. 
[20] S.-m. Chang, W.-s. Liu, Appl. Catal., B 101 (2011) 333-342.

[21] Y. Shen, T. Xiong, T. Li, K. Yang, Appl. Catal., B 83 (2008) 177-185.

[22] G. Colon, M. Maicu, M. Hidalgo, J. Navio, Appl. Catal., B 67 (2006) 41-51.

[23] A. M. T. Silva, C. G. Silva, G. Dražić, J. L. Faria, Catal. Today 144 (2009) 13-18.

[24] E. Prociow, J. Domaradzki, A. Podhorodecki, A. Borkowska, D. Kaczmarek, J. Misiewicz, Thin Solid Films 515 (2007) 6344-6346.

[25] W. Xiaohong, Q. Wei, D. Xianbo, W. Yang, L. Huiling, J. Zhaohua, J. Phys. Chem. Solids 68 (2007) 2387-2393.

[26] D. Mitoraj, H. Kisch, Angew. Chem., Int. Ed. 47 (2008) 9975-9978.

[27] R. Asahi, T. Morikawa, T. Ohwaki, K. Aoki, Y. Taga, Science 293 (2001) 269-271.

[28] L. Szatmáry, S. Bakardjieva, J. Šubrt, P. Bezdička, J. Jirkovský, Z. Bastl, V. Brezová, M. Korenko, Catal. Today 161 (2011) 23-28.

[29] K. Takeshita, A. Yamakata, T. Ishibashi, H. Onishi, K. Nishijima, T. Ohno, J. Photochem. Photobiol., A 177 (2006) 269-275.

[30] Y. Y. Lv, L. S. Yu, H. Y. Huang, H. L. Liu, Y. Y. Feng, J. Alloys Compd. 488 (2009) 314-319.

[31] Q. Xiao, J. Zhang, C. Xiao, Z. Si, X. Tan, Solar Energy 82 (2008) 706-713.

[32] M. Janus, M. Inagaki, B. Tryba, M. Toyoda, A. Morawski, Appl. Catal., B 63 (2006) 272276.

[33] S. Song, J. Tu, Z. He, F. Hong, W. Liu, J. Chen, Appl. Catal., A 378 (2010) 169-174.

[34] K. S. Yang, Y. Dai, B. B. Huang, J. Phys. Chem. C 114 (2010) 19830-19834.

[35] N. D. Feng, A. M. Zheng, Q. A. Wang, P. P. Ren, X. Z. Gao, S. B. Liu, Z. R. Shen, T. H. Chen, F. Deng, J. Phys. Chem. C 115 (2011) 2709-2719.

[36] L. X. Yang, Y. Xiao, S. H. Liu, Y. Li, Q. Y. Cai, S. L. Luo, G. M. Zeng, Appl. Catal., B 94 (2010) 142-149.

[37] B. G. Yacobi, Semiconductor Materials. Kluwer Academic Publishers: New York, 2003.

[38] A. W. Bott, Curr. Separ. 17 (1998) 87-91.

[39] C. Di Valentin, E. Finazzi, G. Pacchioni, A. Selloni, S. Livraghi, M. C. Paganini, E. Giamello, Chemical Physics 339 (2007) 44-56.

[40] S. Sato, Chemical Physics Letters 123 (1986) 126-128.

[41] S. Sato, R. Nakamura, S. Abe, Appl. Catal., A 284 (2005) 131-137. 
[42] Y. Sakatani, J. Nunoshige, H. Ando, K. Okusako, H. Koike, T. Takata, J. N. Kondo, M. Hara, K. Domen, Chem. Lett. 32 (2003) 1156-1157.

[43] C. Di Valentin, G. Pacchioni, A. Selloni, S. Livraghi, E. Giamello, J. Phys. Chem. B 109 (2005) 11414-11419.

[44] M. Miyauchi, A. Ikezawa, H. Tobimatsu, H. Irie, K. Hashimoto, Phys. Chem. Chem. Phys. 6 (2004) 865-870.

[45] Z. S. Lin, A. Orlov, R. M. Lambert, M. C. Payne, J. Phys. Chem. B 109 (2005) 2094820952.

[46] O. Diwald, T. L. Thompson, E. G. Goralski, S. D. Walck, J. T. Yates, J. Phys. Chem. B 108 (2004) 52-57.

[47] O. Diwald, T. L. Thompson, T. Zubkov, E. G. Goralski, S. D. Walck, J. T. Yates, J. Phys. Chem. B 108 (2004) 6004-6008.

[48] N. Balázs, K. Mogyorósi, D. Srankó, A. Pallagi, T. Alapi, A. Oszkó, A. Dombi, P. Sipos, Appl. Catal., B 84 (2008) 356-362.

[49] C. Tian, Z. Zhang, J. Hou, N. Luo, Mater. Lett. 62 (2008) 77-80.

[50] G. Liu, X. Wang, L. Wang, Z. Chen, F. Li, G. Q. Lu, H.-M. Cheng, J. Colloid Interface Sci. 334 (2009) 171-175.

[51] S. Livraghi, A. M. Czoska, M. C. Paganini, E. Giamello, J. Solid State Chem. 182 (2009) 160-164.

[52] X. Qiu, C. Burda, Chemical Physics 339 (2007) 1-10.

[53] J. Widoniak, S. Eidenassmann, G. Maret, Colloids Surf., A (2005).

[54] M. Zamora, T. Lopez, R. Gomez, M. Asomoza, R. Melendrez, Appl. Surf. Sci. 252 (2005) 828-832.

[55] D.-G. Huang, S.-J. Liao, J.-M. Liu, Z. Dang, L. Petrik, J. Photochem. Photobiol., A 184 (2006) 282-288.

[56] G. Colón, Appl. Catal., B 45 (2003) 39-50.

[57] D. L. Liao, G. S. Wu, B. Q. Liao, Colloids Surf., A 348 (2009) 270-275.

[58] M. Alvaro, B. Cojocaru, A. A. Ismail, N. Petrea, B. Ferrer, F. A. Harraz, V. I. Parvulescu, H. Garcia, Appl. Catal., B 99 (2010) 191-197.

[59] A. B. Corradi, F. Bondioli, B. Focher, A. M. Ferrari, C. Grippo, E. Mariani, C. Villa, J. Am. Ceram. Soc. 88 (2005) 2639-2641. 
[60] M. Popa, L. Diamandescu, F. Vasiliu, C. M. Teodorescu, V. Cosoveanu, M. Baia, M. Feder, L. Baia, V. Danciu, J. Mater. Sci. 44 (2009) 358-364.

[61] S. Dai, Y. Wu, T. Sakai, Z. Du, H. Sakai, M. Abe, Nanoscale Res. Lett. 5 (2010) 18291835.

[62] S. Yuan, Q. Sheng, J. Zhang, F. Chen, M. Anpo, Mater. Lett. 58 (2004) 2757-2760.

[63] B. Rajesh, N. R. Sasirekha, Y. W. Chen, Mater. Res. Bull. 43 (2008) 682-692.

[64] P. Calza, E. Pelizzetti, K. Mogyorosi, R. Kun, I. Dekany, Appl. Catal., B 72 (2007) 314321.

[65] J. Bai, B. Zhou, L. Li, Y. Liu, Q. Zheng, J. Shao, X. Zhu, W. Cai, J. Liao, L. Zou, J. Mater. Sci. 43 (2008) 1880-1884.

[66] L. Baia, A. Peter, V. Cosoveanu, E. Indrea, M. Baia, J. Popp, V. Danciu, Thin Solid Films 511-512 (2006) 512-516.

[67] H. Hao, J. Zhang, Mater. Lett. 63 (2009) 106-108.

[68] G. Colon, M. Hidalgo, G. Munuera, I. Ferino, M. Cutrufello, J. Navio, Appl. Catal., B 63 (2006) 45-59.

[69] G. Colón, J. M. Sánchez-España, M. C. Hidalgo, J. A. Navío, J. Photochem. Photobiol., A 179 (2006) 20-27.

[70] J. A. Chang, M. Vithal, I. C. Baek, S. I. Seok, J. Solid State Chem. 182 (2009) 749-756.

[71] J. Yuan, D. Chen, M. Yang, P. Yue, Mater. Lett. 61 (2007) 5265-5267.

[72] H. Tsuchiya, J. Macak, L. Taveira, E. Balaur, A. Ghicov, K. Sirotna, P. Schmuki, Electrochem. Commun. 7 (2005) 576-580.

[73] X. G. Zhang, X. Ge, C. Wang, Cryst. Growth Des. 9 (2009) 4301-4307.

[74] G. Liu, Y. Liu, G. Yang, S. Y. Li, Y. H. Zu, W. X. Zhang, M. J. Jia, J. Phys. Chem. C 113 (2009) 9345-9351.

[75] J. Yang, D. Li, X. Wang, X. Yang, L. Lu, Mater. Sci. Eng., A 328 (2002) 108-112.

[76] D. Y. Wu, M. C. Long, W. M. Cai, C. Chen, Y. H. Wu, J. Alloys Compd. 502 (2010) 289-294.

[77] J. A. Leon-Ramos, D. Kibanova, P. Santiago-Jacinto, Y. Mar-Santiago, M. Trejo-Valdez, J. Sol-Gel Sci. Technol. 57 (2011) 43-50.

[78] L. Wan, Y. Gao, X. H. Xia, Q. R. Deng, G. Shao, Mater. Res. Bull. 46 (2011) 442-446.

[79] Y. Huang, G. Xie, S. P. Chen, S. L. Gao, J. Solid State Chem. 184 (2011) 502-508. 
[80] E. Bae, T. Ohno, Appl. Catal., B 91 (2009) 634-639.

[81] E. Bae, N. Murakami, T. Ohno, J. Mol. Catal. A: Chem 300 (2009) 72-79.

[82] K. Yasui, T. Isobe, A. Nakajima, Mater. Lett. 64 (2010) 2036-2039.

[83] T. D. N. Phan, H. D. Pham, T. V. Cuong, E. J. Kim, S. Kim, E. W. Shin, J. Cryst. Growth 312 (2009) 79-85.

[84] M. Safaei, R. Sarraf-Mamoory, M. Rashidzadeh, M. Manteghian, J. Porous Mat. 17 (2010) 719-726.

[85] Z. Zhang, X. Wang, J. Long, Q. Gu, Z. Ding, X. Fu, J. Catal. 276 (2010) 201-214.

[86] Z. Ambrus, N. Balazs, T. Alapi, G. Wittmann, P. Sipos, A. Dombi, K. Mogyorosi, Appl. Catal., B 81 (2008) 27-37.

[87] G. Colon, M. Hidalgo, J. Navio, E. Melian, O. Diaz, J. Dona, Appl. Catal., B 78 (2008) 176-182.

[88] K. Lv, J. Yu, K. Deng, J. Sun, Y. Zhao, D. Du, M. Li, J. Hazard. Mater. 173 (2010) 539543.

[89] J. A. Rengifo-Herrera, J. Kiwi, C. Pulgarin, J. Photochem. Photobiol., A 205 (2009) 109115.

[90] P. Sampedro, G. Colon, M. Fernandezgarcia, J. Photochem. Photobiol., A 199 (2008) 136-143.

[91] L. Sang, H. Dai, J. Sun, L. Xu, F. Wang, C. Ma, Int. J. Hydrogen Energy 35 (2010) 70987103.

[92] M. D’Arienzo, R. Scotti, L. Wahba, C. Battocchio, E. Bemporad, A. Nale, F. Morazzoni, Appl. Catal., B 93 (2009) 149-155.

[93] C. Shifu, L. Xuqiang, L. Yunzhang, C. Gengyu, Appl. Surf. Sci. 253 (2007) 3077-3082.

[94] A. Morawski, M. Janus, B. Tryba, M. Inagaki, K. Kalucki, C. R. Chim. 9 (2006) 800-805.

[95] S. A. K. Leghari, S. Sajjad, F. Chen, J. L. Zhang, Chem. Eng. J. 166 (2011) 906-915.

[96] S. Photong, V. Boonamnuayvitaya, Appl. Surf. Sci. 255 (2009) 9311-9315.

[97] R. Silveyra, L. Delatorresaenz, W. Flores, V. Martinez, A. Elguezabal, Catal. Today 107108 (2005) 602-605.

[98] C. Jin, R. Y. Zheng, Y. Guo, J. L. Xie, Y. X. Zhu, Y. C. Xie, J. Mol. Catal. A: Chem 313 (2009) 44-48. 
[99] M. Maicu, M. C. Hidalgo, G. Colon, J. A. Navio, J. Photochem. Photobiol., A 217 (2011) 275-283.

[100] S. M. Marques, C. J. Tavares, L. F. Oliveira, A. M. F. Oliveira-Campos, J. Mol. Struct. 983 (2010) 147-152.

[101] L. Mi, P. Xu, P. Wang, Appl. Surf. Sci. 255 (2008) 2574-2580.

[102] T. Morikawa, T. Ohwaki, K.-i. Suzuki, S. Moribe, S. Tero-Kubota, Appl. Catal., B 83 (2008) 56-62.

[103] M. S. Nahar, K. Hasegawa, S. Kagaya, Chemosphere 65 (2006) 1976-1982.

[104] M. S. Nahar, K. Hasegawa, S. Kagaya, S. Kuroda, Sci. Technol. Adv. Mat. 8 (2007) 286291.

[105] F. Peng, L. Cai, H. Yu, H. Wang, J. Yang, J. Solid State Chem. 181 (2008) 130-136.

[106] R. Pérez-Hernández, D. Mendoza-Anaya, M. E. Fernández, A. Gómez-Cortés, J. Mol. Catal. A: Chem. 281 (2008) 200-206.

[107] E. Piera, M. Isabel Tejedor-Tejedor, M. E. Zorn, M. A. Anderson, Appl. Catal., B 46 (2003) 671-685.

[108] S. Song, J. Tu, L. Xu, X. Xu, Z. He, J. Qiu, J. Ni, J. Chen, Chemosphere 73 (2008) 14011406.

[109] J. Li, H. P. Yu, Q. F. Sun, Y. X. Liu, Y. Z. Cui, Y. Lu, Appl. Surf. Sci. 256 (2010) 50465050 .

[110] S. Song, C. Wang, F. Hong, Z. He, Q. Cai, J. Chen, Appl. Surf. Sci. 257 (2011) 34273432.

[111] S. Joung, T. Amemiya, M. Murabayashi, K. Itoh, Appl. Catal., A 312 (2006) 20-26.

[112] S.-K. Joung, T. Amemiya, M. Murabayashi, K. Itoh, Chemistry - A European Journal 12 (2006) 5526-5534.

[113] D. Beydoun, R. Amal, Mater. Sci. Eng., B 94 (2002) 71-81.

[114] H. Zhang, J. F. Banfield, J. Phys. Chem. B 104 (2000) 3481-3487.

[115] K. Mogyorosi, I. Dekany, J. H. Fendler, Langmuir 19 (2003) 2938-2946.

[116] C. Lettmann, K. Hildenbrand, H. Kisch, W. Macyk, W. F. Maier, Appl. Catal., B 32 (2001) 215-227.

[117] S. A. Chambers, S. H. Cheung, P. Nachimuthu, A. G. Joly, M. H. Engelhard, M. K. Bowman, Surf. Sci. 601 (2007) 1754-1762. 
[118] K. Mogyorósi, N. Balázs, D. F. Srankó, E. Tombácz, I. Dékány, A. Oszkó, P. Sipos, A. Dombi, Appl. Catal., B 96 (2010) 577-585.

[119] J. Ryu, W. Choi, Environ. Sci. Technol. 42 (2008) 294-300.

[120] E. Giamello, S. Livraghi, M. C. Paganini, A. Selloni, C. Di Valentin, G. Pacchioni, J. Am. Chem. Soc. 128 (2006) 15666-15671.

[121] D. Chen, D. Yang, J. Geng, J. Zhu, Z. Jiang, Appl. Surf. Sci. 255 (2008) 2879-2884.

[122] J. Senthilnathan, L. Philip, Chem. Eng. J. 161 (2010) 83-92.

[123] T. Bezrodna, J. Mol. Struct. 700 (2004) 175-181.

[124] C. Divalentin, E. Finazzi, G. Pacchioni, A. Selloni, S. Livraghi, M. Paganini, E. Giamello, Chemical Physics 339 (2007) 44-56.

[125] J. Yang, H. Bai, X. Tan, J. Lian, Appl. Surf. Sci. 253 (2006) 1988-1994.

[126] R. L. Kurtz, R. Stockbauer, T. E. Madey, E. Roman, J. L. Desegovia, Surf. Sci. 218 (1989) 178-200.

[127] Y. Hu, H. L. Tsai, C. L. Huang, J. Eur. Ceram. Soc. 23 (2003) 691-696.

[128] J. Yu, Y. Su, B. Cheng, M. Zhou, J. Mol. Catal. A: Chem. 258 (2006) 104-112.

[129] M. Li, J. C. Li, Mater. Lett. 60 (2006) 2526-2529.

[130] S. J. Huang, A. B. Walters, M. A. Vannice, J. Catal. 192 (2000) 29-47.

[131] N. Balázs, D. F. Srankó, A. Dombi, P. Sipos, K. Mogyorósi, Appl. Catal., B 96 (2010) 569-576. 


\section{Scientific activity}

\section{Participation at conferences PhD thesis related participations}

1.) Zsolt Pap, Virginia Danciu, András Dombi, Károly Mogyorósi

"Activity enhancement of titania based photocatalysts by special heat treatment and nonmetal doping"

Tudomány Hete a Dunaújvárosi Főiskolán, 9-14 November 2009, Dunaújváros, Hungary

2.) Zsolt Pap, Zsuzsanna Cegléd, Virginia Danciu, András Dombi, Károly Mogyorósi

"Nitrogénnel modosított titán-dioxid elöállítása, gyors kalcinálással"

IX. Környezetvédelmi Analitikai és Technológiai Konferencia, 7-9 October 2009, Sopron, Hungary

3.) Zsolt Pap, Virginia Danciu, Zsuzsanna Cegléd, András Dombi, Károly Mogyorósi

"Activity enhancement of titania-based photocatalysts by special heat treatment"

$16^{\text {th }}$ Symposium on Analytical and Environmental Problems, 28 September 2009, Szeged, Hungary

4.) Zsolt Pap, Zsuzsanna Cegléd, András Dombi, Pál Sipos, Károly Mogyorósi

"The effects of the fast heat treatment on the $\mathrm{N}$-doped $\mathrm{TiO}_{2}$ photocatalysts activity and morphology"

$5^{\text {th }}$ European Meeting on Solar Chemistry and Photocatalysis: Environmental Applications, 4-8 October 2008, Palermo, Italy

5.) Zsolt Pap, Zsuzsanna Cegléd, András Dombi, Sipos Pál, Károly Mogyorósi

"A gyors kalcinálás kedvezö hatása a nitrogénnel dópolt titán-dioxid fotokatalizátorok aktivitására"

XIV Nemzetközi Vegyészkonferencia, 7-9 november, 2008, Cluj-Napoca, Romania

6.) Zsolt Pap, Ioana Ladiu, Károly Mogyorósi, András Dombi, Emil Indrea, Virginia Danciu 
"Synthesis of nanosized $\mathrm{N}$-doped $\mathrm{TiO}_{2}$ in extreme $\mathrm{pH}$ conditions"

Nanotech Insight '09, 29 March - 2 April 2009, Barcelona, Spain

7.) Zsolt Pap, András Dombi, Károly Mogyorósi, Virginia Danciu, Lucian Baia

"The influence of the acetic acid and nitric acid concentration on the morpho-structural properties of $N$-doped titania"

SP3 - Third International Conference on Semiconductor Photochemistry, 12-16. April 2010, Glasgow, Scotland

8.) Zsolt Pap, Virginia Danciu, András Dombi, Károly Mogyorósi

"The influence of rapid heat treatment on the photocatalytic activity of titania photocatalysts"

COST Workshop - Recent Achievements In Photocatalysis: Fundamentals, Applications And Standardized Test Methods, 18-19. January 2010, Grenoble, France

9.) Zsolt Pap, Éva Karácsonyi, András Dombi, Károly Mogyorósi

"Gyors kalcinálású nitrogénnel dópolt titán-dioxid fotokatalizátorok elöállítása és vizsgálata"

DUF Tudomány Hete, 6-12 november 2010, Dunaújváros, Hungary

10.) Zsolt Pap, Éva Karácsonyi, Cegléd Zsuzsanna, András Dombi, Danciu Virginia, IonelCătălin Popescu, Baia Lucian, Oszkó Albert, Károly Mogyorósi,

"Dynamic changes on the surface during the calcination of rapid heat treated $\mathrm{TiO}_{2}$ photocatalysts"

Photocatalytic and Advanced Oxidation Technologies for Treatment of Water, Air, Soil and Surfaces, 4-8 July 2011, Gdansk, Poland

11.) Zsolt Pap, Éva Karácsonyi, Ceglédi Zsuzsanna, András Dombi, Virginia Danciu, Károly Mogyorósi

"Gyors kalcinálású titán-dioxid fotokatalizátorok fenolbontó-képessége és felületének vizsgálata"

X. Környezetvédelmi Analitikai és Technológiai Konferencia, 5-7 October 2011, Sümeg, Hungary 


\section{Other conference participations}

1.) Virginia Danciu, Mihaela Popa, Zsolt Pap, Lucian Baia, Monica Baia, Veronica Coșoveanu, Florin Vasiliu, Lucian Diamandescu

“Iron doped and undoped $\mathrm{TiO}_{2}$ catalysts for advanced water treatment"

Environmental Applications of Advanced Oxidation Processes 7-9 September 2006, Chania, Greece

2.) Gábor Veréb, László Manczinger, Attila Gácsi, Zsolt Pap, Ákos Kmetykó, András Dombi, Károly Mogyorósi

"Water purification and disinfection on UV and visible light irradiated doped titanium dioxide photocatalysts immobilized on ceramic papers"

SP3 - Third International Conference on Semiconductor Photochemistry 12-16. April 2010, Glasgow, Scotland

3.) Károly Mogyorósi, Gábor Veréb, Zoltán Ambrus, Zsolt Pap, Ákos Kmetykó, András Dombi "Comparative study on different synthesis pathways for obtaining UV and visible light active bare and doped titanium dioxide photocatalysts”

SP3 - Third International Conference on Semiconductor Photochemistry, 12-16. April 2010, Glasgow, Scotland

4.) Attila Gácsi, Veréb Gábor, Zsolt Pap, András Dombi, Károly Mogyorósi

”Titán-dioxid alapú fotokatalizátorokkal kezelt kerámiapapír alkalmazása gázfázisú acetaldehid ártalmatlanítására”

DUF Tudomány Hete, 6-12 november 2010, Dunaújváros, Hungary

5.) András Dombi, Ákos Kmetykó, Károly Mogyorósi, Zsolt Pap, Krisztina Vajda, Gábor Veréb “Titán-dioxid nanorészecskék fotokatalitikus alkalmazása vízkezelési eljárásokban”

X. Környezetvédelmi Analitikai és Technológiai Konferencia, 5-7 October 2011, Sümeg, Hungary 


\section{Papers}

\section{Papers related to the PhD thesis}

1.) Zsolt Pap, Virginia Danciu, Zsuzsanna Cegléd, Ákos Kukovecz, Albert Oszkó, András Dombi, Károly Mogyorósi,

"The influence of rapid heat treatment in still air on the photocatalytic activity of titania photocatalysts for phenol and monuron degradation”, Applied Catalysis B: Environmental 101 (2011) 461-470

I.F.: 4.749

Cited: 0

2.) Zsolt Pap, Lucian Baia, Károly Mogyorósi, András Dombi, Albert Oszkó, Virginia Danciu, "Correlating the visible light photoactivity of $\mathrm{N}$ doped $\mathrm{TiO}_{2}$ with brookite particle size and bridged - nitro surface species"

Catalysis Communications Catalysis Communications 17 (2012) 1-7

I.F.: 2.827

Cited: 0

3.) Zsolt Pap, Éva Karácsonyi, Zsuzsanna Cegléd, András Dombi, Virginia Danciu, IonelCătălin Popescu, Lucian Baia, Albert Oszkó, Károly Mogyorósi,

"Dynamic changes on the surface during the calcination of rapid heat treated $\mathrm{TiO}_{2}$ photocatalysts"

Applied Catalysis B: Environmental; doi:10.1016/j.apcatb.2011.11.012

I.F.: 4.749

Cited: 0 


\section{Other papers}

1.) Éva Bajnóczi, Nándor Balázs, Károly Mogyorósi, Dávid Srankó, Zsolt Pap, Zoltán Ambrus, Sophie Canton, Katarina Norén, Ernő Kuzmann, Attila Vértes, Zoltán Homonnay, Oszkó Albert, Pálinkó István, Pál Sipos,

"The influence of the local structure of $\mathrm{Fe}(\mathrm{III})$ on the photocatalytic activity of doped $\mathrm{TiO}_{2}$ photocatalysts-An EXAFS, XPS and Mössbauer spectroscopic study”, Applied Catalysis B: Environmental 103 (2011) 232-239

\section{I.F.: 4.749}

Cited: 1

\section{Submitted papers}

1.) Gábor Veréb, Zoltán Ambrus, Zsolt Pap, Ákos Kmetykó, András Dombi, Virginia Danciu, Andrew Cheesman, Károly Mogyorósi

"Comparative study on UV and visible light sensitive bare and doped titanium dioxide photocatalysts for the decomposition of environmental pollutants in water"

Submitted to Applied Catalysis A: General (Ms. No.: APCATA-D-11-00920, under major revision)

I.F.: 3.383

\section{Papers under preparation}

Chinese Journal of Catalysis: 1 (I.F. 0.566)

Reaction Kinetics, Mechanisms and Catalysis Letters: 1 (I.F.: 0.62)

Journal of Sol-Gel Science and Technology: 1 (I.F.: 1.393)

Journal of Materials Chemistry 1 (I.F. 5.1)

Current cumulative impact factor: 17.074 ;

Expected cumulative impact factor until the PhD defense: 20.457

Book chapters: None

Paper peer-reviewing count: 9; Chosen as reviewer for:

Journal of Materials Chemistry (I.F. 5.1) - 7 paper peer-reviews 


\section{Acknowledgements}

As the thesis author, I would like to thank the scientifical, financial and moral support to my thesis supervisors, Prof. András Dombi, Prof. Ionel-Cătălin Popescu, Dr. Károly Mogyorósi and Dr. Virginia Danciu. They made possible for me to learn and to gather the necessary knowledge to achieve this scientific level.

Many thanks to: Dr. Albert Oszkó for the XPS measurements; Dr. Lucian Baia and Dr. Ottó Berkesi for the Raman and IR spectra; Dr. Ákos Kukovecz for the SEM images; Zsuzsanna Cegléd and Éva Karácsonyi for the photocatalytic experiments; and Katalin Kacsala for the laboratory management. Dr. Andrew Cheesman is also thanked for the linguistic checks on the manuscripts.

I want to express my gratitude to the projects that provided the financial support during my PhD studies: Hungarian National Office of Research and Technology (NKFP DA THERM TECH 08 A4); Hungarian-Romanian TeT cooperation project (OMFB-00415/2008/RO21/2007); National Romanian Center of Programs Management (PNII71-136).

Nevertheless I want to thank to my family, friends and colleagues for their moral support. 


\section{Appendices}

Table 1 - Summary of several papers investigating the influence of the calcination on sol-gel made titanias

\begin{tabular}{|c|c|c|c|c|}
\hline \multicolumn{5}{|c|}{ Parameters investigated (yes/no)/applied } \\
\hline Article & Heat treatment temperature & $\begin{array}{l}\text { Treatment } \\
\text { atmosphere }\end{array}$ & Heat treatment time & Heating rate \\
\hline Adan et al. [5] & no $/ 450^{\circ} \mathrm{C}$ & no/air & $\mathrm{no} / 2 \mathrm{~h}$ & not specified \\
\hline Alvaro et al. [58] & $\mathrm{no} / 500^{\circ} \mathrm{C}$ & no/air & no/ $4 \mathrm{~h}$ & $\mathrm{no} / 2{ }^{\circ} \mathrm{C} / \mathrm{min}$ \\
\hline Baia et al. [66] & $\begin{array}{c}\text { yes/ } 300,350,450,475,500,550, \\
600{ }^{\circ} \mathrm{C}\end{array}$ & not specified & not specified & not specified \\
\hline Carbajo et al. [17] & $\mathrm{no} / 450^{\circ} \mathrm{C}$ & no/air & $\mathrm{no} / 2 \mathrm{~h}$ & not specified \\
\hline Chang et al. [20] & $\mathrm{no} / 300^{\circ} \mathrm{C}$ & no/ air & no/ 3h & not specified \\
\hline $\begin{array}{l}\text { Colón et al. [22, 56, 68- } \\
69]\end{array}$ & yes $/ 400,500,600,700,800{ }^{\circ} \mathrm{C}$ & no/ air & $\mathrm{no} / 2 \mathrm{~h}$ & not specified \\
\hline Colón et al. [87] & yes $/ 300,500^{\circ} \mathrm{C}$ & no/ air & $\mathrm{no} / 2 \mathrm{~h}$ & not specified \\
\hline D’Arienzo et al. [92] & yes/ $450,500,600^{\circ} \mathrm{C}$ & $\mathrm{no} / \mathrm{O}_{2}$ & no/ $1 \mathrm{~h}$ & not specified \\
\hline Dai et al. [61] & $\mathrm{no} / 450^{\circ} \mathrm{C}$ & not specified & $\mathrm{no} / 2 \mathrm{~h}$ & not specified \\
\hline Fan et al. [19] & $\mathrm{no} / 400^{\circ} \mathrm{C}$ & no/ air & no/ 3h & $\mathrm{no} / 1^{\circ} \mathrm{C} / \mathrm{min}$ \\
\hline Hao et al. [67] & $\mathrm{no} / 400^{\circ} \mathrm{C}$ & not specified & $\mathrm{no} / 2 \mathrm{~h}$ & $\mathrm{no} / 1^{\circ} \mathrm{C} / \mathrm{min}$ \\
\hline Huang et al. [55] & no/ $320^{\circ} \mathrm{C}$ & no/ air & no/ $6 \mathrm{~h}$ & not specified \\
\hline Huang et al. [79] & $\mathrm{no} / 500^{\circ} \mathrm{C}$ & no $/ \mathrm{N}_{2}$ & no/ 4h & $\mathrm{no} / 2^{\circ} \mathrm{C} / \mathrm{min}$ \\
\hline Jin et al. [98] & yes $/ 500,600^{\circ} \mathrm{C}$ & not specified & no/ $4 \mathrm{~h}$ & not specified \\
\hline Leghari et al.[95] & $\mathrm{no} / 500^{\circ} \mathrm{C}$ & not specified & not specified & not specified \\
\hline
\end{tabular}




\begin{tabular}{|c|c|c|c|c|}
\hline \multicolumn{5}{|c|}{ Parameters investigated (yes/no)/applied } \\
\hline Article & Heat treatment temperature & $\begin{array}{l}\text { Treatment } \\
\text { atmosphere }\end{array}$ & Heat treatment time & Heating rate \\
\hline Liao et al. [57] & yes/ $500,600,700,800^{\circ} \mathrm{C}$ & not specified & not specified & not specified \\
\hline Liu et al. [50] & yes $/ 350{ }^{\circ} \mathrm{C}$ & not specified & no/ $1 \mathrm{~h}$ & not specified \\
\hline Livraghi et al. [51] & $\mathrm{no} / 500^{\circ} \mathrm{C}$ & no/ air & no/ 1h & $\mathrm{no} / 20^{\circ} \mathrm{C} / \mathrm{min}$ \\
\hline Lv et al. [88] & $\mathrm{no} / 500^{\circ} \mathrm{C}$ & no/ air & $\mathrm{no} / 2 \mathrm{~h}$ & not specified \\
\hline Maicu et al. [99] & yes/ $500,700^{\circ} \mathrm{C}$ & not specified & $\mathrm{no} / 2 \mathrm{~h}$ & not specified \\
\hline Marques et al. [100] & $\mathrm{no} / 500^{\circ} \mathrm{C}$ & not specified & no/ $2 \mathrm{~h}$ & $\mathrm{no} / 5^{\circ} \mathrm{C} / \mathrm{min}$ \\
\hline Mi et al. [101] & yes/ $500,550,600,650^{\circ} \mathrm{C}$ & $\begin{array}{c}\text { yes/ } \mathrm{N}_{2} \text { and } \mathrm{NH}_{3} \\
\text { and after } \\
\text { calcination in } \mathrm{Ar}\end{array}$ & $\begin{array}{l}\text { no/ } 15 \text { min and } 1 \mathrm{~h} \text { after } \\
\text { calcination }\end{array}$ & not specified \\
\hline Morawski et al. [94] & yes $/ 400,450,500^{\circ} \mathrm{C}$. & no/n-hexane & yes/ 3, 4.5 and $6 \mathrm{~h}$ & not specified \\
\hline Morikawa et al. [102] & $\mathrm{no} / 300,400^{\circ} \mathrm{C}$ & not specified & $\mathrm{no} / 2 \mathrm{~h}$ & not specified \\
\hline Nahar et al. [103] & $\mathrm{no} / 550{ }^{\circ} \mathrm{C}$ & not specified & no/ 2h & $\mathrm{no} / 2.5^{\circ} \mathrm{C} / \mathrm{min}$ \\
\hline Nahar et al. [104] & no/ $550^{\circ} \mathrm{C}$ & not specified & no/ $2 \mathrm{~h}$ & not specified \\
\hline Peng et al. [105] & no/ $600^{\circ} \mathrm{C}$ & $\mathrm{no} / \mathrm{NH}_{3}$ & no/ $3 \mathrm{~h}$ & not specified \\
\hline Perez-Hernandez [106] & $\mathrm{no} / 500^{\circ} \mathrm{C}$ & not specified & no/ $5 \mathrm{~h}$ & not specified \\
\hline Photong et al. [96] & $\mathrm{no} / 500{ }^{\circ} \mathrm{C}$ & not specified & not specified & not specified \\
\hline Piera et al. [107] & $\mathrm{no} / 300^{\circ} \mathrm{C}$ & not specified & no/ $1 \mathrm{~h}$ & $\mathrm{no} / 2^{\circ} \mathrm{C} / \mathrm{min}$ \\
\hline Qamar et al. [3] & yes/ $300,400,450,500,600,700^{\circ} \mathrm{C}$ & not specified & yes/3, 4 and $6 \mathrm{~h}$ & not specified \\
\hline Qiu et al. [52] & $\mathrm{no} / 450^{\circ} \mathrm{C}$ & $\mathrm{no} / \mathrm{NH}_{3}$ & not specified & not specified \\
\hline
\end{tabular}




\begin{tabular}{|c|c|c|c|c|}
\hline \multicolumn{5}{|c|}{ Parameters investigated (yes/no)/applied } \\
\hline Article & Heat treatment temperature & $\begin{array}{c}\text { Treatment } \\
\text { atmosphere }\end{array}$ & Heat treatment time & Heating rate \\
\hline $\begin{array}{l}\text { Rengifo-Herrera et al. } \\
\text { [89] }\end{array}$ & no/ $400{ }^{\circ} \mathrm{C}$ & no/ air & no/ $1 \mathrm{~h}$ & $\mathrm{no} / 10^{\circ} \mathrm{C} / \mathrm{min}$ \\
\hline Sampedro et al.[90] & $\mathrm{no} / 450^{\circ} \mathrm{C}$ & no/ air & not specified & $\mathrm{no} / 2{ }^{\circ} \mathrm{C} / \mathrm{min}$ \\
\hline Sang et al. [91] & $\mathrm{no} / 600,700{ }^{\circ} \mathrm{C}$ & no/ air & no/ $6 \mathrm{~h}$ & not specified \\
\hline Shen et al. [21] & $\mathrm{no} / 400^{\circ} \mathrm{C}$ & $\mathrm{no} / \mathrm{N}_{2}$ & no/ $1 \mathrm{~h}$ & not specified \\
\hline Shifu et al. [93] & yes/ $450,500,550,600,650,700{ }^{\circ} \mathrm{C}$ & $\mathrm{no} / \mathrm{NH}_{3}$ & yes/ 3, 5 and 8h & not specified \\
\hline Silva et al. [23] & $\mathrm{no} / 400^{\circ} \mathrm{C}$ & no/air & $\mathrm{no} / 2 \mathrm{~h}$ & $\mathrm{no} / 5^{\circ} \mathrm{C} / \mathrm{min}$ \\
\hline Silveyra et al. [97] & yes/ $600,700,800^{\circ} \mathrm{C}$ & not specified & not specified & not specified \\
\hline Song et al. [33] & $\mathrm{no} / 400^{\circ} \mathrm{C}$ & no/air & $\mathrm{no} / 2 \mathrm{~h}$ & not specified \\
\hline Song et al. [108] & $\mathrm{no} / 400,500^{\circ} \mathrm{C}$ & not specified & no/ 2h & not specified \\
\hline Song et al. [110] & yes/ $400,500,600^{\circ} \mathrm{C}$ & not specified & $\mathrm{no} / 2 \mathrm{~h}$ & $\mathrm{no} / 5^{\circ} \mathrm{C} / \mathrm{min}$ \\
\hline Szatmáry et al. [28] & yes/ $400,500,600,700^{\circ} \mathrm{C}$ & not specified & no/ 3h & $\mathrm{no} / 5^{\circ} \mathrm{C} / \mathrm{min}$ \\
\hline Vijayan et al. [18] & $\mathrm{no} / 500^{\circ} \mathrm{C}$ & not specified & not specified & not specified \\
\hline Wan et al. [78] & yes/ $400,500,700^{\circ} \mathrm{C}$ & no/air & no/ 1h & not specified \\
\hline Wang et al. [13] & yes/ $400,500,650,800,1000^{\circ} \mathrm{C}$ & no/air & no/ 5h & not specified \\
\hline
\end{tabular}


Table 2 - Structural parameters and initial photodecomposition rates of phenol and monuron under UV irradiation, for the prepared titania samples at different calcination temperatures

\begin{tabular}{|c|c|c|c|c|c|c|c|}
\hline \multirow{3}{*}{$\begin{array}{l}\text { Sample name } \\
\text { RHSE-400-10 }\end{array}$} & \multirow{3}{*}{$\begin{array}{c}\text { Anatase } \\
\text { (wt\%) } \\
100.0\end{array}$} & \multirow{3}{*}{$\begin{array}{c}\text { Rutile } \\
\text { (wt\%) }\end{array}$} & \multirow{3}{*}{$\begin{array}{c}\begin{array}{c}\mathbf{D}_{\mathrm{A}} \\
(\mathbf{n m})\end{array} \\
15.0\end{array}$} & \multirow{3}{*}{$\begin{array}{c}\mathbf{D}_{\mathrm{R}} \\
(\mathbf{n m}) \\
-\end{array}$} & \multirow{3}{*}{$\begin{array}{c}\mathbf{a}_{\text {BET }}^{\mathrm{s}} \\
\left(\mathrm{m}^{2} / \mathrm{g}\right) \\
63.6\end{array}$} & \multirow{3}{*}{$\begin{array}{c}\mathbf{r}_{\mathbf{0}, \mathbf{p h e n o l}} \\
\mathbf{( \times 1 0} \\
15.3\end{array}$} & \multirow{3}{*}{$\begin{array}{c}\mathbf{r}_{\mathbf{0}, \text { monuron }} \\
\mathbf{M} / \mathbf{s}) \\
-\end{array}$} \\
\hline & & & & & & & \\
\hline & & & & & & & \\
\hline RHSE-500-10 & 94.5 & 5.5 & 27.3 & $\sim 90$ & 42.1 & 10.9 & - \\
\hline RHSE-550-10 & 88.2 & 11.8 & 30.0 & $\sim 90$ & 36.0 & 17.6 & - \\
\hline RHSE-600-10 & 82.4 & 17.6 & 41.4 & $\sim 95$ & 20.1 & 19.0 & 28.8 \\
\hline RHSE-700-10 & 51.2 & 48.8 & 53.8 & $\sim 100$ & 12.0 & 14.6 & - \\
\hline wRHSE-600-10 & 79.9 & 20.1 & 38.5 & $\sim 89$ & 16.1 & 9.6 & - \\
\hline RHLE-600-180 & 82.0 & 18.0 & 40.5 & $\sim 92$ & 15.1 & 9.1 & - \\
\hline wSHLE-450-180 & 100.0 & 0.0 & 16.7 & - & 60.0 & 10.0 & 14.9 \\
\hline SHLE-600-180 & 81.2 & 18.8 & 40.0 & $\sim 93$ & 13.8 & 8.2 & - \\
\hline P25 A & 79.0 & 21.0 & 26.0 & $\sim 85$ & 49.0 & 16.7 & - \\
\hline P25 B & 89.0 & 11.0 & 26.0 & $\sim 85$ & 50.0 & 20.5 & 37.1 \\
\hline
\end{tabular}


Table 3 - Structural parameters and initial photodecomposition rates of phenol and monuron under UV irradiation, for the prepared titania samples at different calcination temperatures

\begin{tabular}{|c|c|c|c|c|c|c|c|}
\hline \multirow{3}{*}{$\begin{array}{l}\text { Sample name } \\
\text { RHSE-400-10 }\end{array}$} & \multirow{3}{*}{$\begin{array}{c}\text { Anatase } \\
\text { (wt\%) } \\
100.0\end{array}$} & \multirow{3}{*}{$\begin{array}{c}\text { Rutile } \\
\text { (wt\%) }\end{array}$} & \multirow{3}{*}{$\begin{array}{c}\begin{array}{c}\mathbf{D}_{\mathrm{A}} \\
(\mathbf{n m})\end{array} \\
15.0\end{array}$} & \multirow{3}{*}{$\begin{array}{c}\mathbf{D}_{\mathrm{R}} \\
(\mathbf{n m}) \\
-\end{array}$} & \multirow{3}{*}{$\begin{array}{c}\mathbf{a}_{\text {BET }}^{\mathrm{s}} \\
\left(\mathrm{m}^{2} / \mathrm{g}\right) \\
63.6\end{array}$} & \multirow{3}{*}{$\begin{array}{c}\mathbf{r}_{\mathbf{0}, \mathbf{p h e n o l}} \\
\mathbf{( \times 1 0} \\
15.3\end{array}$} & \multirow{3}{*}{$\begin{array}{c}\mathbf{r}_{\mathbf{0}, \text { monuron }} \\
\mathbf{M} / \mathbf{s}) \\
-\end{array}$} \\
\hline & & & & & & & \\
\hline & & & & & & & \\
\hline RHSE-500-10 & 94.5 & 5.5 & 27.3 & $\sim 90$ & 42.1 & 10.9 & - \\
\hline RHSE-550-10 & 88.2 & 11.8 & 30.0 & $\sim 90$ & 36.0 & 17.6 & - \\
\hline RHSE-600-10 & 82.4 & 17.6 & 41.4 & $\sim 95$ & 20.1 & 19.0 & 28.8 \\
\hline RHSE-700-10 & 51.2 & 48.8 & 53.8 & $\sim 100$ & 12.0 & 14.6 & - \\
\hline wRHSE-600-10 & 79.9 & 20.1 & 38.5 & $\sim 89$ & 16.1 & 9.6 & - \\
\hline RHLE-600-180 & 82.0 & 18.0 & 40.5 & $\sim 92$ & 15.1 & 9.1 & - \\
\hline wSHLE-450-180 & 100.0 & 0.0 & 16.7 & - & 60.0 & 10.0 & 14.9 \\
\hline SHLE-600-180 & 81.2 & 18.8 & 40.0 & $\sim 93$ & 13.8 & 8.2 & - \\
\hline P25 A & 79.0 & 21.0 & 26.0 & $\sim 85$ & 49.0 & 16.7 & - \\
\hline P25 B & 89.0 & 11.0 & 26.0 & $\sim 85$ & 50.0 & 20.5 & 37.1 \\
\hline
\end{tabular}


Table 4 - Crystal phase composition and primary particle size of the key samples treated at 400, 550 and $600{ }^{\circ} \mathrm{C}$

\begin{tabular}{|c|c|c|c|c|c|c|}
\hline Sample name & $\begin{array}{c}\text { Anatase } \\
\text { (wt \%) }\end{array}$ & $\begin{array}{l}\text { Rutile } \\
\text { (wt \%) }\end{array}$ & $\begin{array}{c}\text { Brookite } \\
\text { (wt \%) }\end{array}$ & $\begin{array}{c}D_{A} \\
(n m)\end{array}$ & $\begin{array}{c}\mathrm{D}_{\mathrm{R}} \\
(\mathrm{nm})\end{array}$ & $\begin{array}{c}\mathrm{S}_{\mathrm{BET}} \\
\left(\mathrm{m}^{2} / \mathrm{g}\right)\end{array}$ \\
\hline RHSE-400-05 & 100 & - & \multirow{5}{*}{$\begin{array}{c}\text { trace } \\
\text { amounts }\end{array}$} & 10.6 & - & \\
\hline RHSE-400-10 & 100 & - & & 12.6 & - & 63.6 \\
\hline RHSE-400-15 & 100 & - & & 12.4 & - & \\
\hline RHME-400-60 & 100 & - & & 12.9 & - & \\
\hline RHLE-400-120 & 100 & - & & 14.5 & - & \\
\hline RHSE-550-05 & 88.2 & 11.8 & \multirow{5}{*}{$\begin{array}{c}\text { trace } \\
\text { amounts }\end{array}$} & 26.6 & $\sim 85$ & \\
\hline RHSE-550-10 & 86.5 & 13.5 & & 22.4 & $\begin{array}{l}\sim 86 \\
\end{array}$ & 36.0 \\
\hline RHSE-550-15 & 84.2 & 15.8 & & 30.2 & $\sim 89$ & \\
\hline RHME-550-60 & 85.3 & 14.7 & & 29.8 & $\sim 90$ & \\
\hline RHLE-550-120 & 85.4 & 14.6 & & 33.5 & $\begin{array}{l}\sim 86 \\
\end{array}$ & \\
\hline RHSE-600-05 & 77.8 & 22.2 & \multirow{5}{*}{-} & 38.8 & $\sim 95$ & \\
\hline RHSE-600-10 & 82.4 & 17.6 & & 41.4 & $\sim 95$ & 16.1 \\
\hline RHSE-600-15 & 81.5 & 18.5 & & 41.8 & $\sim 95$ & \\
\hline RHME-600-60 & 79.6 & 20.4 & & 41.2 & $\sim 99$ & \\
\hline RHME-600-120 & 80.0 & 20.0 & & 40.4 & $\sim 100$ & \\
\hline P25 B & 89.0 & 11.0 & - & 26.0 & $\sim 85$ & 50.0 \\
\hline wSHLE-450-180 & 100 & - & - & 16.7 & - & 60.0 \\
\hline
\end{tabular}


Table 5 - The applied nitric acid/TiCl ${ }_{4}$ and acetic acid/TiCl ${ }_{4}$ molar ratios in the synthesis of the photocatalysts

\begin{tabular}{|c|c|c|c|c|c|}
\hline \multirow{3}{*}{$\begin{array}{l}\text { Sample name } \\
\text { N0.00*-A1.34 }\end{array}$} & \multicolumn{3}{|c|}{ Molar ratio } & \multicolumn{2}{|c|}{ Volumes } \\
\hline & \multicolumn{3}{|c|}{$\mathrm{TiCl}_{4}: \mathrm{HNO}_{3}: \mathrm{CH}_{3} \mathrm{COOH}$} & $\mathrm{HNO}_{3}$ & $\begin{array}{c}\mathrm{CH}_{3} \mathrm{COOH} \\
(\mathrm{b} \mathrm{mL})\end{array}$ \\
\hline & 1 & $-^{*}$ & 1.34 & 0 & 3.5 \\
\hline N1.74 - A1.34 & 1 & 1.74 & 1.34 & 5 & 3.5 \\
\hline N3.47 - A0.00 & 1 & 3.47 & - & 10 & 0.0 \\
\hline N3.47 - A0.67 & 1 & 3.47 & 0.67 & 10 & 1.7 \\
\hline N3.47 - A1.34 & 1 & 3.47 & 1.34 & 10 & 3.5 \\
\hline N3.47 - A2.68 & 1 & 3.47 & 2.68 & 10 & 7.0 \\
\hline N5.20 - A1.34 & 1 & 5.20 & 1.34 & 15 & 3.5 \\
\hline
\end{tabular}

* Replaced by $\mathrm{HCl}$ (36\%), with 1:3.47:1.34 $\mathrm{TiCl}_{4}: \mathrm{HCl}: \mathrm{CH}_{3} \mathrm{COOH}$ molar ratios 
Table 6 - Phase composition and average primary particle size of all the prepared samples

\begin{tabular}{|l|c|c|c|c|}
\hline \multirow{2}{*}{$\begin{array}{c}\text { Sample } \\
\text { (* consult Table 5) }\end{array}$} & $\begin{array}{c}|c| \\
\text { Crystallite size } \\
(\mathbf{n m})\end{array}$ & $\begin{array}{c}\text { Content } \\
\mathbf{( w t \% )}\end{array}$ & $\begin{array}{c}\text { Crystallite size } \\
\mathbf{( n m )}\end{array}$ & $\begin{array}{c}\text { Content } \\
\mathbf{( w t \% )}\end{array}$ \\
\hline N0.00*-A1.34-400 & 9.9 & 100 & - & - \\
\hline N1.74-A1.34-400 & 7.3 & 94.0 & 7.2 & 6.0 \\
\hline N1.74-A1.34-500 & 8.6 & 95.5 & 9.0 & 4.5 \\
\hline N1.74-A1.34-600 & 11.4 & 95.6 & 11.7 & 4.4 \\
\hline N3.47-A0.00-400 & 11.4 & 96.3 & 9.8 & 3.7 \\
\hline N3.47-A0.00-500 & 12.5 & 94.2 & 10.0 & 8 \\
\hline N3.47-A0.00-600 & 14.0 & 96.6 & 9.8 & 4.4 \\
\hline N3.47-A0.67-400 & 6.5 & 96.3 & 14.4 & 3.7 \\
\hline N3.47-A0.67-400_slow & 9.6 & 94.1 & 14.0 & 5.9 \\
\hline N3.47-A0.67-500 & 8.6 & 92.8 & 10.1 & 7.2 \\
\hline N3.47-A0.67-600 & 11.0 & 91.4 & 11.4 & 6 \\
\hline N3.47-A1.34-400 & 7.2 & 95.1 & 6.1 & 4.9 \\
\hline N3.47-A1.34-500 & 7.6 & 97.5 & 7.6 & 2.5 \\
\hline N3.47-A1.34-600 & 11.3 & 95.6 & 11.3 & 4.4 \\
\hline N3.47-A2.68-400 & 7.3 & 95.8 & 7.0 & 4.2 \\
\hline N3.47-A2.68-500 & 8.8 & 96.6 & 12.3 & 4 \\
\hline N3.47-A2.68-600 & 11.6 & 96.6 & 14.9 & 3.4 \\
\hline N5.20-A1.34-400 & 9.6 & 92.8 & 7.7 & 7.2 \\
\hline N5.20-A1.34-500 & 9.0 & 92.7 & 12.9 & 7.3 \\
\hline N5.20-A1.34-600 & 7.3 & 94.0 & 9.8 & 6.0 \\
\hline
\end{tabular}


Table 7 - BET surface area of the samples calcined at $400^{\circ} \mathrm{C}$

\begin{tabular}{|c|c|}
\hline Sample & $\mathbf{a}^{\text {S }}$ BET $\left(\mathbf{m}^{2} / \mathbf{g}\right)$ \\
\hline N1.74-A1.34-400 & 151.0 \\
\hline N3.47-A1.34-400 & 144.7 \\
\hline N5.20-A1.34-400 & 135.4 \\
\hline N3.47-A0.00-400 & 152.4 \\
\hline N3.47-A0.67-400 & 101.9 \\
\hline N3.47-A2.68-400 & 151.1 \\
\hline
\end{tabular}

Table 8 - Phenol degradation rates in visible light for all the samples

\begin{tabular}{|c|c|c|c|}
\hline \multirow{3}{*}{ Sample series } & \multicolumn{3}{|c|}{ Calcination temperature } \\
\hline & $400{ }^{\circ} \mathrm{C}$ & $500{ }^{\circ} \mathrm{C}$ & $600{ }^{\circ} \mathrm{C}$ \\
\hline & \multicolumn{3}{|c|}{$\begin{array}{c}\text { Reaction Rates } \\
\left(\mathbf{M} \cdot \mathbf{s}^{-1}\right)\end{array}$} \\
\hline N0.00*-A1.34 & 10.5 & - & - \\
\hline N1.74-A1.34 & 11.7 & 8.4 & 7.3 \\
\hline N3.47-A0.00 & 12.2 & 7.0 & 6.7 \\
\hline N3.47-A0.67 & $\begin{array}{c}14.9 \\
7.3 \text { (slow) }\end{array}$ & 8.5 & 8.1 \\
\hline N3.47-A1.34 & 8.5 & 7.7 & 6.5 \\
\hline N3.47-A2.68 & 8.7 & 8.3 & 3.3 \\
\hline N5.20-A1.34 & 9.8 & 7.0 & 4.4 \\
\hline
\end{tabular}

